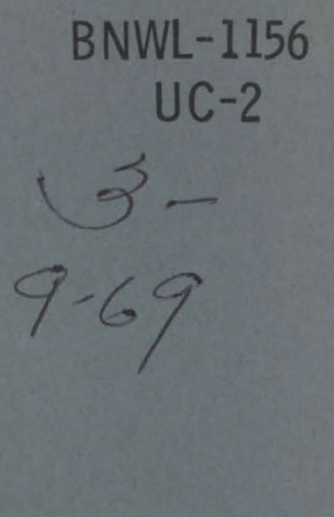

\title{
PROGRESS REPORT ON AERONOMY RESEARCH AT RICHLAND, WASHINGTON, JULY 1969
}

September 1969

\section{AEC RESEARCH \& DEVELOPMENT REPORT}

\begin{tabular}{|l|l|l|l|}
\hline Route ro & & & \\
\hline & & & \\
\hline & & & \\
\hline & & & \\
\hline
\end{tabular}




\section{LEGAL NOTICE}

This report was prepared as an account of Government sponsored work. Neither the United States, nor the Commission, nor any person acting on behalf of the Commission:

A. Makes any warranty or representation, expressed or implied, with respect to the accuracy, completeness, or usefulness of the information contained in this report, or that the use of any information, apparatus, method, or process disclosed in this report may not infringe privately owned rights; or

B. Assumes any liabilities with respect to the use of, or for damages resulting from the use of any information, apparatus, method, or process disclosed in this report.

As used in the above, "person acting on behalf of the Commission" includes any employee or contractor of the Commission, or employee of such contractor, to the extent that such employee or contractor of the Commission, or employee of such contractor prepares, disseminates, or provides access to, any information pursuant to his employment or contract with the Commission, or his employment with such contractor.

\section{PACIFIC NORTHWEST LABORATORY \\ RICHLAND, WASHINGTON}

operated by

BATTELLE MEMORIAL INSTITUTE

for the

UNITED STATES ATOMIC ENERGY COMMISSION UNDER CONTRACT AT(45-1)-1830 
BNWL - 1156

UC-2, Genera1,

Misce 11 aneous,

and Progress Reports

\author{
PROGRESS REPORT \\ ON AERONOMY RESEARCH \\ AT RICHLAND, WASHINGTON, \\ JULY 1969 \\ By \\ R. J. Hoch \\ Aeronomy Department \\ Applied Physics Division
}

September 1969

BATTELLE MEMORIAL INSTITUTE

PACIFIC NORTHWEST LABORATORIES

RICHLAND, WASHINGTON 99352 
BNWL - 1156

Printed in the United States of America Available from

Clearinghouse for Federal Scientific and Technical Information National Bureau of Standards, U.S. Department of Commerce Springfield, Virginia 22151

Price: Printed Copy $\$ 3.00 ;$ Microfiche $\$ 0.65$ 


\section{TABLE OF CONTENTS}

List of Figures. . . . . . . . . . . . . . . v

List of Tables... . . . . . . . . . . . . vi

Introduction . . . . . . . . . . . . . . 1.0

Summary of Program Progress. . . . . . . . . . . 2.0

Recent Appearances of Stable Auroral Red Arcs. . . . . 3.0 Spectrographic Monitoring of Auroral Activity at Midlatitudes . . . . . . . . . . . 4.0 Spectrographic Studies . . . . . . . . . . . . 5.0 Photometric Map of the Milky Way . . . . . . . . 6.0 Forbidden Transitions. . . . . . . . . . . . 7.0 The Nightglow and the F-Region Ionosphere. . . . . . 8.0 Automation of Aeronomy Equipment . . . . . . . . . 9.0 Special Equipment and Facilities Development . . . . . 10.0 Planning . . . . . . . . . . . . . . . . 11.0 


\section{LIST OF FIGURES}

3.1 Occasions on Which SAR Arcs have been Recorded at Richland, Washington From Late September 1967

Through Mid-June 1969 . . . . . . . . . . . 3.5

3.2 Maps of SAR Arcs. . . . . . . . . . . . . . 3.6

4.1 Spectrogram and Densitometer Tracing, 15 Min Exposure $23 / 24$ March, 1969 - 0258 PST Richland Station (Measurements are in Angstroms) . . . . . . . 4.2

4.2 Auroral Activity Recorded at Banff, April 1968 Through July 1969 . . . . . . . . . . . . . 4.4

4.3 Auroral Activity Recorded at Banff August 1968 Through November 1968 . . . . . . . . . . . 4.5

4.4 Auroral Activity Recorded at Banff December 1968 Through March 1969. . . . . . . . . . . . 4.6

4.5 Logarithmic Planetary Magnetic Index ( $\left.A_{p}\right)$ Versus

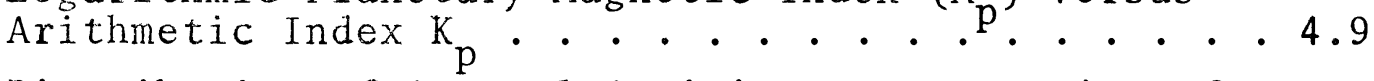

4.6 Distribution of Auroral Activity as a Function of $A_{p}$ Magnetic Index on Clear Nights . • • • • • • • . 4.10

4.7 Fraction of Clear NIghts on Which Auroral Activity was Recorded Versus A Index. . . . . . • . • . . 4.11

5.1 Spectrogram and Densitometer Tracing from North to South Along the 6300 A Line, 23/24 March, 1969, 2023 PST, Richland Station. . . . . . . . . 5.2

5.2 Spectrogram and Densitometer Tracing. $25 \mathrm{~min}$, 23/24 March 1969, 0307 MST Banff Station (Measurements are in Angstroms) . . . . . . . . . . . 5.3

5.3 Position of the $\mathrm{H}_{\alpha}$ and $\mathrm{H}_{\beta}$ Emitting Regions Determined

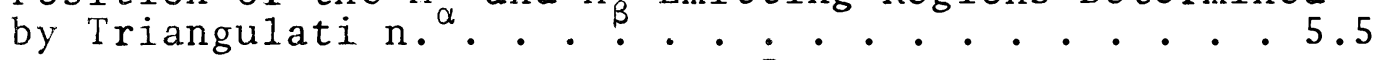

5.4 Intensity (in ergs/proton $-\mathrm{cm}^{3}$ ) and the Latitudinal Distribution of $\mathrm{H} \alpha$ Emission Excited by Protons and Hydrogen Atoms Entering the Atmosphere at Geomagnetic Latitude $67.1^{\circ}$, with an Isotropic Injection Pitch Angle and Injection Energy of $10 \mathrm{Kev}$. . . . . . 5.6

5.5 Calibration Geometry. . . . . . . . . . . . . 5.9

5.6 Standard Lamp Output Used for Calibration . . . . 5.10

6.1 Zodiacal Light Map (SlOVIS) . . . . . . . . . 6.3

6.2 Milky Way Map (S1OVIS). . . . . . . . . . . . 6.4

8.1 Plots of $\mathrm{n}(\max ), \mathrm{Q}_{6300}, \mathrm{~h}^{\prime} \mathrm{F}$ and $\mathrm{dn}(\max ) / \mathrm{dt}$ Versus Time for the Night 610 September $11 / 12$, 1961, as Observed at Maui. 
8.2 Comparison of the Diurnal Variation of $\mathrm{n}(\mathrm{max})$ at Stations in the Tropics (Maui) and in a Mid-Latitude (Washington) Based on Median Values for the Month of October, 1957... . . . . . . . . . . . 8.5

8.3 Above - Diurnal Variations of $h^{\prime} \mathrm{F}$ at Maui and at Washington; Median Values for October, 1957. Below Corresponding Plot of $\mathrm{dn}(\max ) / \mathrm{dt}$ Based on $\mathrm{n}(\max )$ from Figure 8.2. . . . . . . . . . . . . . 8.6

8.4 Diurnal Variation Plotted on a Logarithmic Scale of $\mathrm{n}(\max )$ at Maui for October, 1957 and October, 1964. 8.9

8.5 Graphical Representation of Electromagnetic Drift Speeds (not Fluxes) of Ionization in the $F$ Region

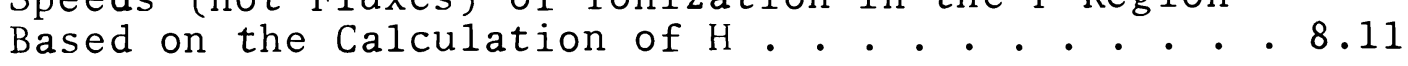

9.1 Block Diagram of Automated System . . . . . . . 9.2

10.1 Special Equipment Development . . . . . . . . 10.3

10.2 Photometers in Use. . . . . . . . . . . . 10.5

10.3 Control Room for Programming Mount and Recording Observations from Photometers . . . . . . . 10.7

10.4 ESSA Data Processing System . . . . . . . . . 10.8

10.5 Data Editing and Storage Area . . . . . . . . . 10.9

10.6 Staff Office Facilities... . . . . . . . . 10.10

\section{$\underline{\text { LIST OF TABLES }}$}

3.1 Occasion of Definite and Probable SAR Arcs. . . . 3.4

7.1 Forbidden Atomic Emissions in the Upper Atmosphere. 7.3

7.2 Molecular Band Systems Observed in the Upper

7.3 Some Properties of the Atmosphere . . . . . . . 7.6 
BNWL -1156

PROGRESS REPORT ON AERONOMY RESEARCH AT RICHLAND, WASHINGTON

\section{INTRODUCTION}

This report covers progress in FY 1969 on the "Investigation of Aurora and Airglow." It also covers progress on "Automation of Aeronomy Equipment" which is part of the whole aeronomy program at Richland sponsored by the Division of Research.

According to the usual way of predicting, we should now be in a period of maximum solar and auroral activity. Solar activity, sunspot number, and frequency of magnetic storms have all increased but not nearly as strongly as they did during the 1957-58 maximum.

Based on over 250 years records of sunspot number, the time between maxima has actually varied as much as 4 years about an 11.6 year mean. It is possible that this maximum could be late but it is equally likely that it is on schedule and we will simply have a less spectacular solar season than the corresponding 1957-58 peak.

The auroral phenomena we are recording are both the polar auroras and the Stable Auroral Red (SAR) arcs. They are both occurring, and their appearances are well correlated with solar activity. The SAR arcs, for example, reappeared at midlatitudes in September, 1967, for the first time since the last maximum. They have been recurring sporadically since then. Most of the recent auroral events including the SAR arcs have been much more subtle than might have been expected for a time of maximum activity but this does not necessarily reduce the

- amount of physical information that we can extract. It does, however, require that observations be made with some finesse.

No international cooperative effort like that of the IGY has been set up to coordinate observations during the present 
solar maximum. The distribution of observing stations in operation is such that the task of recording and analyzing the SAR arcs and midlatitude auroral activity in the Western United States falls to us if these events are to be recorded at all.

The SAR arcs remain a primary concern of this research program. When we began our investigation, there were several open questions about the behavior of the arcs and several hypotheses as to the possible cause. In this document we explain how we have contributed to the understanding of the arcs in this last year. In the separate sections we discuss the results of other investigations and other tasks undertaken.

Our primary technique for recording and analyzing auroras and airglow is the systematic mapping of the sky with scanning photometers. Spectra and distribution of intensities in the meridian plane are also obtained with a pair of spectrographs monitoring the vertical plane passing through Banff, Alberta, Canada and Richland, Washington. This arrangement permits triangulation spectroscopy that provides detailed information on the bright auroras with which SAR arcs are often associated. Both the photometric mapping technique and the spectrographic method have proved adequately sensitive to detect and record SAR arcs.

Last year, the yearly progress report was presented as a narrative of what had transpired during the year. That was an appropriate way to report activities for a year in which we had to solve many logistics and construction problems. This year we have changed the reporting format to focus attention more sharply on the technical and scientific aspects of the work. Therefore the report is laid out as a series of topical discussions, each covering a different aspect of the work. Because the whole program is the work of several people, we have identified these contributors in the topical discussions along with the work they did. A brief summary preceding topical discussions provides overview of the work. 
BNWL -1156

\section{SUMMARY OF PROGRAM PROGRESS}

This has been a year of data accumulation. The basic instrumentation, set up the year before, was kept in operation throughout a winter which was unusually severe for this locale. We established the routine examination and organization of data as they were accumulated. This operation is going smoothly although it is time consuming. We have also begun to report the results of systematic observations.

Early in the year we reported the occasions of the SAR arcs recorded since September, 1967. This prompted a review by Jacques Blamont of photometric data gathered by the 0GO-4 polar-orbiting satellite. With the time and place of the SAR arc supplied, he was able to verify our observations and to determine for the first time that the arc indeed spanned the entire dark side of the earth. It was also determined that another arc was present at the conjugate position in the southern hemisphere, a fact which was previously suspected but never before directly verified. We now have the OGO-4 photometric data in hand at Richland and are conducting a more detailed analysis of it.

Our collaborating observer Marovich at Fritz Peak alerted ESSA personnel responsible for Allouette satellite data, to the time and position of the first SAR arc that we observed. We subsequently relayed the time and position of other arcs to assist the scanning of the Allouette data. These Allouette data provide electron density and temperature above the SAR arc and they show that there is sharp increase ( 5 fold) in electron temperature above the arc and a sharp drop in electron density.

This new information strongly implies electron bombardment causes the arc. Of the three or four hypotheses originally set forth for the cause of the arc (outlined in our original 
proposa1), the "hot electron" hypothesis seems to be emerging as the correct one. Of course, we now must seek a mechanism for the electron excitation. We have been invited to participate in a collaborative analysis of the Allouette data combined with our photometric data.

Just before preparation of this report, a unique set of spectrograms of a SAR arc was obtained with the spectrograph at the Richland station. The simultaneous records made by our spectrograph at Banff were essentially swamped in [OI] 6300 by the extremely bright polar aurora at that site. Therefore, the long awaited spectrographic triangulation on a SAR arc still eludes us. Unexpectedly, however, the combined records of the two stations permit beautiful triangulations on a bright hydrogen arc which occurred that same night over Banff. Preliminary results based on these records are included in this report.

Records of auroral activity detected by the spectrographs have been compiled on a day by day basis. A graphical summary which gives concurrent visibility and magnetic activity is used for reporting.

The relationship between temporal variations in [OI] 6300 intensity, peak electron density $n(\max ), \mathrm{dn}(\max ) / \mathrm{d} t$ and virtual height $h^{\prime} F$ were analyzed and an attempt made to evaluate and interpret correlation on a worldwide basis. A consistent relation (Barbier formula or a modification thereof) holds for tropical regions but breaks down at midlatitudes.

A photometric map has been completed of the local galactic light, one of the predominant background components in the night sky. This map surpasses previously available maps in accuracy and detail, and therefore should be of value to the scientific community for work related to ours, as well as being valuable to our own research. 
There is a continuum component in the spectrum of the airglow itself, and we are attempting the separation of this rather subtle emission from the other continuum sources (galactic, zodiacal, and stellar). The predictable and systematically changing positions of the three astronomical components provide the key to separation if we can maintain careful and continuous calibration of our scanning equipment for a long and continuous sequence of observations. An additional turret photometer has been added to the scanning mount for this work.

The whole calibration effort has been very much improved this year. We now know the absolute response of the spectrographs and have improved the intercalibration between the spectrographic and photometric equipment. Intensity calibration necessarily requires continual attention. Practically every environmental change as well as simple aging of the system components changes the absolute response. Routine use of a radioactive standard light source that was obtained this year has helped.

The main item of technical progress in instrumentation is the procurement and imminent installation of the automated control recording and display system. Except for some remaining short-lead time system components to be purchased at the beginning of the new FY, putting the new equipment into operation is primarily a matter of interfacing and programming. Of course, the remaining work is not trivial but the finishing of engineering, design, and procurement of the apparatus represents a major step toward taking the lead in advanced observation techniques in this research field.

Useful refinements were made to the observing equipment. These refinements included development and installation of equipment for direct pulse counting to measure photons incident on the photo cathodes of the scanning photometer, for 
logarithmic scaling of bright auroral data, for on-line printout of digital data, and for automatic closure of the shutters when a bright source such as the moon is scanned. In addition, new auxiliary equipment, including the magnetometer, an all-sky camera and a semiautomatic analog-to-digital converter were put into use.

The hilltop laboratory facilities are now being greatly improved. We shall soon occupy comfortable, first-class working facilities.

Interaction between personnel of our program and University staff and students was increased with a corresponding increase in exchange of information. Plans were laid for further cooperative research.

Plans were postponed to improve the intensity response of the spectrographs by the addition of image intensifiers. Plans to construct and interferometer to measure the temperature of the emitting gases were also temporarily set aside.

In looking for some way to summarize the general status of the program we are reminded of Dr. Roach's remark earlier this year as he surveyed the data accumulated. He said "We are now in the process of digestion after a large meal." While it is best not to press the analogy further in predicting the end results, his casual remark does summarize the overall situation concisely. We have more work to do with equipment, but we are taking care to report the observations we make which are timely and useful. This has had scientifically productive results that we have already mentioned. As noted in the section of this report on "Planning," we have recognized that our effort must now emphasize interpretation and detailed analysis of the data. As this year closes, we have shifted emphasis of the program in that direction, and new analytical work is underway. 


\section{RECENT OCCURRENCES OF STABLE AURORAL RED ARCS} R. J. HOCh

\section{INTRODUCTION}

Stable Auroral Red (SAR) arcs appeared at midlatitudes during the peak and subsequent decline of the IGY solar maximum. It has been generally assumed that this phenomenon ceased to occur at midlatitudes during the solar minimum, but in view of recent observations to be discussed, this assumption might be questioned. It is certain, however, that since the autumnal equinox of 1967 (when we set up equipment near Richland, Washington and began systematic observations) the SAR arcs have been occurring. These recent SAR arcs have typically been fainter than the ones reported during the last maximum and the occurrences have been somewhat sporadic.

Characteristics of SAR arcs, which have also been called M-arcs, midlatitude arcs, and 1 'arc monochromatique $(1,2,3)$ are given by Barbier (1,2) who first observed and reported them. Observational data of the last solar season are also summarized by Roach and Roach (3). Some of the distinguishing characteristics are:

- SAR arcs occur at midlatitudes; that is they are observed southward of the usual polar auroras.

- In the octave of visible radiation SAR arcs consist predominately of the 6300-6364A red emission lines of atomic oxygen (but none of the arcs ever recorded is believed to have been bright enough to be visible to the unaided eye.)

- The arcs are magnetically controlled, appearing during times of high magnetic activity.

- They are aligned approximately parallel to lines of constant L.

- The brightest region is near $400 \mathrm{~km}$ altitude and they typically extend several hundred $\mathrm{km}$ in altitude and in north-south width. 
- They are quite stable though a motion (often equatorward) of the whole arc is often observed.

In addition to these characteristics, strong though indirect evidence obtained before the solar minimum suggested that a SAR arc might span the entire dark side of the earth and that an arc probably occurred in the conjugate position in the southern hemisphere when one occurred in the northern hemisphere. We report here some recent direct evidence in support of both of these suggestions.

The cause of the SAR arcs has been an open question. The several hypotheses set forth have been summarized by Roach and Roach (3) and examined by others including Cole (4), who has advanced a hypothesis and by Walker \& Rees (5) who have suggested tests of several hypotheses. We shall comment on the status of the hypotheses in view of recent data.

Marovich (6) and Roach and Roach (3) have summarized occurrences of SAR arcs from the IGY to the solar minimum. Hoch, Marovich and $\mathrm{Clark}{ }^{(7)}$ reported the initial reappearance of the arc after the last solar minimum.

\section{OBSERVATIONAL ARRANGEMENT}

Photoelectric scanning photometers are operated during clear moonless night hours at a station on Rattlesnake Mountain near Richland, Washington. Altitude of the site is $1100 \mathrm{~m}$ and coordinates of the station are $52^{\circ} 51^{\prime} \mathrm{N}, 298^{\circ} 51^{\prime} \mathrm{E}$ Geomagnetic. The remote desert locale of the station provides relatively clear viewing conditions and a low stray light level. The McIlwain's L coordinate assocaited with the site (2.7 at altitude $400 \mathrm{~km}$ ) locates it near the middle of the zone where SAR arcs were observed with highest statistical frequency before the last solar minimum ${ }^{(3)}$.

The sky is routinely scanned with the photometers every 5 min by a sequence of five almucantar sweeps and a zenith 
reading. The sweeps are spaced to give approximately even coverage of an imaginary surface at $300 \mathrm{~km}$ altitude. A $5^{\circ}$ field of view is used in the photometers and the data of each sweep are recorded in analog and digital form. The digital data are divided into 432 samples which are recorded together with time, angular coordinates, and other data for data processing. Narrow pass band interference filters (10-20A) are used to select the wavelength to be mapped. The filters are kept at constant temperature to assure stability of transmission characteristics. One photometer monitors only 6300A while another maps 4278,5577 and 6300A sequentially. A third photometer maps 5350,6080 and $7150 \mathrm{~A}$ sequentially to provide data on the underlying continuous spectrum of the airglow, zodiacal, stellar, galactic and man-made light.

Sensitivity of the equipment is such that a region that is 25 Rayleighs (R) brighter than its background will be delineated on the sky maps. Extraction of galactic, stellar, and zodiacal background light and correction for geometrical effects are done numerically by high speed electronic data processing. For objects at $400 \mathrm{~km}$ altitude the circle of coverage is approximately $3000 \mathrm{~km}$ in diameter.

This photometric installation has been in essentially continuous operation during clear weather moonless nighttime hours since late september of 1967. Weather has permitted approximately $40 \%$ of these moonless hours to be monitored. Backup data for hours when the moon is up and the photometer is not operated are provided by a pair of meridian spectrographs, one at Rattlesnake Mountain and one at Banff, Alberta. These spectrographs are described in section 4 of this report. The spectrographs provide a check of whether or not any bright SAR arc occurred on a clear night when the photometers were not operated because of moonlight. One such arc was recorded by the Richland spectrograph when the moon was up on the night of $23 / 24$ March; 1969. 
The spectrograms show no evidence in the SAR arc of any emissions in the optical wave region other than the [OI] 6300A doublet.

\section{THE DATA}

Table 3.1 lists nights on which SAR arcs were definitely recorded at Richland, Washington along with other nights on which there is some evidence of a SAR arc but some circumstance such as poor weather or faintness of the emission makes the identification uncertain.

\section{TABLE 3.1 Occasion of Definite and Probable SAR Arcs}

Occasion of Definite SAR Arcs

$28 / 29$ Sept 67

$30 / 31$ Dec 67

$2 / 3$ Jan 68

$27 / 28$ Feb 68

$28 / 29$ Feb 68

31 oct/ 1 Nov 68

$20 / 21 \operatorname{Mar} 69$

$23 / 24$ Mar 69

14/15 May 69
Occasion of Probable SAR Arcs

$3 / 4$ Nov 67

$1 / 2 \operatorname{Mar} 68$

$2 / 3$ Mar 68

$30 / 31$ oct 68

$19 / 20$ Mar 69

24/25 Mar 69

A SAR arc typically persists for several hours and the identifications in Table 3.1 are based on some three hundred and fifty sky maps of the SAR arcs. The occasions of recorded SAR arcs are displayed along a time axis in Figure 3.1 .

The position of the brightest region of eight definite SAR arcs at the time each was best defined on our records is shown in Figure 3.2. On every occasion of a SAR arc there has been a polar auroral display to the north of the arc. 6300A emission was almost always more intense in the northward auroral display than in the brightest region of the SAR arc. The only exceptions have been cases in which the polar aurora 
was almost out of range. The figures show the area of the sky (marked PA) where the polar aurora was brighter than the SAR arc.

OCCASIONS OF SAR-ARCS

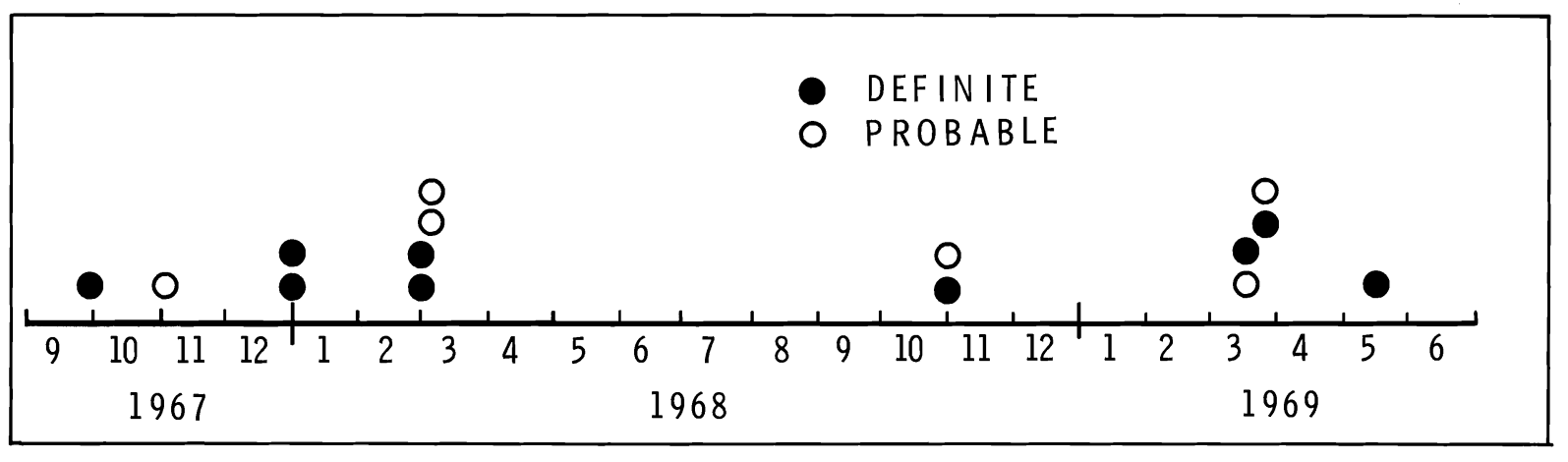

FIGURE 3.1. Occasions on Which SAR Ares Have Been Recorded at Richland, Washington from Late september 1967 Through Mid-June 1969

The distinct SAR arcs observed have the general characteristics described in the introduction. Rather than describe each arc, we will discuss some features and results that seem to us to add something new or help resolve a questionable point.

Occasionally the suggestion has arisen that the SAR arcs are simply the top most part of a normal auroral display (8) and that there only appears to be a separate arc from the vantage point of the observations. Figure $3.2 b, f$, and $h$ show that this is not the case. On these maps the SAR arc is plotted when it was overhead or south of the station while the auroral display was to the north of the station. This situation occurred on several other nights as well when the SAR arc passed over the station. The light maps shown were selected on the basis of when the arc was best defined which is not necessarily the time when the arc was overhead or south of the station.

Thus the SAR arc and the auroral display are spatially separate. We often "see" the SAR arc to our south or overhead while the polar aurora is to our north. However, we know of 
BNWL -1156

MAPS OF SAR ARCS

$2 a$

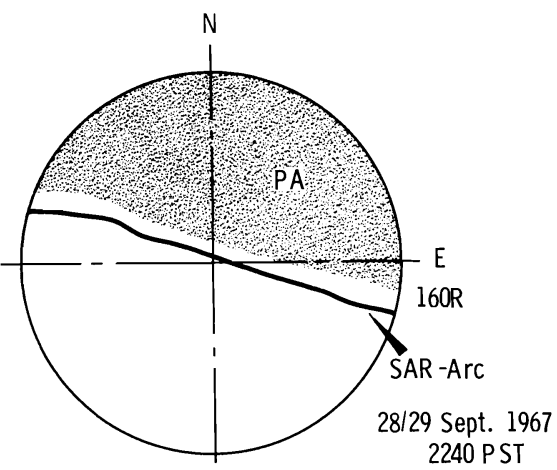

2

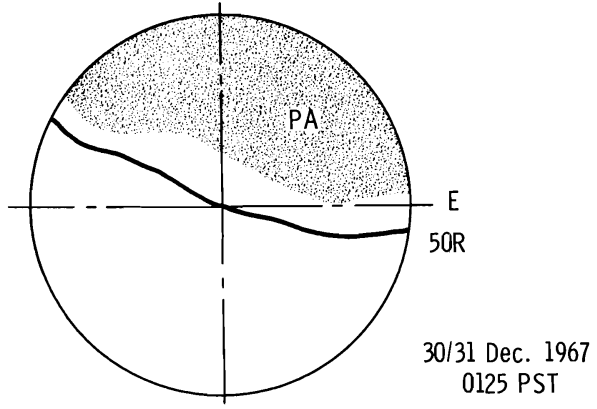

$2 c$

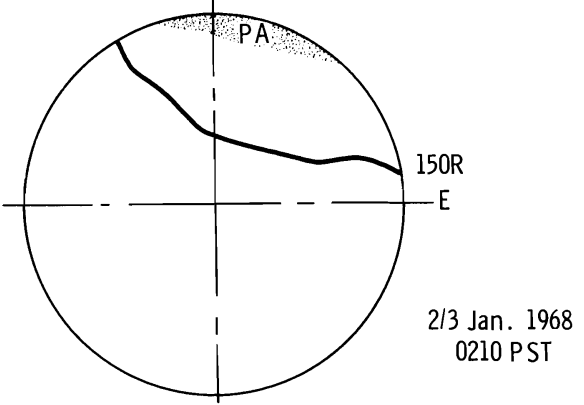

$2 d$

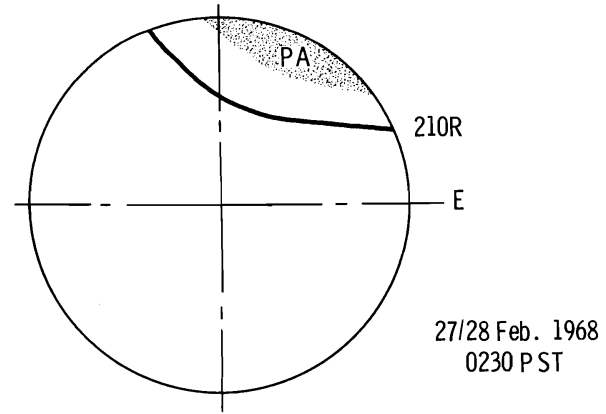

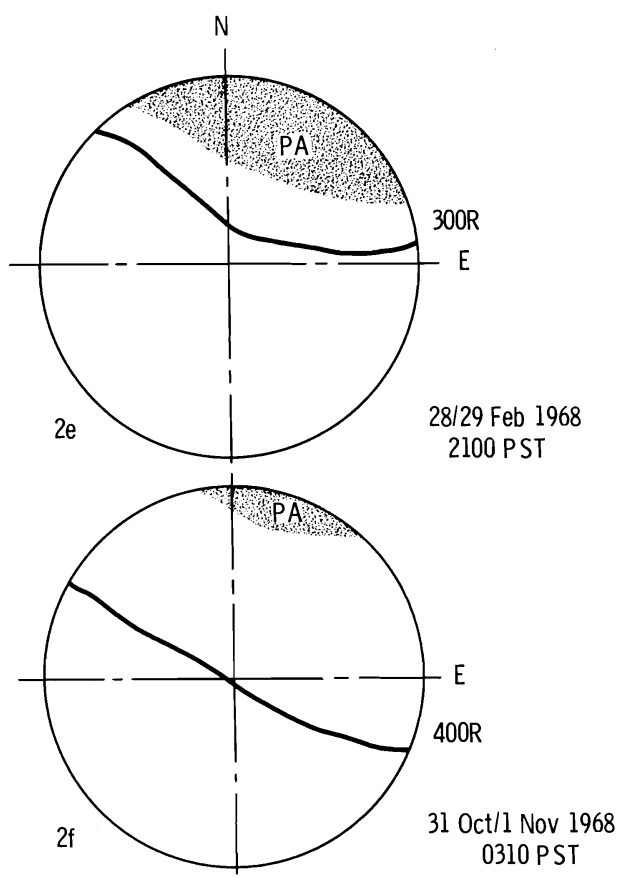
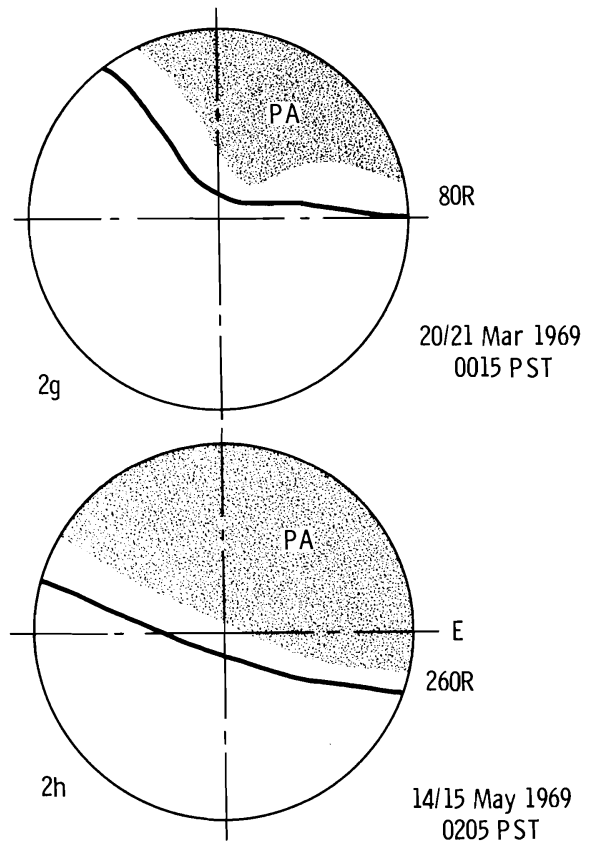

FIGURE 3.2 Maps of SAR Arcs. The Shaded Region (PA) Marks the Portion of the sky in which [OI] 6300A, from the Poleward Aurora was Brighter than the Region of the SAR Arc. The Intensities Shown are Rough Averages of the Brightest Region Taken Along the Length of the SAR Arc. Each Map Covers a Circle Approximately $3000 \mathrm{~km}$ in Diameter. Geographic coordinates of the Center of the Maps are $46^{\circ} 25^{\prime} \mathrm{N}$ and $119^{\circ} 38^{\prime} \mathrm{W}$. 
no instance in which there was a SAR arc without a bright poleward aurora occurring simultaneously. Therefore, although the SAR arc is not the top part of a polar aurora, there is some close connection between these two phenomena.

There appears to be no lower limit on the intensity of a SAR arc. We have cases where repeated scans show that there is a systematically brightened arc-1ike zone of $6300 \mathrm{~A}$ emission south of the main aurora. However, on a single map the arc would be difficult to discriminate from noise. Thus, Figure $3.2 \mathrm{~b}$ shows a SAR arc of only $50 \mathrm{R}$. We believe it entirely possible that there is usually (perhaps always) an incipient or faint arc equatorward of the polar aurora but that the arc is often too faint to be detected by present instrumentation.

No enhancement of [OI] 5577 could be found in the region of any of the SAR arcs recorded photometrically. The spectrographic record of a SAR arc on 23/24 March 1969, shows no emission other than [OI] 6300 doublet enhanced in the region of the SAR arc.

Several SAR arcs with intensity greater than one $k R$ were recorded before the solar minimum, but many fainter ones were also recorded. A comparison of the records of recent arcs with ones recorded during the last solar season show no apparent difference between the recent SAR arcs and the ones recorded before the minimum except, as mentioned, we have recently delineated some arcs which are fainter than those reported in the past.

Some of the arcs shown in Figure 3.2 were so far north at the time they were best defined that they would not have been easily observed from the established stations southward of ours. Fritz Peak is the most northerly of those stations which were operated routinely during the solar minimum. The SAR arcs shown on maps $3.2 \mathrm{a}, \mathrm{b}, \mathrm{f}$, and $\mathrm{h}$ were within range of Fritz Peak. The circumstance, of location of our station coupled with the 
tendency of auroral phenomena to occur generally nearer the poles during times of low activity and also coupled with the fact that we began recording SAR arcs occasionally as soon as we set up equipment northward of other stations, leads us to suggest that it is not at all certain that the SAR arcs stopped occurring during the solar minimum. The arcs may simply have been very faint and/or out of range during the solar minimum.

There have been recent occasions when the SAR arcs have been relatively strong and well defined. The first of these (Figure $3.2 \mathrm{a}$ ) has led to some new information of interest through correlation of these ground based data with data gathered by satellites.

Blamont ${ }^{(9)}$ and Reed have examined OGO-4 polar orbiting satellite data for evidence of the SAR arc we detected 28/29 September, 1967 and have found that the arc shown in Figure 3.2 a extended around the entire dark side of the earth. Furthermore, they found a similar SAR arc to have been present simultaneously in the magnetically conjugate position in the southern hemisphere. This is the first direct verification of both the east-west extent of the arc and the presence of the conjugate arc.

Norton $(10)$ has examined Allouette I and II satellite topside ionosonde data taken at approximately $1000 \mathrm{~km}$ and $1800 \mathrm{~km}$ respectively. Norton indicates that for the 28/29 September, 1967 event there was a sharp rise, actually a pair of peaks in electron temperature approximately above the arc. The electron temperature at the highest peak was about $6000{ }^{\circ} \mathrm{K}$ compared to about $3000^{\circ} \mathrm{K}$ in the region immediately northward of the arc. Electron density showed a striking depression in the vicinity of the arc falling nearly $10^{4} \mathrm{~cm}^{-3}$ to about $6 \times 10^{2} \mathrm{~cm}^{-3}$ in a region about as wide as the half width of the arc. Going northward, the density increased slowly to about $8 \times 10^{3} \mathrm{~cm}^{-3}$ at $\mathrm{L}=5.0$. 
The several candidate hypotheses tendered as SAR arc mechanisms include: excitation by proton bombardment (11), a postulated electric field perpendicular to the field, (12)(13)(14) a flux of $400 \mathrm{eV}$ electrons, (15) and a thermal electron mechanism(16)(11)(4). Of these, Cole's "thermal electron" mechanism seems to us to be strongly favored by these recent data which show a region of high temperature electrons to be present. Should subsequent measurements and analyses bear out these recent findings, there remains to be clarified the details of the energy transfer to the electrons. CONCLUSIONS

While SAR arcs may be very subtle in intensity, at least nine distinct arcs have occurred since 27/28 September, 1967. Evidence that SAR arcs did not occur during the solar minimum is at best inconclusive. The nature of the connection between SAR arcs and polar-type auroras deserves further investigation because the two phenomena are temporally connected in that a polar aurora always seems to accompany a SAR arc. However, it is not clear whether a SAR arc always accompanies a polar aurora. If it does, it must be very faint. The main regions of [OI] 6300A emission of the SAR arcs and polar type auroras are spatially separate. There is direct evidence that a SAR arc may span the entire dark side of the earth and that a conjugate pair of SAR arcs may occur simultaneously. There is also direct evidence that a region of hot electrons is temporally and spatially correlated with a SAR arc. The fact that the major spectral emission of a SAR arc in the visual wavelength region is the 6300-6364A doublet has been checked spectrographically. 
BNWL - 1156

\section{REFERENCES}

1. D. Barbier. Ann. Geophys., vol. 14, p. 334. 1958.

2. D. Barbier. Ann. Geophys., vol. 16, p. 544. 1960.

3. F. E. Roach and J. R. Roach. Planetary Space Sci., vol. $X X, p .523 .1963$.

4. K. D. Cole. J. Geophys. Res., vol. 70, p. 1689.1965.

5. J. C. G. Walker and M. H. Rees, Planetary Space Sci., vol. 16, p. 915. 1968 .

6. E. Marovich. Fritz Peak Observations of SAR Arcs Summary (1955-65), IERA16-ITSA16. December 1966.

7. R. J.Hoch, E. Marovich and K. C. Clark. J. Geophys. Res., vol. 73, p. 4213. 1968 .

8. V. I. Krassovsky. Solar Terrestrial Physics. Academic Press, London, England, 1967.

9. Jacques Blamont. Unpublished Data. (Personal Communication)

10. Richard Norton. Unpublished Data. 1969. Personal Communication: Publication in J. Geophys. Res. is anticipated.

11. F. E. Roach. Unpublished Data. (Personal Communication) Battelle-Northwest Richland, Washington.

12. L. R. Megizl, M. H. Rees and J. D. Droppleman. Planetary Space Sci., vol. 11, p. 45. 1963.

13. L. R. Megizz and N. P. Carleton. J.Geophys. Res., voi. 69, p. 101. 1963 .

14. L. R. Megizz and T. Van Zandt. Trans. Am. Geophys. Union, vol. $45, p .355 .1964$.

15. A. Dalgarno. Ann. Geophys., vol. 20, p. 65. 1964.

16. M. J. Seaton. The Airglow and Aurora, Pergamon Press, New York. 1955 . 
BNWL-1156

4. SPECTROGRAPHIC MONITORING OF AURORAL

Meridian spectrographs of the type described by Clark and Romick (1) which function automatically and continuously at night have been used to monitor auroral activity in the two following locations:

- Sulphur Mountain near Banff, Alberta, Canada (since November 1967), Altitude 7,465 ft, geomagnetic latitude and longitude $58^{\circ} 6^{\prime}$ and $300^{\circ} 36^{\prime}$, respectively

- Rattlesnake Mountain near Richland, Washington (since March 1966), altitude 3,568 ft, geomagnetic latitude and longitude $52^{\circ} 51^{\prime}$ and $289^{\circ} 57^{\prime}$, respectively.

The base line between the stations is approximately $600 \mathrm{~km}$. Each spectrograph is oriented to accept light only from the common vertical plane passing through the two stations; and eachinstrument records light from horizon to horizon in this plane. The geographic bearing of the common plane is $301 / 2^{\circ}$ to the east of north at Banff, and $271 / 2^{\circ}$ to the east of north at Richland.

For either instrument, the effective light source is a very narrow strip of sky which is optically transformed to a line image and dispersed by a grating to display wavelength and intensity as a function of angle of incidence. Each instrument automatically records sequential 5- and 25-min exposures on Kodak 103 AF 35 mm spectrographic film every 30 min from dusk until dawn.

A conventional F-ratio cannot be used to give a meaningful measlire of photographic sensitivity of the equipment because of the elongated entrance aperture. However, in functional terms, the sensitivity is such that a record of the $5577 \mathrm{~A}$ airglow is routinely obtained on the 25 -mir exposures but never obtaired on the 5-min exposures. Therefore, when visibility is good, auroral aciivity brighter than abcut 500 F at $5577 \mathrm{~A}$ will be recorded on the 25 -min spectrograms. The spectral range covered is approximately $3700 \mathrm{~A}$ to $7000 \mathrm{~A}$. 
BNWL - 1156

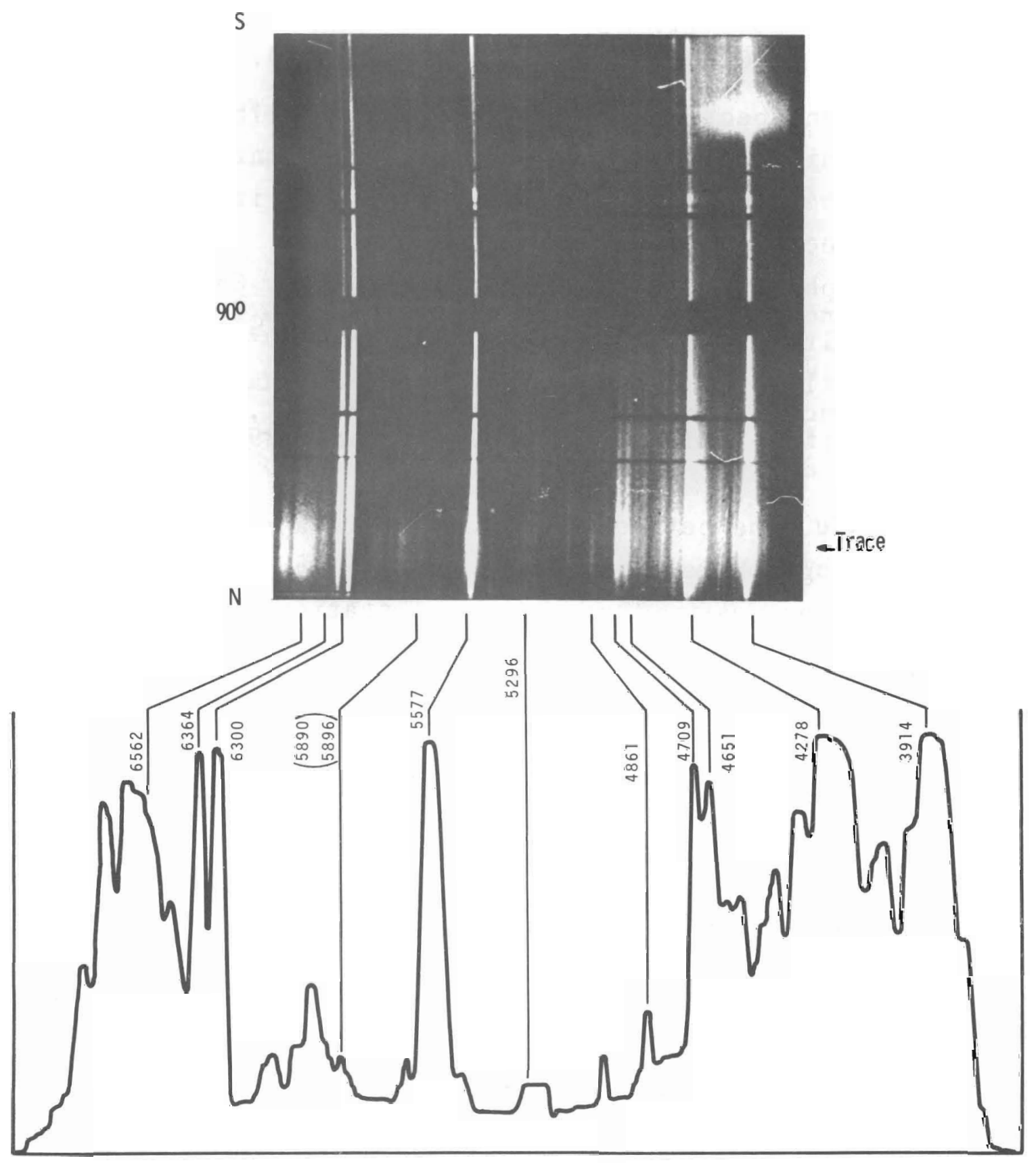

FIGURE 4.1 Spectrogram and Densitometer Tracing, 15 Min Exposure 23/24 March, 1969-0258 PST Richland Station (Measurements are in Angstroms.) 
Such optical data are, of course, mitigated by local cloud cover which may diminish or entirely mask incident auroral 1ight. The visibility conditions at the site of the measurements are reported here to indicate when such attenuation may have occurred.

Figure 4.1 presents an example of the raw data recorded by the spectrographs and also gives a corresponding densitometer tracing across the 25-min exposure shown. There is, of course, much detailed information that can be extracted from these spectrograms. Here we will only discuss the first part of the analysis which is concerned with describing presence or absence of activity. This analysis primarily uses the [OI] $5577 \mathrm{~A}$ emission 1 ine radiance to describe the auroral activity as "no aurora" when the [OI] $5577 \mathrm{~A}$ emission is $<500 \mathrm{R}$; "faint aurora:" when > $500 \mathrm{R}$ but <1 kR; and "distinct aurora:" when $>1 \mathrm{kR}$. To avoid confusion with airglow in faint auroras we also require that there be some evidence of spectral emissions in the first negative system of $\mathrm{N}_{2}^{+}$. A review of the accumulated data from both stations for this analysis shows that the best set of data is from Banff for the period of Apri1, 1968 through March, 1969.

The graphical representation of the auroral activity, as described above, for the period April, 1968 through March, 1969 for the Banff station is given in Figures 4.2, 4.3 and 4.4. For convenience of this and other analysis, the concurrent planetary magnetic index $\left(A_{p}\right)$ is also plotted. The visibility plot accompanying the auroral data is meant to suggest whether an auroral display would have been hidden or attenuated by local clouds. The visibility information presented has been deduced from the spectrograms by noting the intensity of cloudreflected city lights (mostly mercury emission apectra). It is ususally possible to make a qualitative distinction between a hazy sky and a cloudy sky by comparing the ratio of reflected blue mercury lines (e.g., 4358A) to yellow mercury 1 ines 

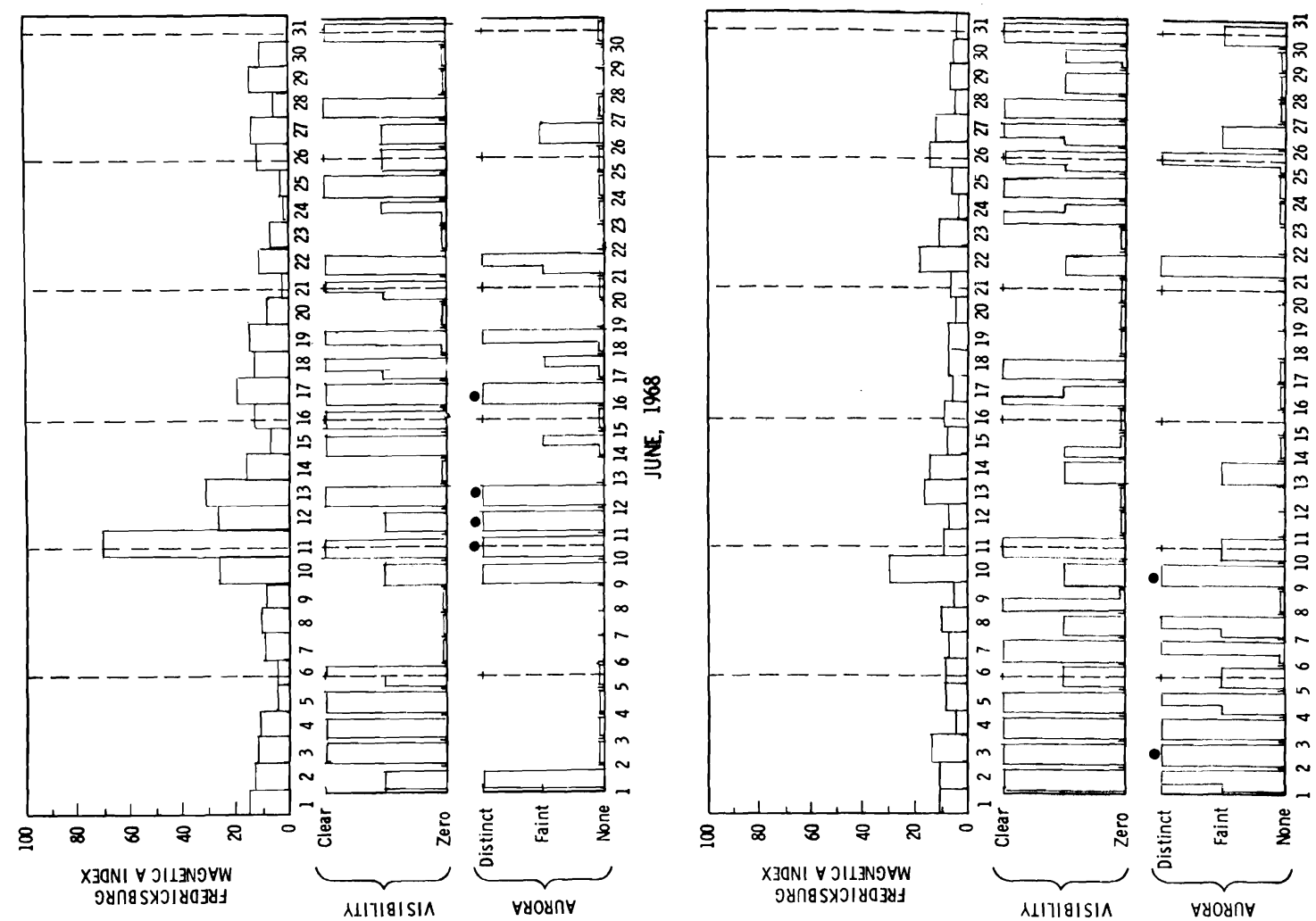

4 $=4$ $\Rightarrow$

nos 0
0 $0 \mathrm{~T}$ ชै $\pi$ \& 2 07 वै x-1 5 ง $\begin{array}{lll}-4 & 8 \\ 4 & 0\end{array}$ 5 5 त E N $0 \infty$ $\checkmark \omega$
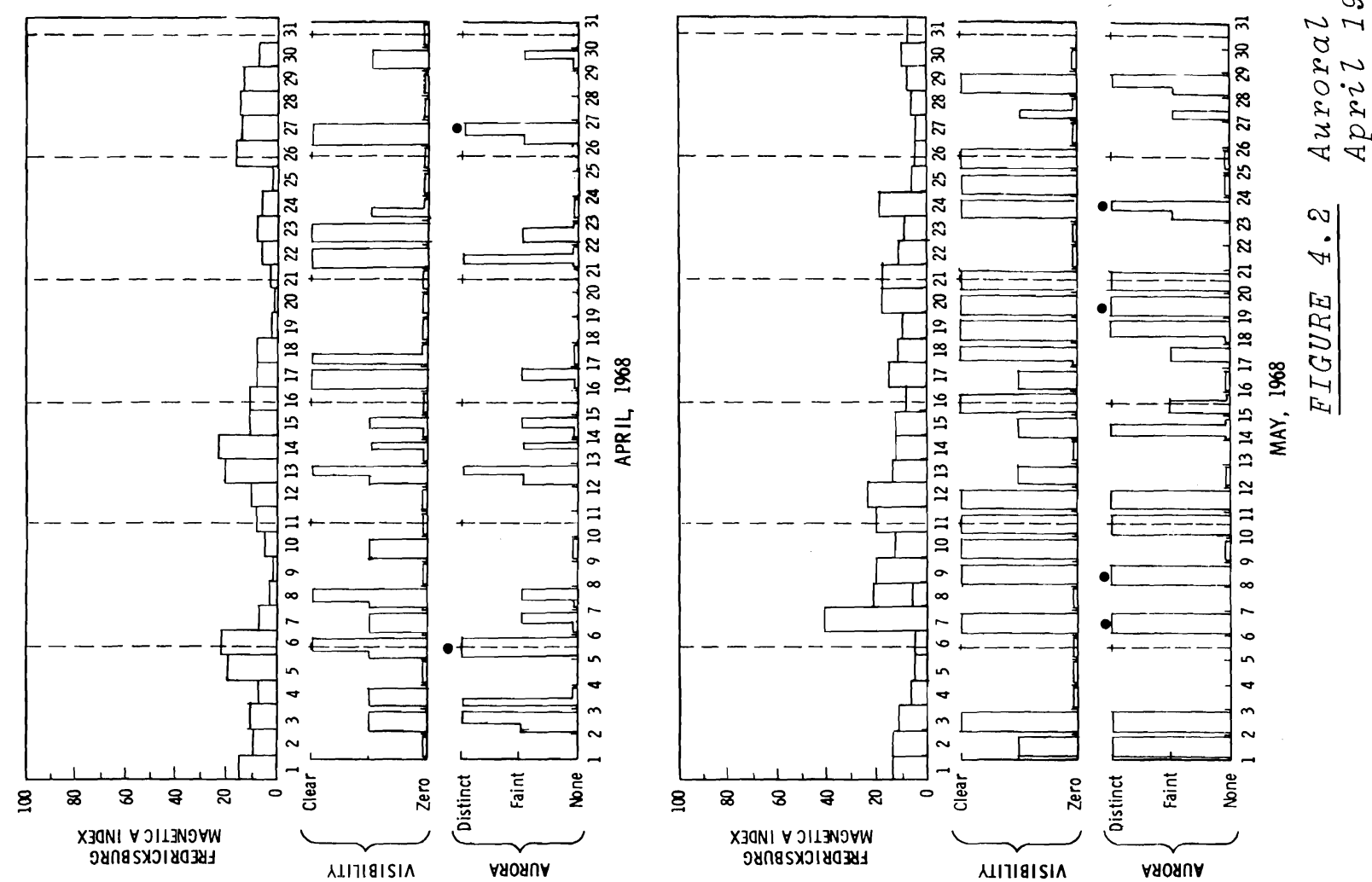

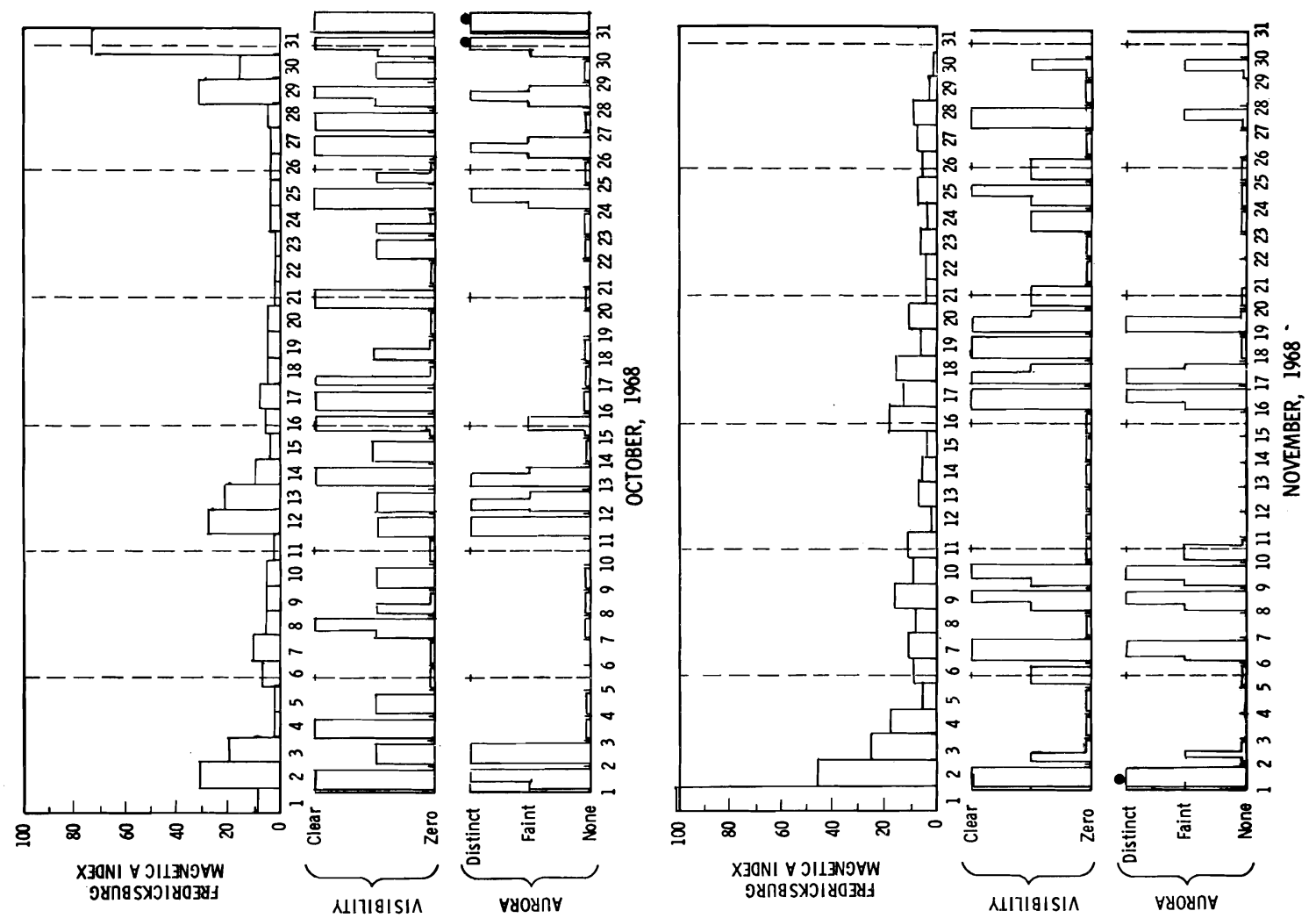

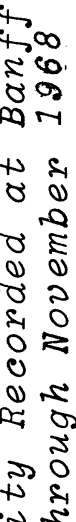
. 5 ह ก
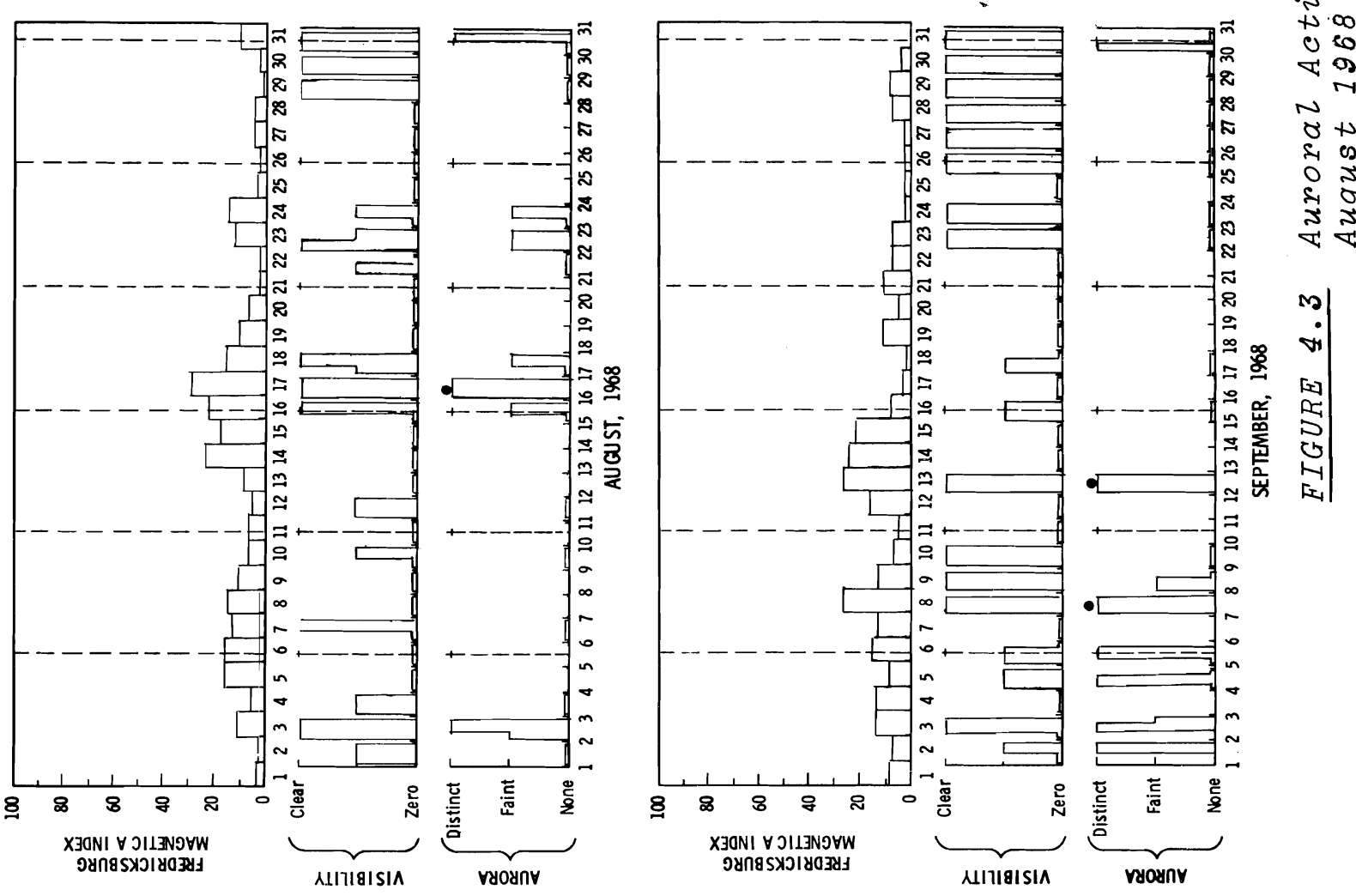

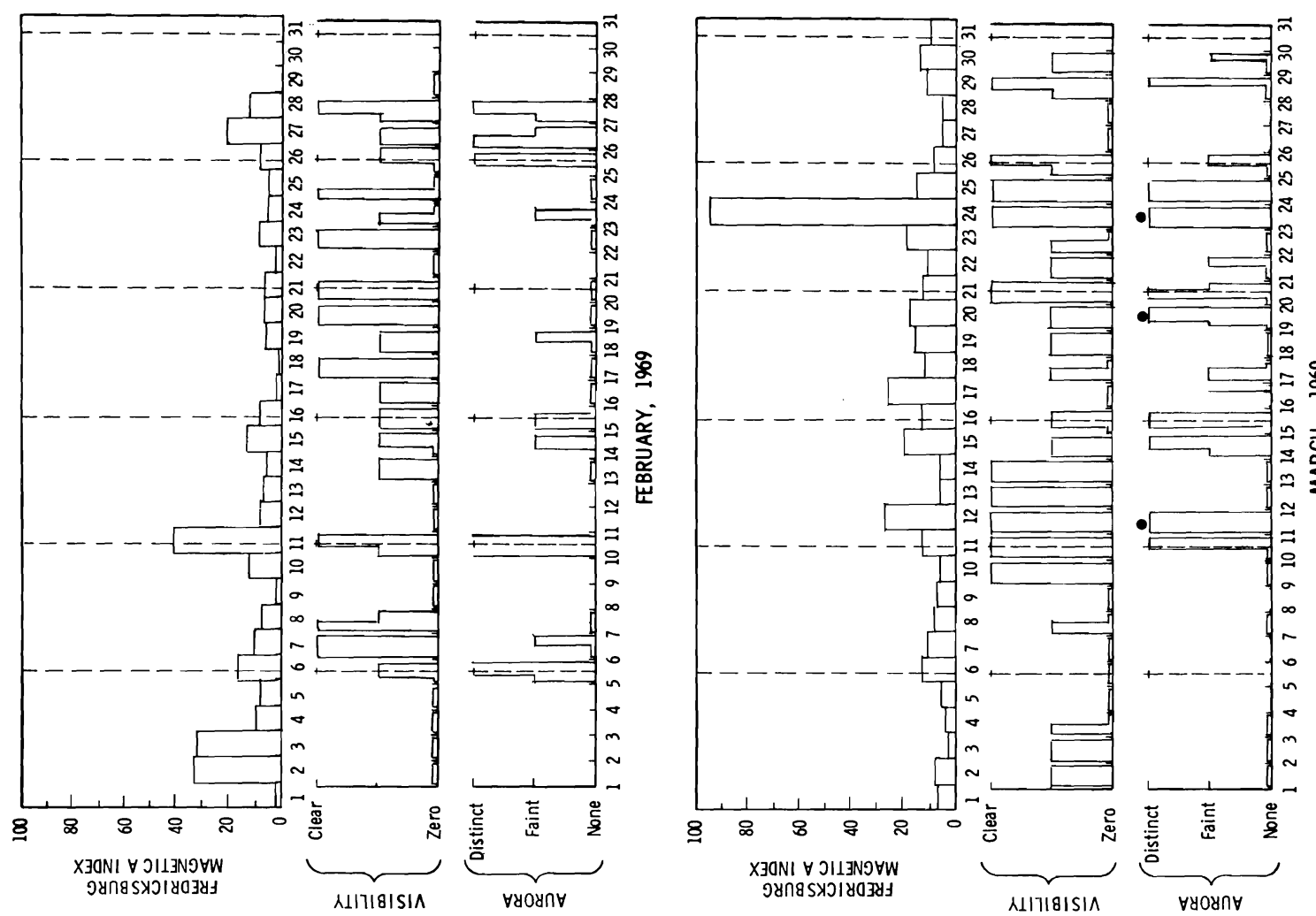

4

दo

$\begin{array}{ll}0 & 0 \\ 0 & 0\end{array}$

4

$0 \pi$

$\gamma$

ชี

\&

0 is

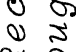

बri 0

NTE

5 20

- N 0

W O
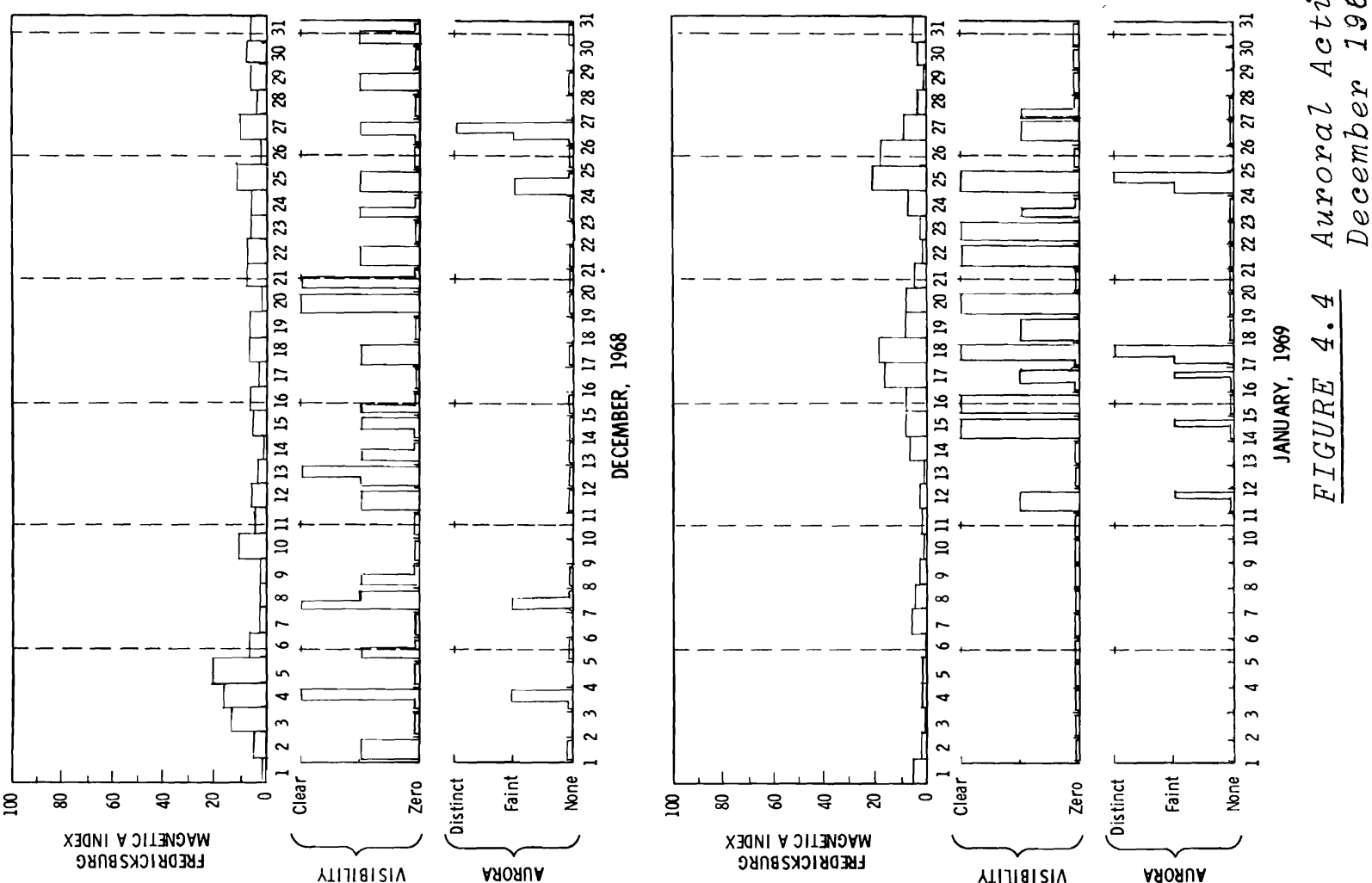
(5770-90A). This spectrographic information is supplemented by local weather observations of the general cloud cover for the particular light. Particularly brilliant auroras are noted by an asterisk on the graphical data.

From this year's data at Banff, we find that the percentage of clear nights on which there was no aurora was $47 \%$, faint aurora $19 \%$ and distinct aurora $34 \%$. It is interesting to compare the frequency of auroral activity to magnetic activity. The comparison is best displayed in terms of an arithmetic scale of magnetic indices ( $A_{p}$ ) rather than the popular logarithmic index $\left(K_{p}\right)$. For convenience, a plot of $K_{p}$ versus $A_{p}$ is given in Figure 4.5. In Figure 4.6 we have shown the frequency distribution of clear nights for which $A_{p}$ was in a given interval, and we have also plotted the corresponding number of those nights on which auroras were recorded. It appears that there is a certain threshold of magnetic activity above which auroral activity occurs. For the most frequently occurring values of magnetic index (A $A_{p}$ in the interval [4,6]) we note that auroral activity seldom occurred. However, for the expectation value of $A_{p}$, which is in the $[10,12]$ interval, an aurora was recorded on 10 of the 20 nights for which magnetic activity was in that interval. This suggests that the probability of recording an aurora at Banff on any clear night picked at random is approximately one half. In fact, we find the quotient of all auroras recorded over all clear nights is $120 / 230$ for the year.

Figure 4.6 indicates that the probability of recording an aurora increases with increasing $A_{p}$. This correspondence is specifically displayed in Figure 4.7 where we have plotted the fraction of clear nights on which auroral activity was recorded when magnetic activity was in a certain interval. The fewer data at high $A_{p}$ have required the use of a broader interval ( 6 units $A_{p}$ ) on the abscissa. These data show that it is virtually certain that there will be a distinct aurora 
if $A_{p}$ exceeds 32 . One exception may be noted in Figure 4.6 where $A_{p}$ was in the interval [50,52], but no aurora was logged. However, on that night (October 4, 1968), the continuum spectrum of moonlight made the analysis somewhat difficult. Moonlight usually does not mask the auroral lines entirely since the continuum is only recorded for a short time when the moon is in or near the field of view. 
BNWL-1156

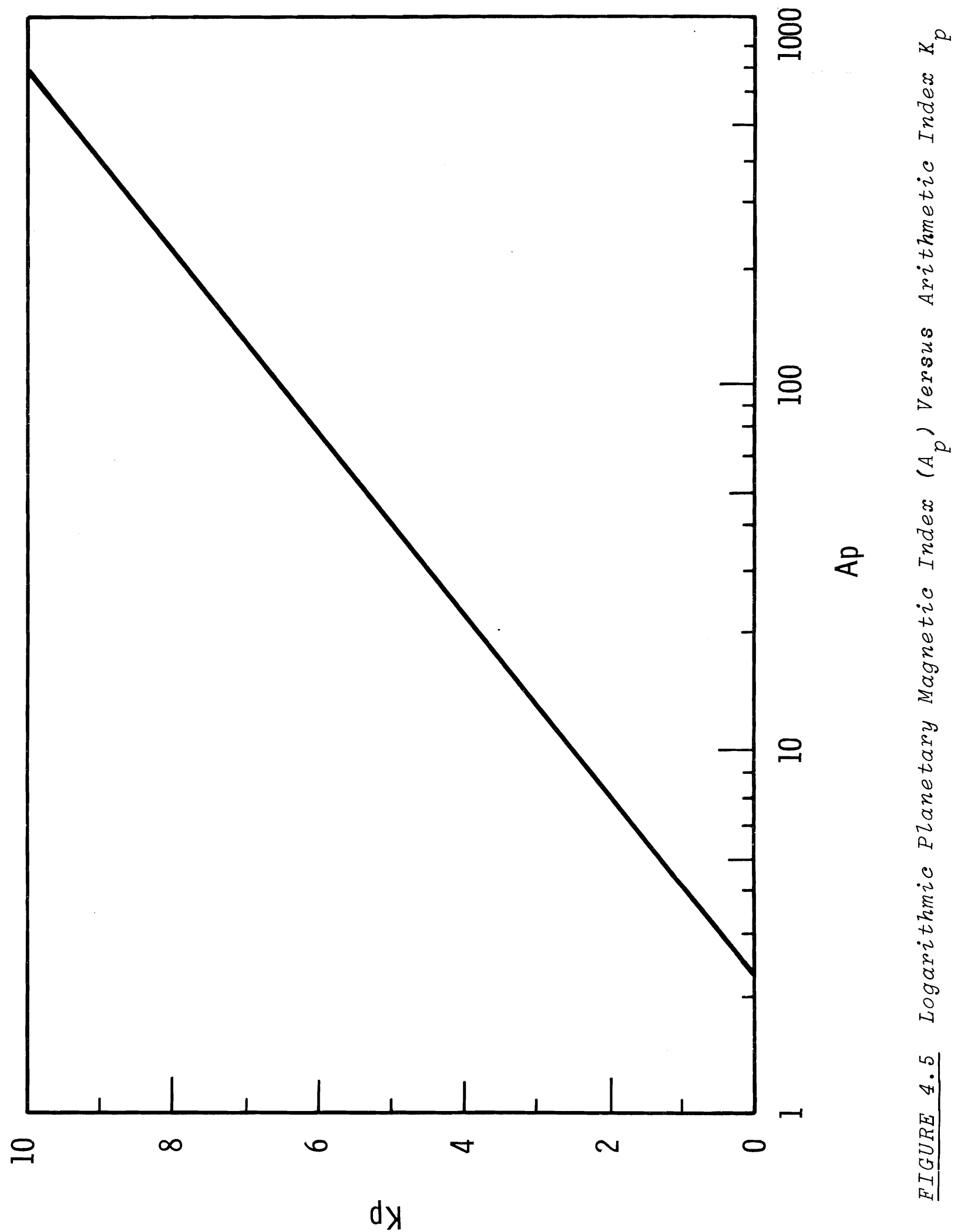

4-9 


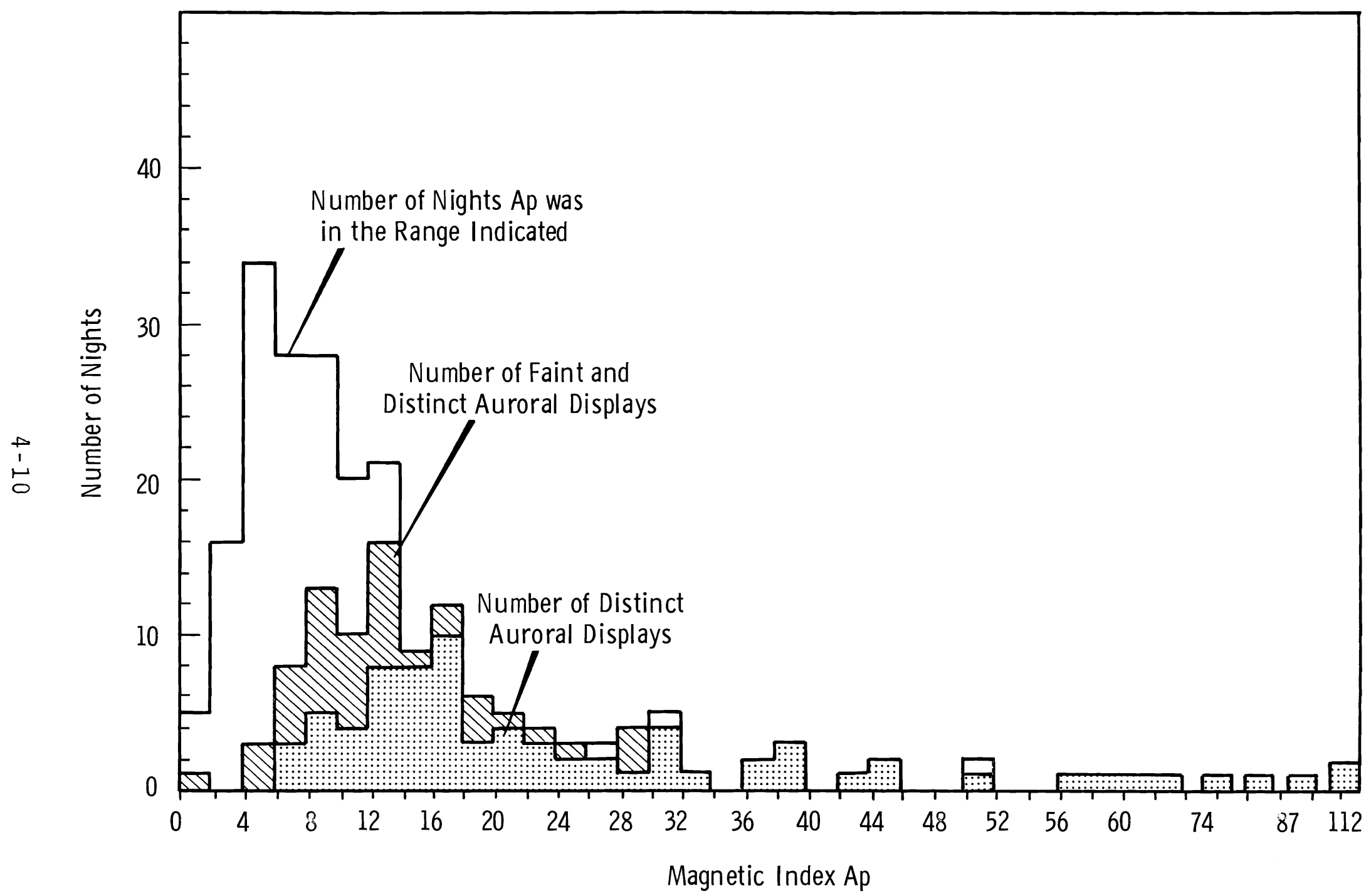

FIGURE 4.6 Distribution of Auroral Activity as a Function of $A_{p}$ Magnetic Index on Clear Nights 


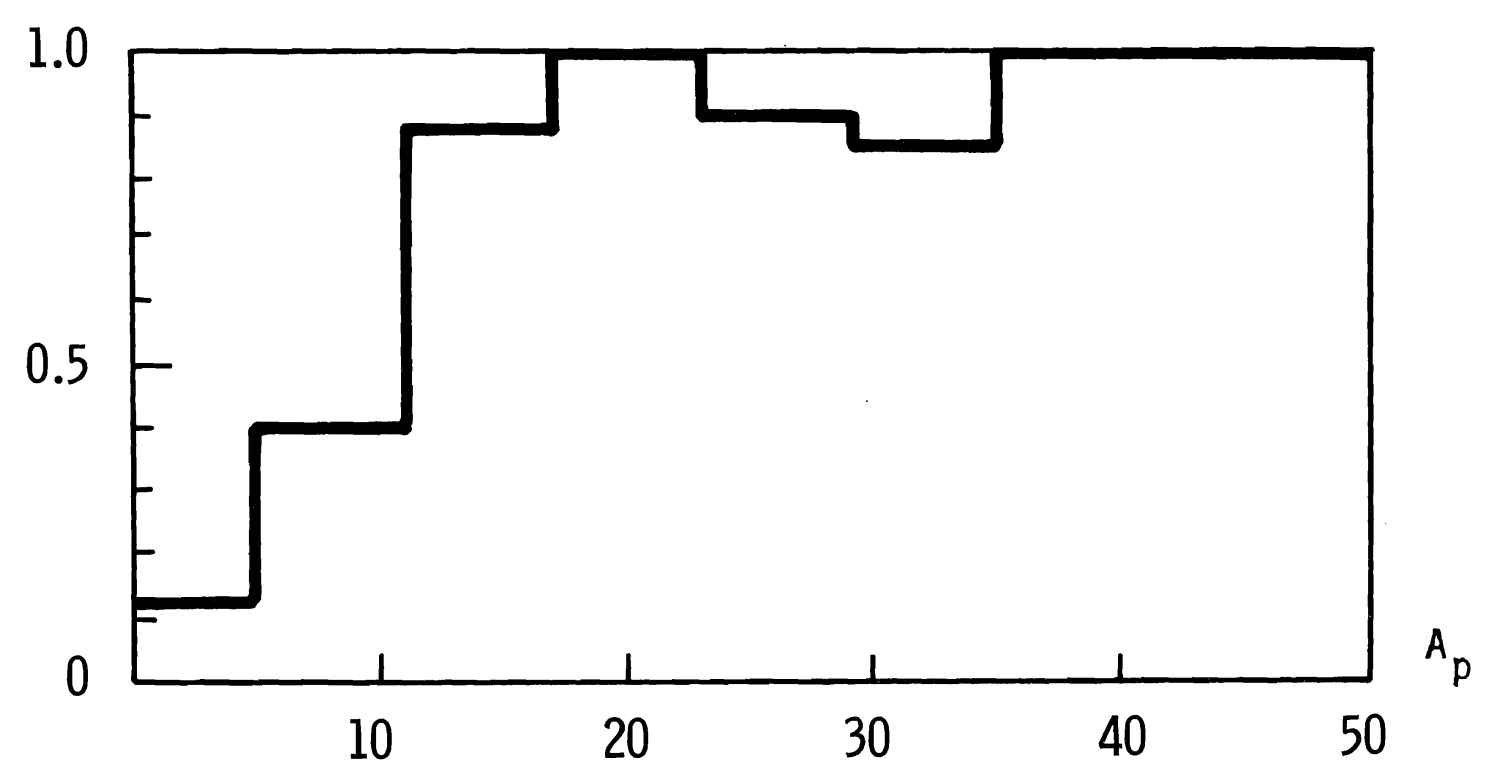

FIGURE 4.7 Fraction of Clear Nights on Which Auroral
Activity was Recorded Versus ${ }_{p}$ Index

\section{REFERENCE}

1. K. C. Clark and G. J. Romick. "An Auroral Spectrograph" Optical Soc, vol. 49, pp. 141-145. February 1959. 
BNWL - 1156

\section{SPECTROGRAPHIC STUDIES}

C. R. Batishko and R. J. Hoch

The meridian spectrographs described in the preceding section have a resolution of $20 \AA$ and a dispersion of $310 \AA / \mathrm{mm}$.

Some of the most interesting data of the year were recorded on the night of March 23, 1969 when both the Banff and Rattlesnake Stations simultaneously recorded strong auroral activity. During this activity a stable auroral red arc occurred well southward of the main auroral display and the sequence of spectrograms recorded at Richland show this arc clearly. For this reason this set of spectrograms is unique and the spectrogram and densitometer tracing shown in Figure 5.1 are, to our knowledge, the first such data published. The spectrogram shows the [OI] 6300 emission of the arc approximately $40^{\circ}$ south of the Richland zenith. Assuming a height of $400 \mathrm{~km}$ for the brightest region, the north-south width of the arc between half maximum intensities was approximately $210 \mathrm{~km}$. The SAR arc is clearly separate from the main auroral display. In the region of the arc there is no trace of enhancement of any other emission than [OI] 6300 to be found on the spectrogram.*

At Banff, the auroral display was essentially overhead and so intense that the SAR arc some $700 \mathrm{~km}$ south was too faint to appear on the spectrograms. Figure 5.2 shows the very intense and profuse auroral spectrum at 0307 MST at Banff. Figure 4.1 (See Section 4) shows the simultaneous exposure from Richland, when even there the aurora became so bright the SAR arc could not be distinguished clearly on the spectrogram.

* The light in the upper right hand corner of the spectrogram is due to local reflected man-made light and is to be ignored. 
BNWL - 1156

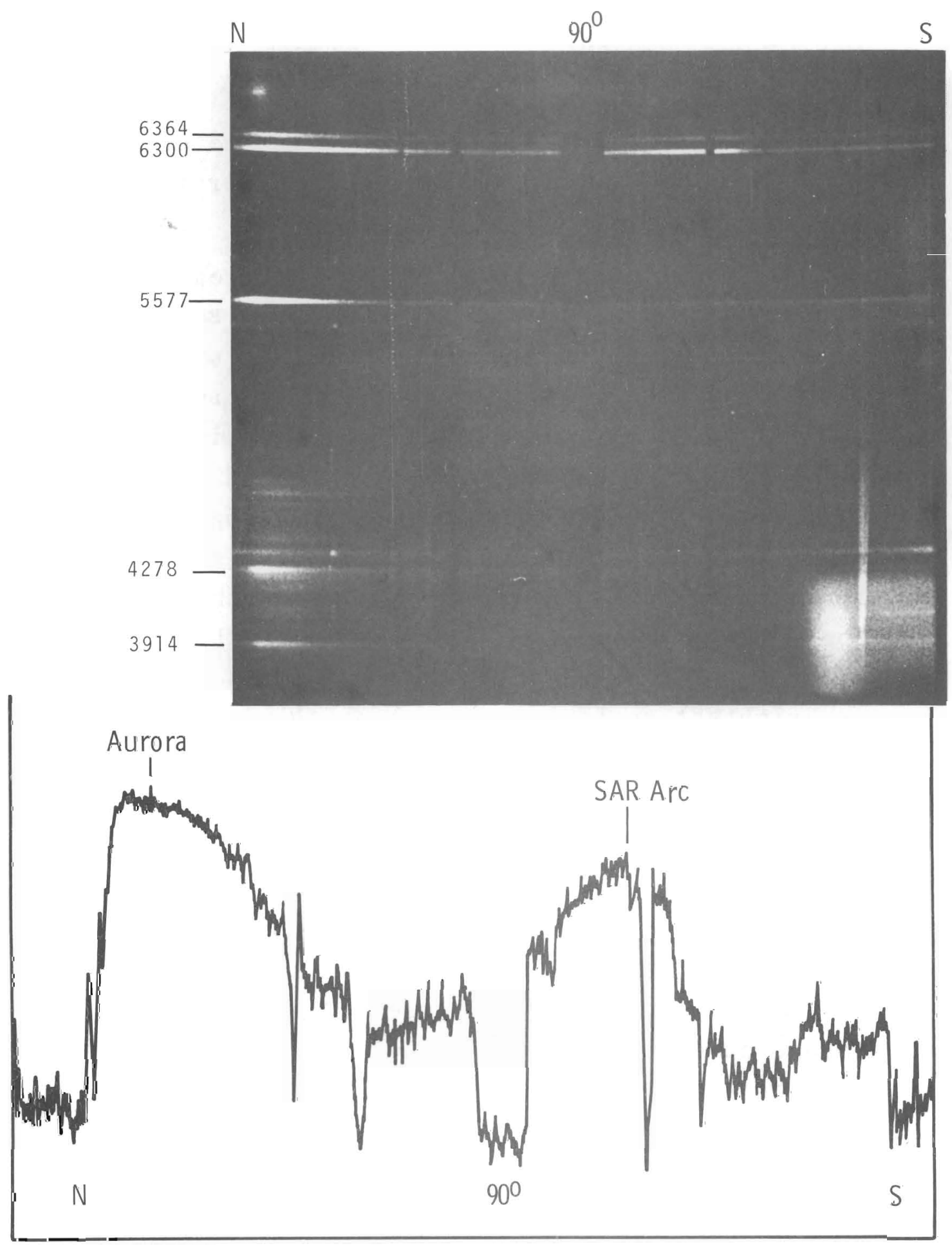

FIGURE 5.1 Spectrogram and Densitometer Tracing from North to South along the 6300 A Line, 23/24 March 1969, 2023 PST, Richland Station 
BNWL - 1156

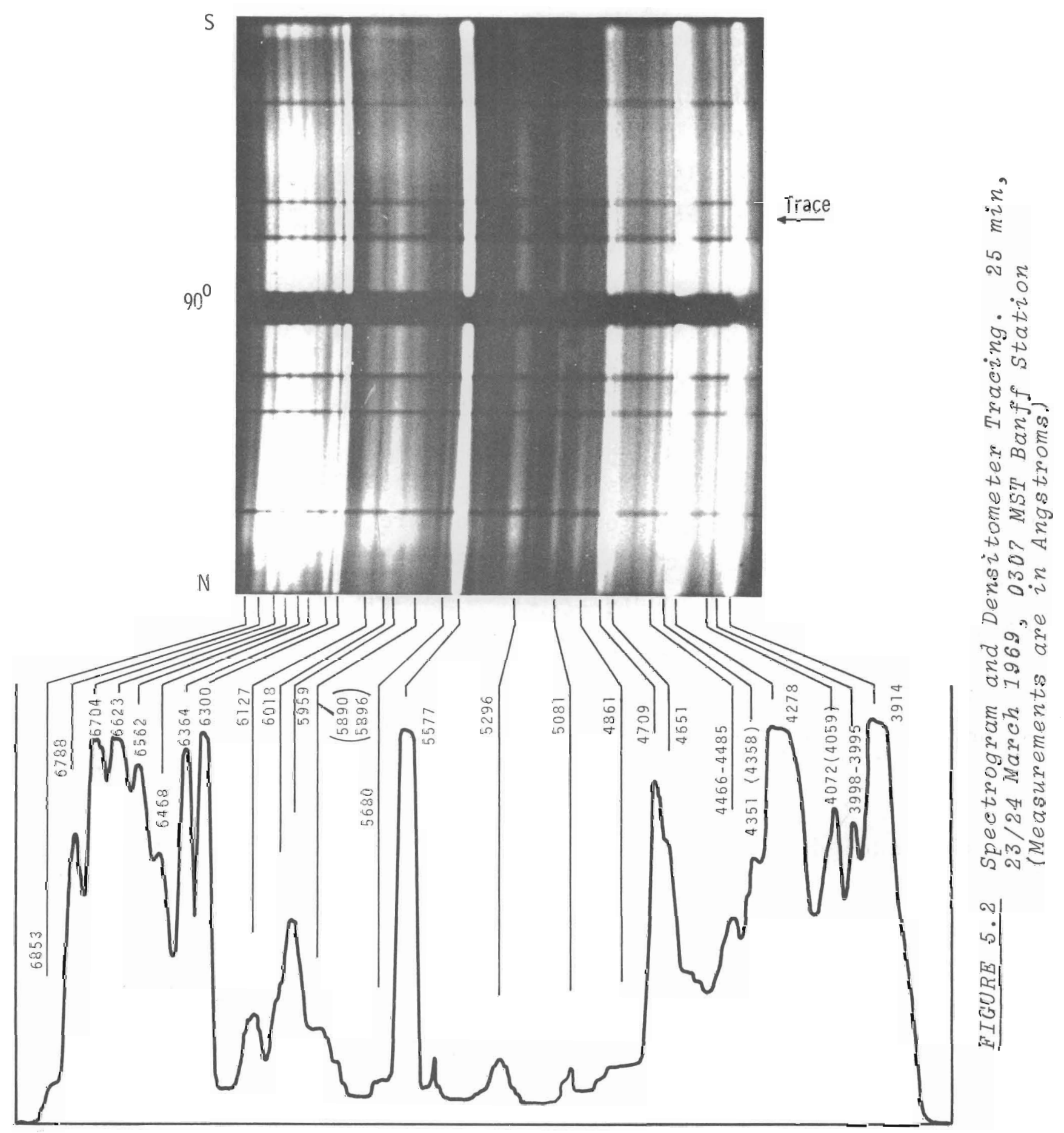


These spectrograms also show a strong hydrogen arc over Banff. The hydrogen arc is caused by protons which are incident along field lines at the latitude of Banff. The hydrogen arc was flattened horizontally above the Banff station and recorded "edge-on" from Richland. The relatively long optical path through the hydrogen arc along the line of sight from Richland enhanced the intensity so the record was obtained despite the distance and atmospheric attenuation.

The simultaneous records from the Banff and Richland stations permit triangulation to determine the position of the emitting volume of the hydrogen arc. Figure 5.3 shows the positions of the volume and extent of the half-maximum regions. The Ho emission was used for these triangulations. The height of the emitting volume ranges from $110 \mathrm{~km}$ to $150 \mathrm{~km}$ according to these data. It is of interest to compare these measurements to the theoretical prediction of Davidson shown in Figure 5.4. Both the height and general horizontal spread appear to agree reasonably we11 in measured and predicted values.

The aurora of $23 / 24$ March, 1969 was so intense that normally faint, weak lines were easily recorded. For example, the usually faint $5296 \mathrm{~A}$ and $6127 \mathrm{~A}$ emissions are identified in Figure 5,2. Further analysis of these data for this aurora is schedulled for completion in coming months.

Among the situdies being conducted on the 23/24 March, 1969 data are temporah and spatial comparisons between the red arc and other standard auraral emissions, comparison with photometric data, and absolute intensity measurements of various emissions :

Four studies are also underway using spectrograms of 5 or 6 strong auroras. The first of these is a temporal study of the ratio of intensity of $\mathrm{N}_{2}^{+}$(IN) at $4278.1 \mathrm{~A}$ to the [OI] 1 ine at $5577.3 \mathrm{~A}$. This ratio has been predicted to be about 3 if the common excitation mechanism is primary electrons. 
BNWL - 1156

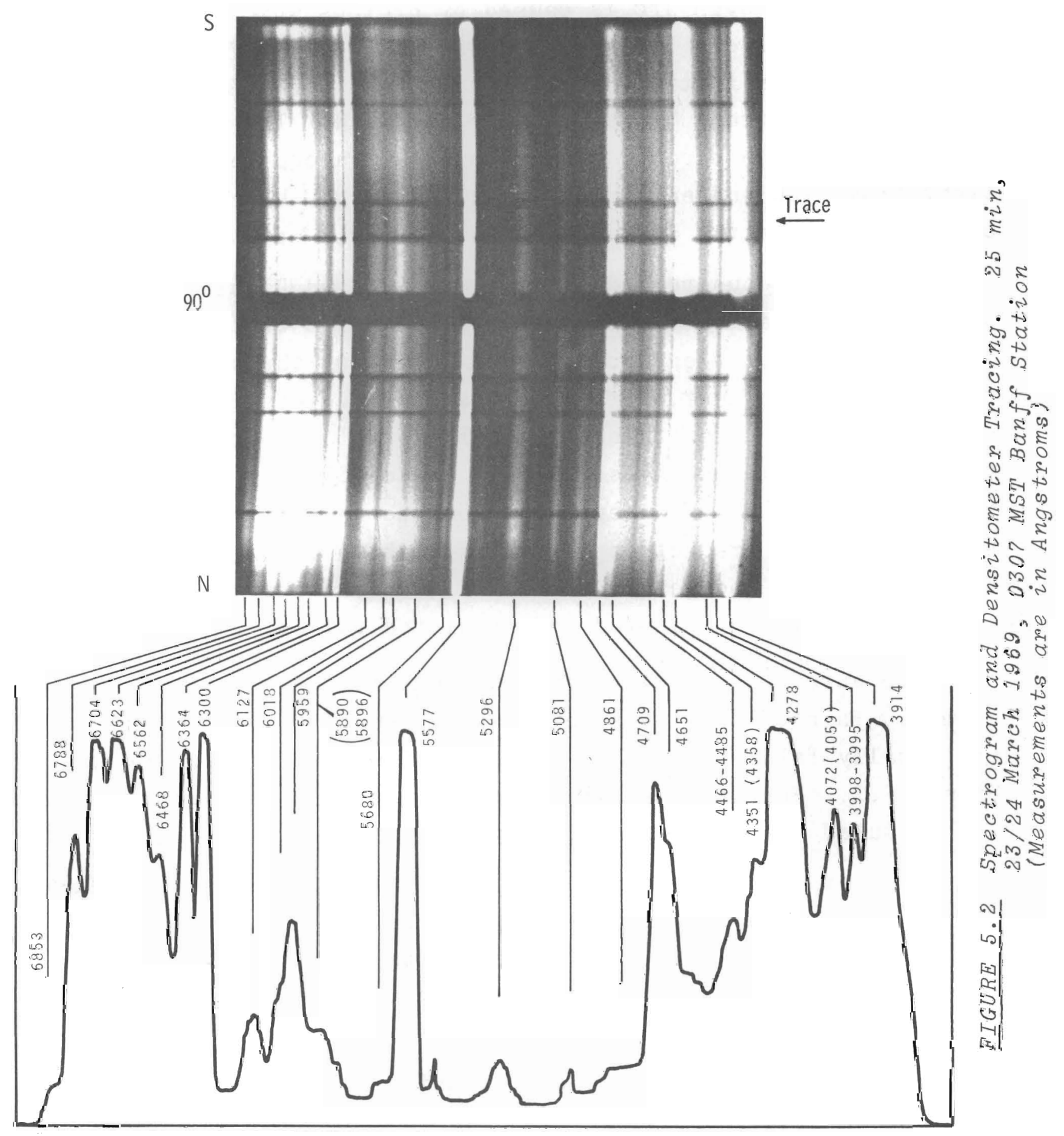


BNWL-1156

These spectrograms also show a strong hydrogen arc over Banff. The hydrogen arc is caused by protons which are incident along field lines at the latitude of Banff. The hydrogen arc was flattened horizontally above the Banff station and recorded "edge-on" from Richland. The relatively long optical path through the hydrogen arc along the line of sight from Richland enhanced the intensity so the record was obtained despite the distance and atmospheric attenuation.

The simultaneous records from the Banff and Richland stations permit triangulation to determine the position of the emitting volume of the hydrogen arc. Figure 5.3 shows the positions of the volume and extent of the half-maximum regions. The Ho emission was used for these triangulations. The height of the emitting volume ranges from $110 \mathrm{~km}$ to $150 \mathrm{~km}$ according to these data. It is of interest to compare these measurements to the theoretical prediction of Davidson shown in Figure 5.4. Both the height and general horizontal spread appear to agree reasonably well in measured and predicted values.

The aurora of 23/24 March, 1969 was so intense that normally faint, weak lines were easily recorded. For example, the usually faint 5296A and 6127A emissions are identified in Figure 5:2. Further analysis of these data for this aurora is scheduled for completion in coming months.

Among the studies being conducted on the 23/24 March, 1969 data are temporal and spatial comparisons between the red arc and other standard auroral emissions, comparison with photometric data, and absolute intensity measurements of various emissions.

Four studies are also underway using spectrograms of 5 or 6 strong auroras. The first of these is a temporal study of the ratio of intensity of $\mathrm{N}_{2}^{+}$(1N) at $4278.1 \mathrm{~A}$ to the [OI] line at $5577.3 \mathrm{~A}$. This ratio has been predicted to be about 3 if the common excitation mechanism is primary electrons. 


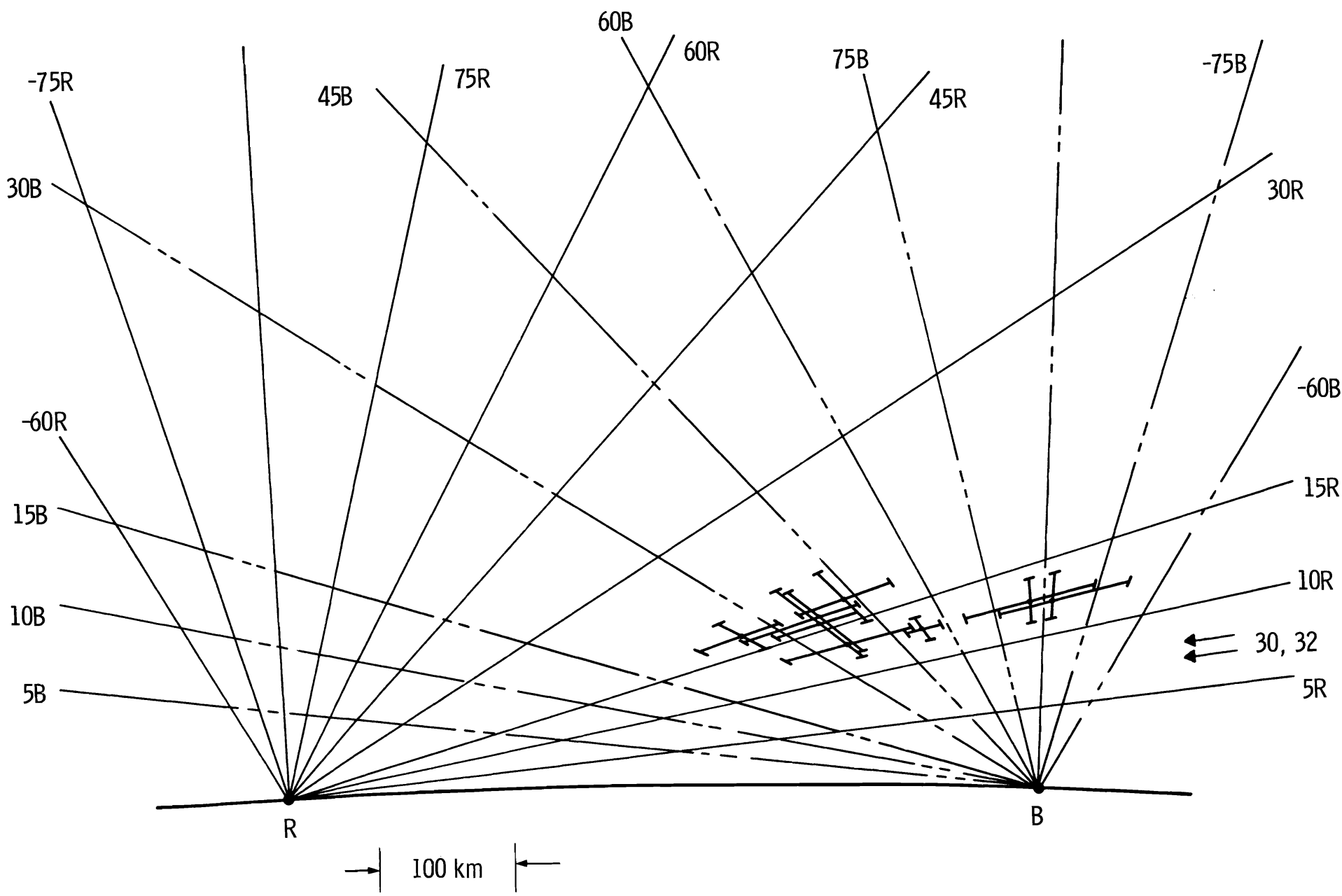

FIGURE 5.3 Position of the $H_{\alpha}$ and $H_{B}$ Emitting Regions Determined by Triangulation. The Extent of the Emitting Volume lat halfmaximum) is Indicated. 


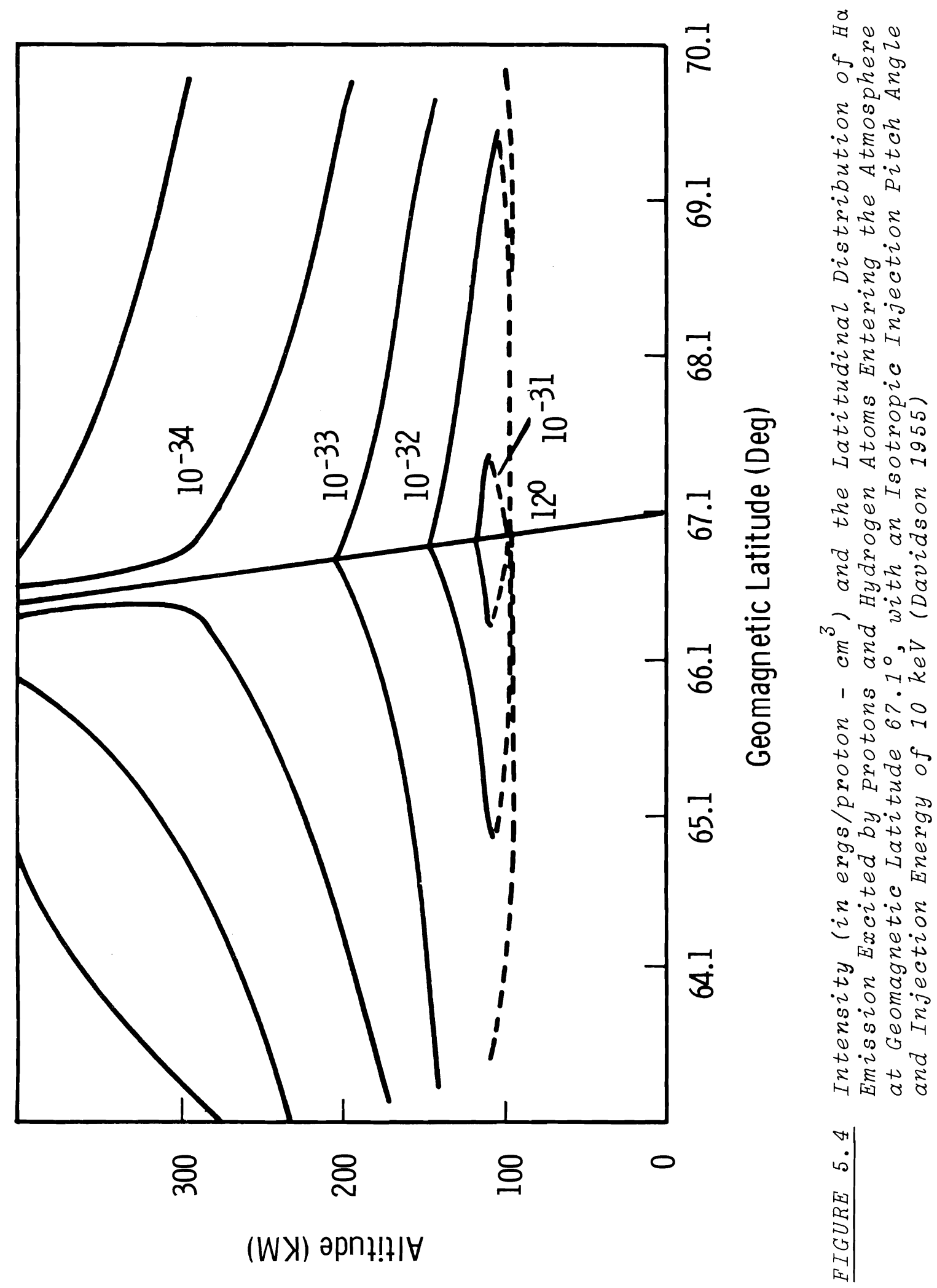


Accurate measurements of intensity are computed from microdensitometer tracings across the 5-min exposure spectrograms on which these emissions do not saturate the film as they do in the 25-min exposures.

A second study is being conducted to examine the temporal variation of the $\mathrm{Na} I$ emission at $5589.9 \mathrm{~A}-5895.9 \mathrm{~A}$ with respect to the $\mathrm{N}_{2}^{+}$band system: $1 \mathrm{~N}$ [0-0] at $3914.4 \mathrm{~A}, 1 \mathrm{~N}[0-1]$ at 4278.1A, and $1 \mathrm{~N}$ [0-2] 4709.2A. Usually the sodium airglow emissions are explained independently of short term magnetic variations and incident primary particle radiation. However, there appears to be some enhancement of the sodium doublet during auroras and this is to be measured and explained. We have also noted and are studying an occasional inversion of the expected intensities of $1 \mathrm{~N}$ [1-3] 4651.8A and [0-2] 4709.2A. Apparently nonequilibrium thermal distributions prevail in such cases and a temporal correlation with other emissions such as $H \alpha$ is sought.

Finally, we are examining the temporal variation of the $\mathrm{O}_{2}^{+}$emission $1 \mathrm{~N}$ [2-0] at $5295.7 \mathrm{~A}$ relative to the OI emission at $5577.3 \mathrm{~A}$ and $\mathrm{N}_{2}^{+}$emission $1 \mathrm{~N}[0-1]$.

\section{CAL IBRATION}

The intercalibration of the spectrograph and the photometers is of crucial importance in determining absolute intensities of the emissions. This calibration is being continually improved. Essentially, there are four standard light sources involved, three of which are used as routine references. One standard source is particular stars of known intensity which are detected during photometric scanning. The second standard source is the apparent surface brightness of the Milky Way. The third is a portable radioactive light source and the fourth is a tungsten filament quartz iodide source. For laboratory calibrations of the spectrograph we use the last of these four. For the photometer, particular 
stars and the radioactive source are used routinely and we are beginning to use the Milky Way. Potentially, the Milky Way is the best standard for photometric work since use of discrete stars raises problems involving nonuniformity of the photocathode surfaces. The centering of the star in the field of view is also important, because incorrect centering can compromise the results. Absolute calibrations of the spectrographs are perhaps more difficult than, for the photometer since spectrographic work involves the peculiarities of photographic emulsions as well as the method of determining photographic densities. We used the following procedure for the Rattlesnake spectrograph, using the geometry of Figure 5.5. The tungsten filament used for spectrographic calibrations was operated at a measured 2 A for which current it had been calibrated by C. S. Deehr at the University of Alaska. The graph in Figure 5.6 is the measured standard lamp output. A mercury arc lamp was used as a wavelength reference and appeared at the opposite edge of the spectrogram from the continuum. Exposures of various durations were made, some incorporating neutral density filters for intensity reduction. A diffuse white reflecting screen was used to simulate a distant light source. The screen was found to have an $18 \%$ loss due to anistropic reflective properties and 3\% loss due to absorption. It was assumed and experimentally confirmed that recorded intensity is independent of diffuse screen-to-instrument distance providing the instrument slit doesn't "see" the edge of the diffuse screen. This allows film densities produced by an aurora at typical distances in excess of $400 \mathrm{~km}$ to be compared directly to film densities produced by the same exposure duration in the $1 \mathrm{ab}$ at a distance of 2 to 3 meters.

All data, both calibration and observational are recorded on Kodak type 103-a spectroscopic film. The film is developed 7 min at $68^{\circ} \mathrm{F}$ in Kodak D-19 developer using standard agitation, washing, fixing and drying procedures. Data are then 
BNWL - 1156

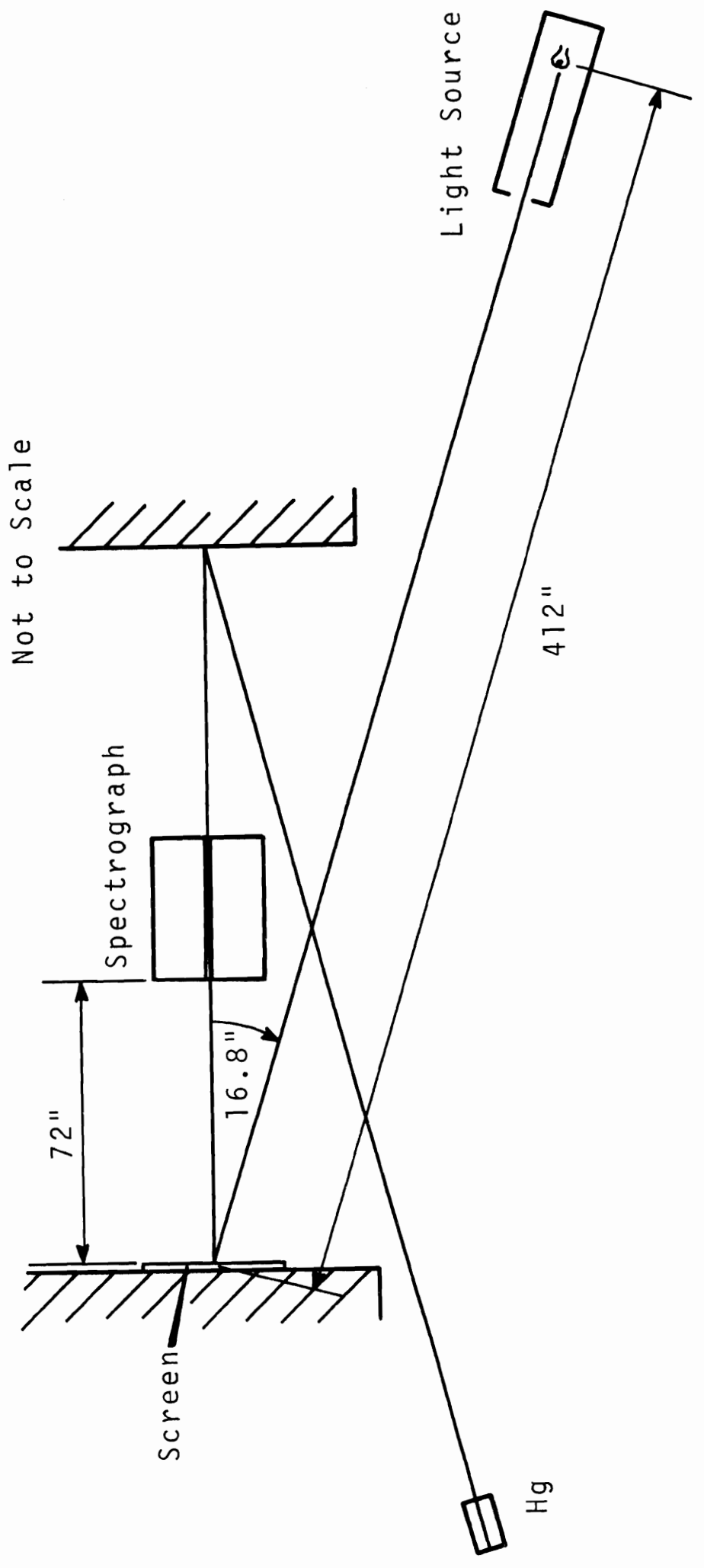

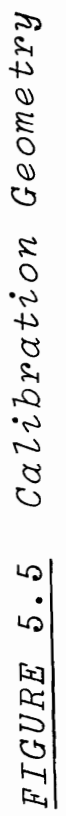




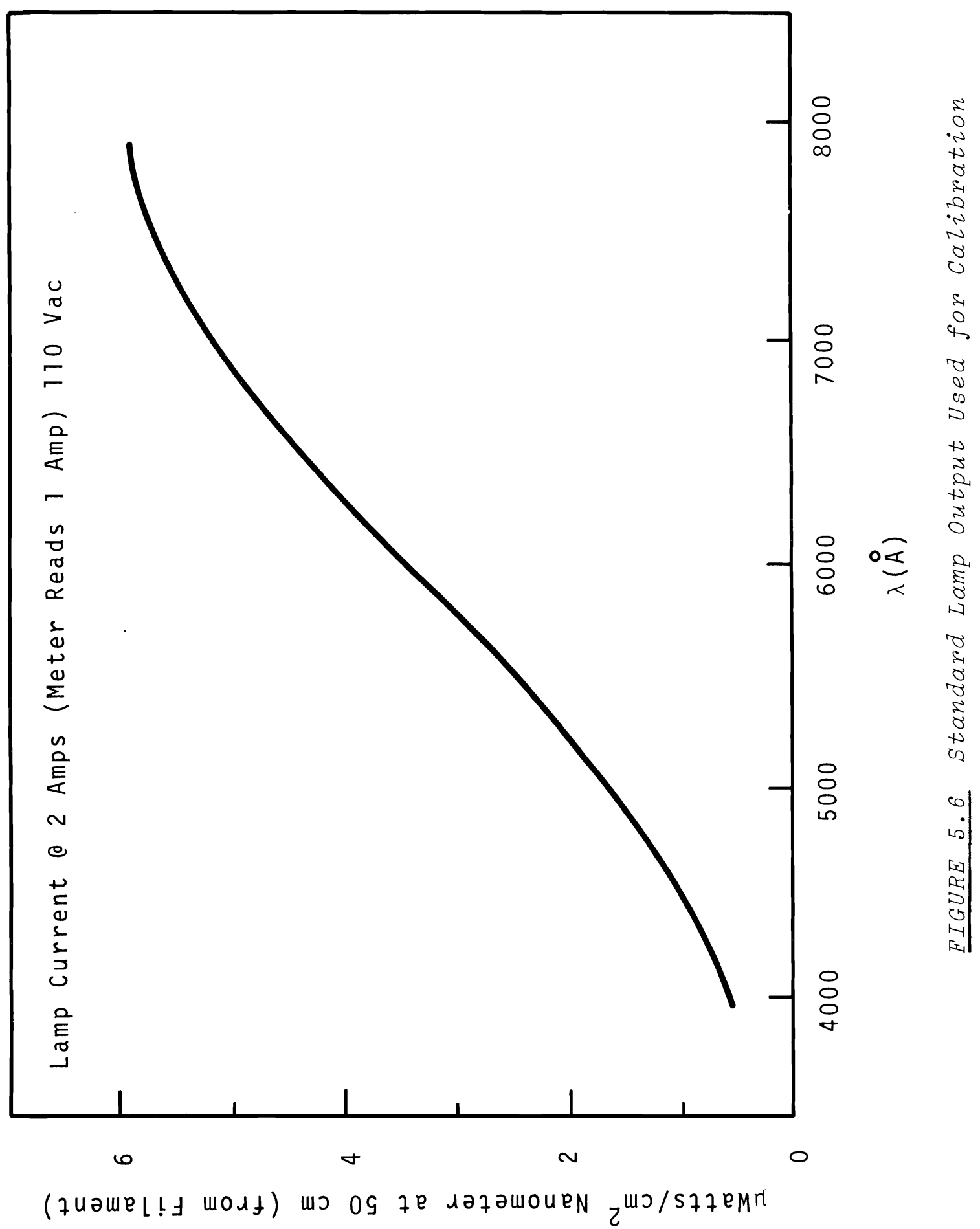


densitometered, a wavelength reference template produced from the mercury spectrum, and densities calculated from the densitometer trace pen deflection, allowing for film background fog level. The densities are related to the energy reflected from the screen. They are then normalized to 5 - and 25-min exposure durations by use of emulsion reciprocity curves provided by Kodak to allow direct comparison to observational data.

Calibration is accomplished for a number of key wavelengths, and extrapolation using instrument spectral response curves allows the calibration to be used for other wavelengths at the loss of a few percent accuracy. Accuracy of the calibrations are estimated to be in the $10 \%$ to $20 \%$ range. 


\section{PHOTOMETRIC MAP OF THE MILKY WAY}

\section{L. Smith}

The light of the night sky includes terrestrial, solar, and astronomical components. The terrestrial components includes night airglow emissions, continuum radiation, and, at high latitudes, auroral radiations. The solar component, zodiacal light, is due to sunlight scattered from interplanetary matter in the solar system. The astronomical component involves radiations from individual stars, integrated starlight, galactic light, and cosmic light.

In photometric investigations of night airglow and weak auroral emissions, the total background must be subtracted from the observations. Normally, a background filter is chosen near the wavelength of the emission of interest and the sky scanned with both the background and the emission filters. To eliminate the total background, the background observations are multiplied by an appropriate factor and the results subtracted from the emission observations. This two-color technique works satisfactorily but doubles the observation program and data processing. Another technique is to tilt the emission filter or the light beam with respect to the filter so that the filter transmission characteristics shift significantly to the short wavelength side of the emission line, resulting in only background transmission. By alternating the tilt and non-tilt modes, the background can be electronically subtracted. However, the mechanics and electronics are considerably more complicated and are apt to have failures compared to the stationary filter system.

Roach and Smith (1964) (1) found that at the wavelength of $5300 \mathrm{~A}$, the combination of the zodiacal light (ZL) and integrated starlight (SL) radiations, was $85 \%$ of the total background at Haleakala, Maui, Hawaii (latitude $20.7^{\circ} \mathrm{N}$ ) and $77 \%$ at FRITZ Peak, Boulder, Colorado (latitude $39.9^{\circ} \mathrm{N}$ ). The spectra of the $\mathrm{ZL}$ 
and SL are, to a first approximation, continua. Consequently, it should be possible through analysis to eliminate these two components from the emission filter observations. Of course, the radiance of the $\mathrm{ZL}$ and $\mathrm{SL}$ as a function of the coordinate system in which each of these radiations can be predicted must be known. Smith, Roach, and Owen (1965) (2) published a ZL map as a function of the ecliptic coordinates deduced from observations at $5300 \mathrm{~A}$, Figure 6.1 . The unit of brightness in Figure 6.1 is S10 (VIS) which is equivalent to the number of tenth magnitude (visual) stars per square degree. By using this map and the SL map (3), attempts were made to eliminate through analysis the $\mathrm{ZL}$ and SL backgrounds from emission observations. The results were encouraging but the SL map was not accurate because milky way crossings were not properly allowed for. Roach and Smith (1964) ${ }^{(1)}$ discuss the inaccuracies of the available SL maps. It was obvious from this work that a new photometric map of the milky way would be useful. We (F. E. Roach and L. L. Smith) have recently completed such a map. This map was compiled from background observations at $5300 \mathrm{~A}$ taken at Haleakala, Maui, Hawaii (latitude $20.7^{\circ} \mathrm{N}$ ) and E1 Leoncito, Argentina (latitude $31.8^{\circ} \mathrm{S}$ ). Figure 6.2 includes the new milky way values for galactic latitudes $<\left|20^{\circ}\right|$. For latitudes away from the milky way, (latitudes $>\left|20^{\circ}\right|$ ) we used the results of Roach and Megill (1961). (3) We now find that for emission radiations as low as 50 Rayleighs observed with interference filters with half-bandwidths of 15-20A, the background can be essentially eliminated through analysis by subtracting the $Z L$ and SL values of Figures 6.1 and 6.2 . 


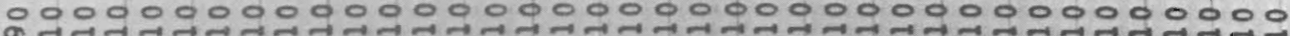

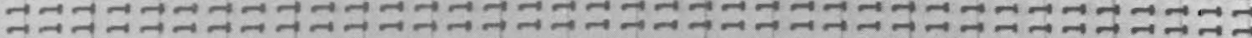

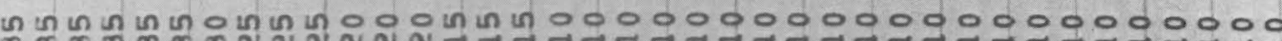

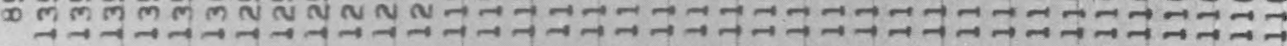

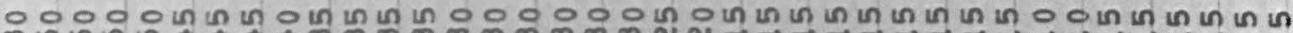

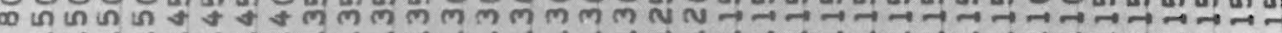

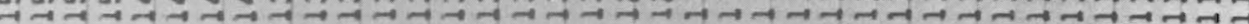

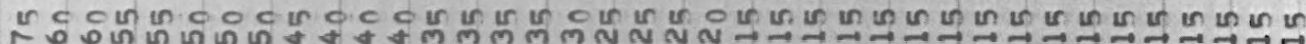

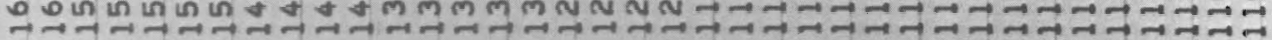

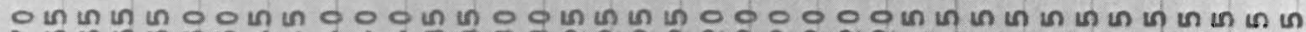
แn

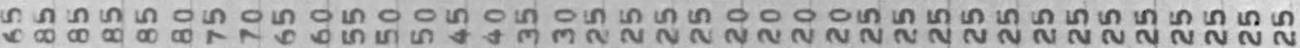

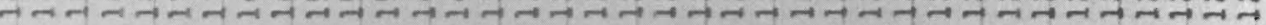

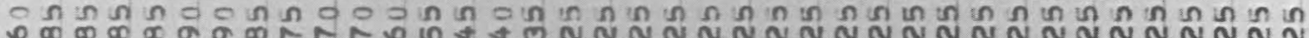

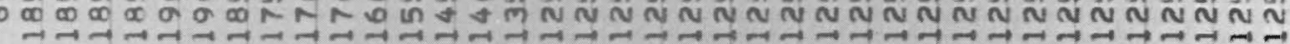

in in in in 0 in 0 in 0 in 000 in 000000000 in un un un un 00 in in in 0 in in in in

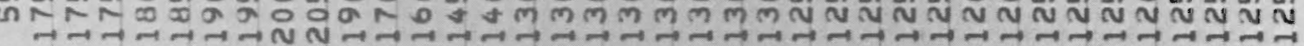

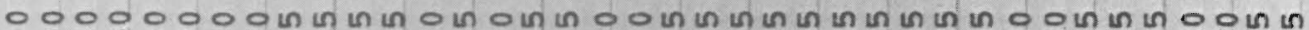

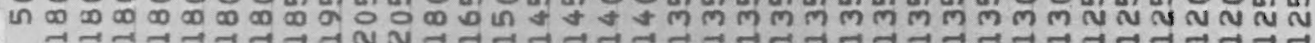
出

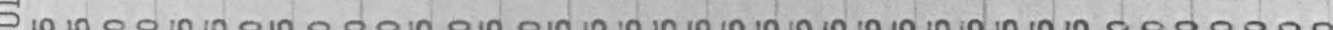
t तN

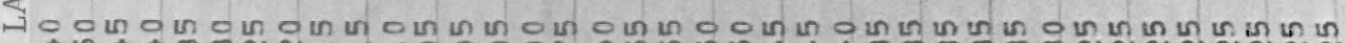

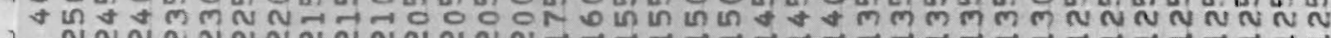
0

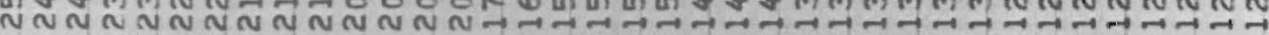

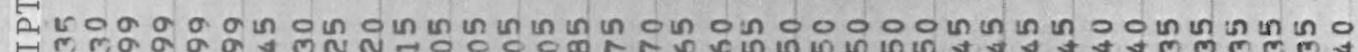
"m magagd

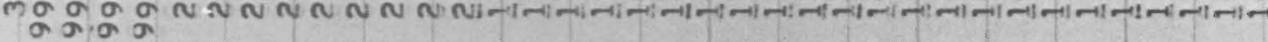

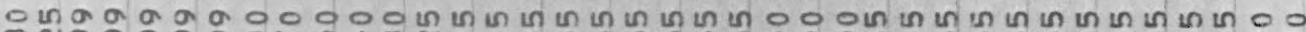

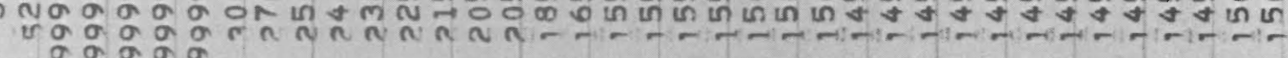
ir

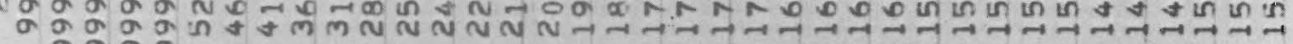
a $\sigma \sigma a$

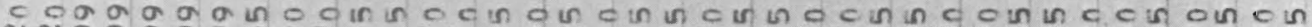

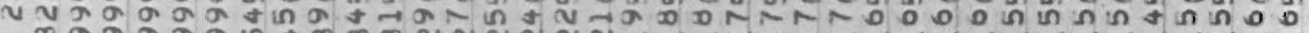

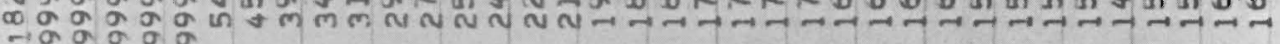

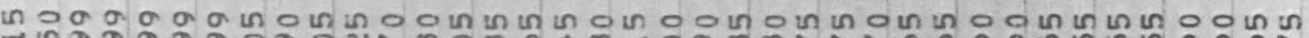

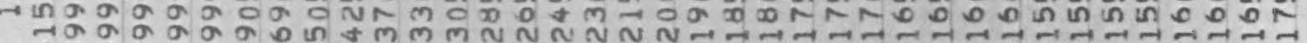

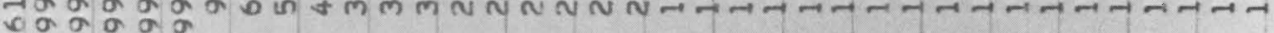

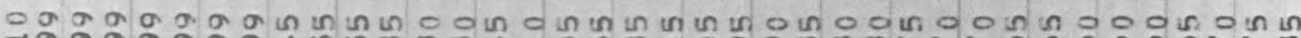
年 a

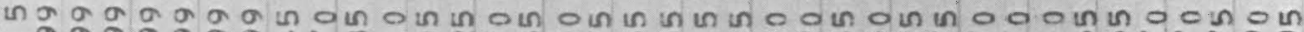

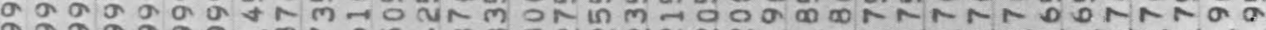

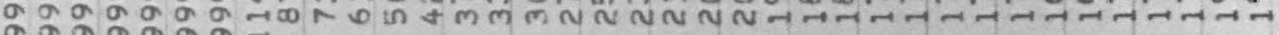

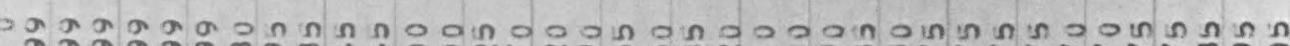

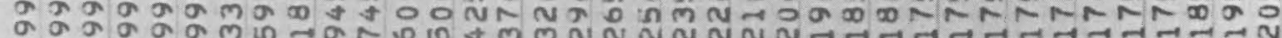

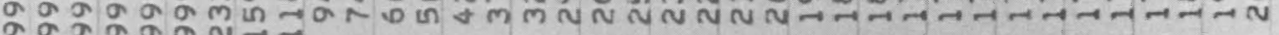

x omomomoun on

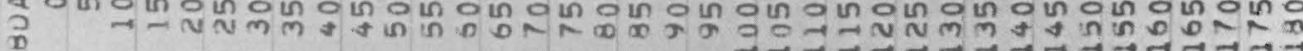




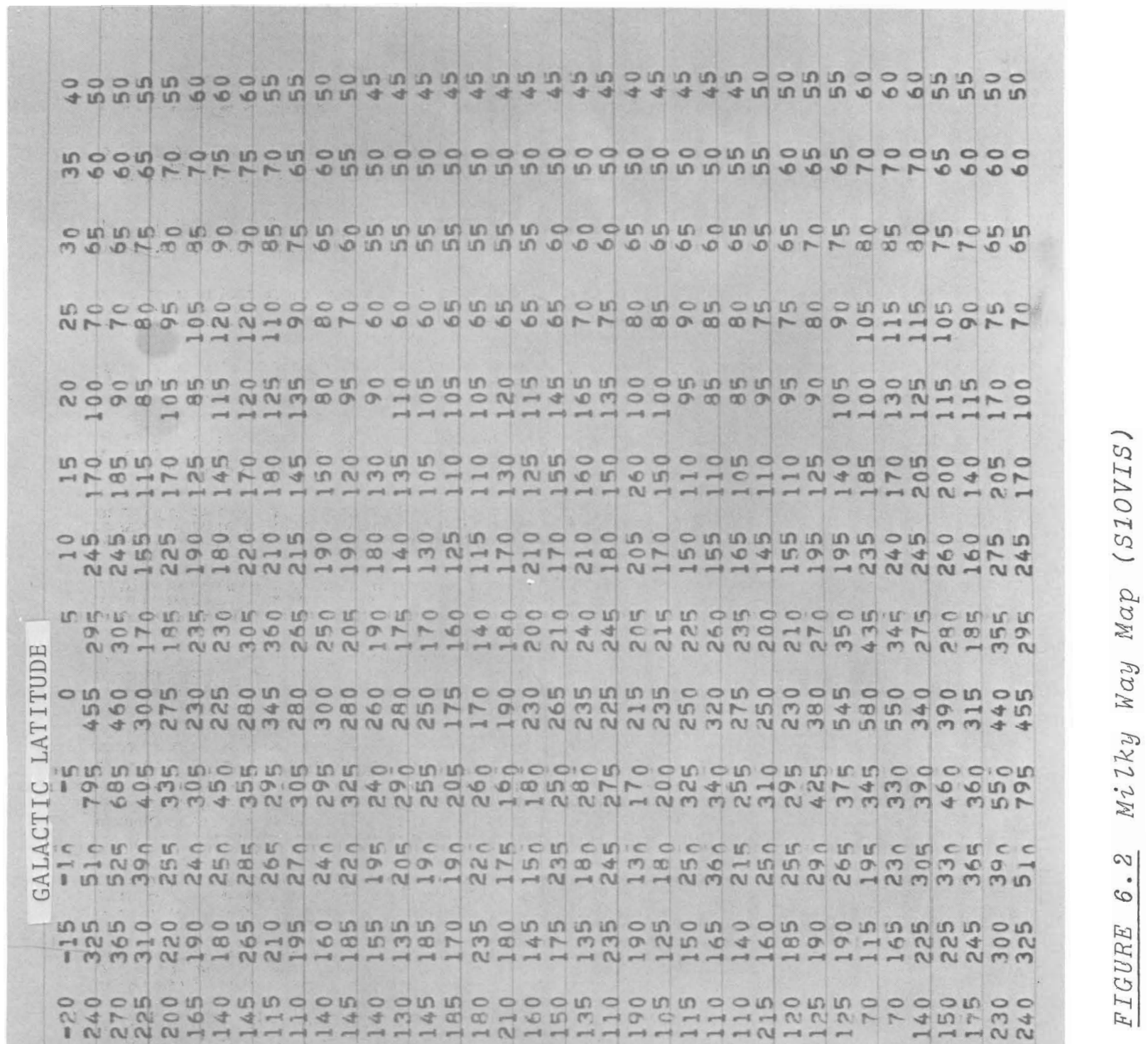

in

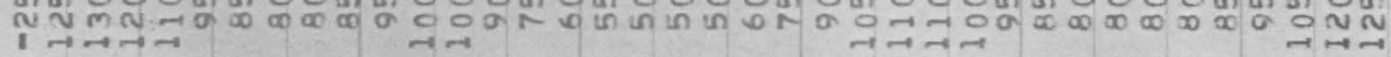

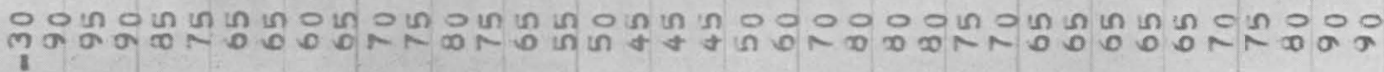

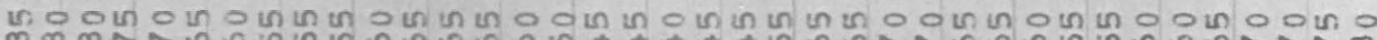
mod

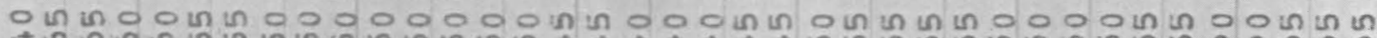
t 0.00 in in in in in in

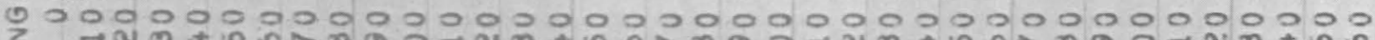

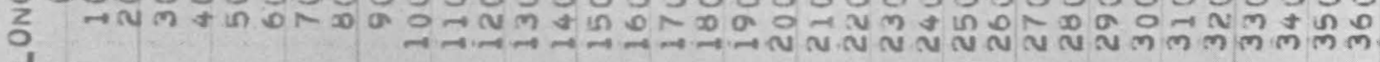




\section{REFERENCES}

1. F. E. Roach and L. L. Smith. Absolute Photometry of the Light of the Night Sky, Tech. Note 214. National Bureau of Standards, Washington, D. C. June 1964.

2. L. L. Smith, F. E. Roach and R. W. Owen." "The Absolute Photometry of the Lodzacal Light," rlanetary space sci, vol. 13, p. 207. 1965.

3. F. E. Roach and L. R. Megizl. The Integrated Starlight Over the Sky, Tech. Note 106, National Bureau of Standards, Washington, D. C., June 1961. 


\section{FORBIDDEN TRANSITIONS IN THE UPPER ATMOSPHERE}

F. E. Roach

\section{INTRODUCTION}

It is convenient to consider that the upper atmosphere spawns optical radiations in the following ways:

- as the result of the direct impingement of solar radiation (dayglow and twilight).

- by the release of stored solar energy (nightglow).

- as a consequence of excitation by impact of energetic particles (aurora).

In the lower atmosphere (troposphere), the overwhelming optical effect of impinging sunlight is the Rayleigh scattering which produces the daytime sky. In the domain above about 70 kilometers, ultraviolet solar radiation is responsible for profound changes in the physical, chemical and electrical composition of the atmosphere. As the number density of the atmosphere decreases with increasing height, atoms, molecules and their ions excited to metastable states are able to emit observable radiations in competition with collisional processes which de-excite ("quench") the excited atom or molecule without emission. The upper-atmosphere analyst is interested in both the interpretation of the mechanism of excitation into the metastable states and in the radiation/ de-excitation processes which exhaust the states.

\section{FORBIDDEN ATOMIC LINES}

In the absence of any collisional de-excitation, the relationship between the observed intensity, $Q$, of a particular emission from state $b$ to $a$ and the Einstein transition probability, $A_{b a}$, is

$$
Q=\int_{0}^{\infty} \mathrm{n}_{b} \cdot A_{b a} \cdot d h \quad \text { quanta } \cdot \mathrm{cm}^{-2} \cdot \mathrm{sec}^{-1}
$$


where $n_{b}$ is the number density of the atom in state $b, h$ is the height in the atmosphere, and $\mathrm{H}$ is the effective "thickness" of the emitting layer referred to the emission at the peak. To a very rough approximation, the effective thickness of the layer may be taken as the scale height. In units of Rayleighs, Equation (2) becomes:

$$
\mathrm{Q}=10^{-6} \cdot \mathrm{n}_{\mathrm{b}}(\max ) \cdot \mathrm{A}_{\mathrm{ba}} \cdot \mathrm{H} \text { Rayleighs }
$$

In the case of forbidden transitions from metastable states, the transition probability or quantal rate, $A$, is very small compared with permitted transitions. Thus a forbidden transition emission must result from a proportionally larger density of atoms in the upper state than a permitted emission of the same intensity. In general, the atmospheric mechanisms of excitation into an excited state are completely independent of the mechanisms of depletion of the state. Therefore, if collisional de-excitation is rapid, depletion of the upper state by the two processes, de-excitation and radiation, will be in competition.

Table 7.1 shows the present knowledge concerning emissions from forbidden atomic transitions in the upper atmosphere. An $x$ in one of the last four columns implies that the emission has been observed in the dayglow, twilight, aurora or nightglow. The absence of an $x$ indicates that the radiation has not been observed which may be due to its actual absence in the phenomenon or to the difficulty of its observation.

\section{MOLECULAR BAND SYSTEMS}

Table 7.2 differs from Table 7.1 in that it includes the molecular band systems, both permitted and forbidden, observed in the upper atmosphere. The transition probabilities vary from the three cases of low probability (the Vegard-Kaplan bands of $\mathrm{N}_{2}$, the IR atmospheric and the atmospheric bands of $\mathrm{O}_{2}$ ) to the Second Positive $\left(\mathrm{N}_{2}\right)$ and First Negative $\left(\mathrm{N}_{2}{ }^{+}\right)$with transition probabilities greater than $10^{7}$ transitions/sec. The 
BNWL - 1156

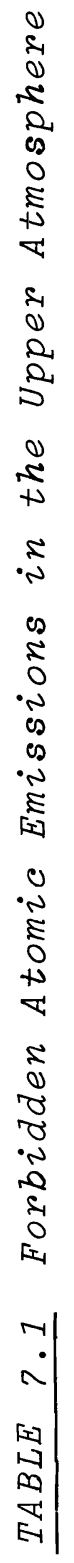

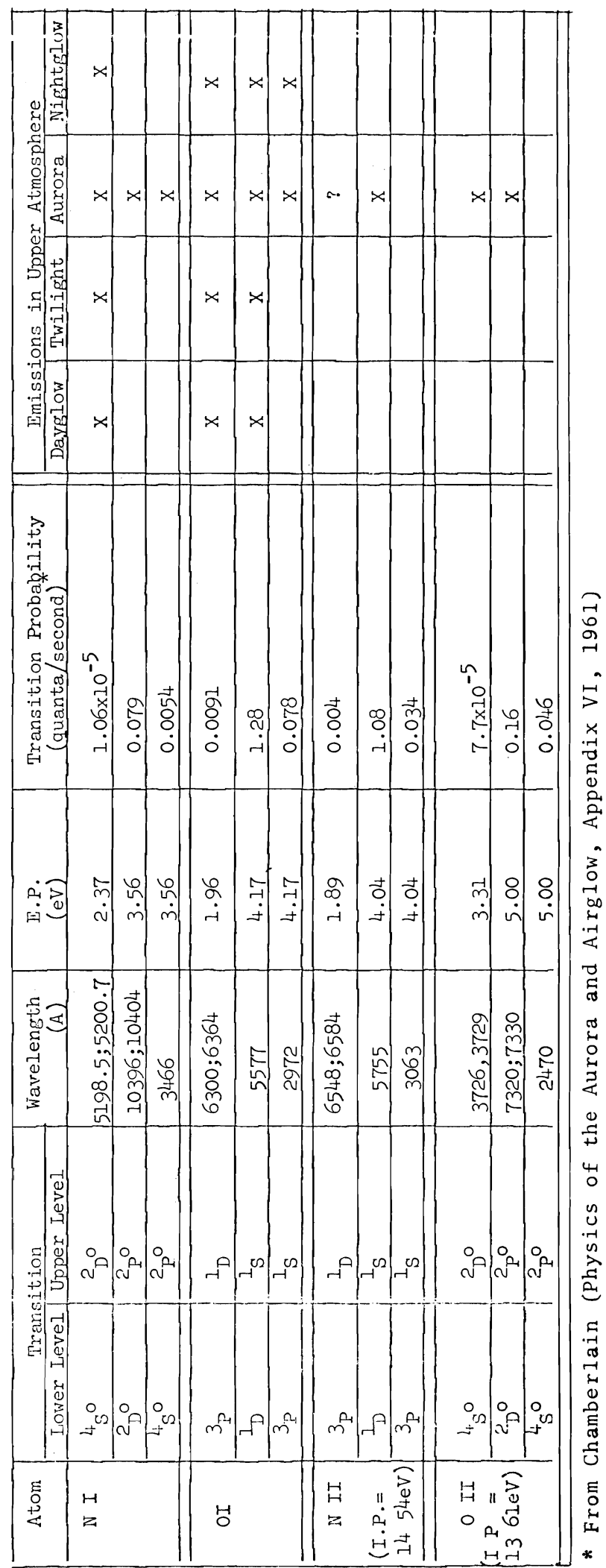


窝

\begin{tabular}{|c|c|c|c|c|c|c|c|c|c|}
\hline $\mathrm{x}$ & & & & & $\begin{array}{l}(6=, \Omega) \\
\varepsilon 己 \cdot \varepsilon\end{array}$ & 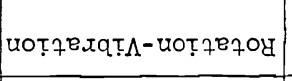 & $\amalg_{2}$ & & но \\
\hline & & $x$ & $\mathrm{x}$ & $s^{0 T \times S}$ & $s \cdot s$ & spureg $\curlywedge$ & $\mathrm{H}_{2} \mathrm{X}$ & $+t^{3}{ }^{V}$ & ON \\
\hline & $\mathrm{x}$ & & & $\varsigma^{0 \tau x \tau \cdot 6}$ & $\tau \cdot 9$ & 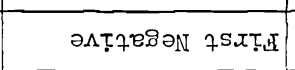 & $n_{u_{t}}{ }^{8}$ & $\begin{array}{l}3 \\
-3+9\end{array}$ & \multirow{2}{*}{ 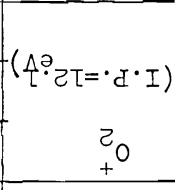 } \\
\hline & & & & $9^{0 \tau x \varepsilon+\tau^{\prime} \tau}$ & $8 \cdot 7$ & 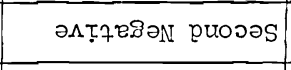 & $n_{U_{2} \mathrm{x}}$ & $n_{L_{2}}$ & \\
\hline \multirow[t]{2}{*}{ لy $\tau>$} & $\mathrm{x}$ & $\mathrm{x}$ & $\mathrm{x}$ & $L^{0 \tau \times 69^{\circ} \tau}$ & $\tau \cdot \varepsilon$ & 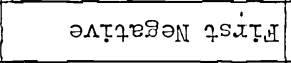 & $\begin{array}{l}8 \\
+35^{x} \\
\end{array}$ & 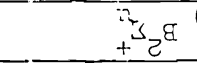 & \multirow{2}{*}{$\begin{array}{c}\Lambda \partial \cdot S \tau=\cdot \tau \cdot I) \\
\partial_{N}\end{array}$} \\
\hline & $\mathrm{x}$ & $i$ & & $\varsigma^{O T \times \varepsilon \cdot \varepsilon}$ & $\tau \cdot \tau$ & โәนTฺ्W & $\begin{array}{r}8 \\
+35^{x} \\
\end{array}$ & $n_{I^{H}}$ & \\
\hline $\mathrm{x}$ & & & & $\varepsilon^{0 \tau}$ & $\varepsilon \cdot \hbar$ & 8.xәq.zxəII & ${ }^{3} \varepsilon^{x}$ & $\begin{array}{l}{ }^{3} \varepsilon^{H} \\
+\varepsilon^{2}\end{array}$ & \multirow[b]{3}{*}{$z_{0}$} \\
\hline $\mathrm{x}$ & $\mathrm{x}$ & $\mathrm{x}$ & $\mathrm{x}$ & $\varepsilon+\pi \cdot 0$ & $09 \cdot \tau$ & จฺ̣xəưđsouxq & $-\varepsilon^{3} \varepsilon^{x}$ & $3^{a}$ & \\
\hline \multirow[t]{5}{*}{$\mathrm{x}$} & $\mathrm{x}$ & $\mathrm{x}$ & $\mathrm{x}$ & $\pi^{-0 โ \times 8 L \cdot 5}$ & $86 \cdot 0$ & 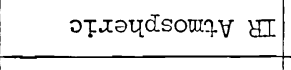 & $-\varepsilon^{3} \varepsilon^{3}$ & ${ }^{3} \nabla_{L}{ }^{2}$ & \\
\hline & $\mathrm{x}$ & & x & $L_{L}^{0 \tau x \tau} \cdot \tau$ & $\cdot 0 \cdot \tau \tau$ & 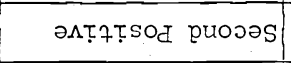 & ${ }^{\mathrm{g}} \mathrm{H}_{\varepsilon}^{\mathrm{q}}$ & ${ }^{11} \varepsilon^{O}$ & \multirow[b]{4}{*}{$\partial_{N}$} \\
\hline & $\mathrm{x}$ & & & $\varepsilon+0 \tau \times 6 \cdot 5$ & $9 \cdot 8 \mathrm{p}$ & $\partial \tau$ & $\begin{array}{l}8{ }^{8} x \\
+{ }^{3} x \\
\end{array}$ & $\mathrm{~g}_{7}{ }^{8}$ & \\
\hline & $\mathrm{x}$ & & & $t_{+} 0 \tau \times \varepsilon \cdot 8$ & $\varepsilon \cdot L$ & 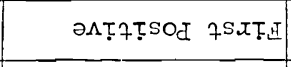 & $\begin{array}{l}n_{3} H \\
+\varepsilon^{3} \\
\end{array}$ & ${ }^{g \varepsilon^{q}}$ & \\
\hline & $\mathrm{X}$ & & & $\angle L O \cdot O$ & $2 \cdot 9$ & 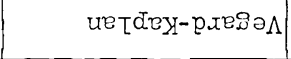 & $\begin{array}{l}3 \\
+3 \\
\end{array}$ & $\begin{array}{l}{ }^{n}{ }^{s} \varepsilon \\
+{ }^{2} \varepsilon\end{array}$ & \\
\hline MOT.974. & exoxny & $74, \overline{3} \div \tau M^{2} \amalg$ & MOTaKed & \multirow{2}{*}{ 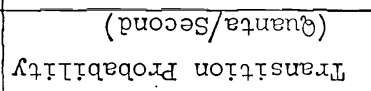 } & $\left(\Lambda^{\partial}\right)$ & \multirow[t]{2}{*}{ uәzS $\hat{S}$ p puधg } & $2787 \mathrm{~S}$ xәMOI & eq87S $x \ni d d n$ & \multirow[t]{2}{*}{ эโทอว โоพ } \\
\hline$\partial \bar{x}$ & udsoufy & xədक uT $\mathrm{s}$ & Uotssțugr & & $\cdot d \cdot \pi$ & & uot? & $\mathrm{u} v \bar{x} \mathrm{I}$ & \\
\hline
\end{tabular}

aтәиdsomz 
relationship between the transition probability and the intensity of a particular band is not as straightforward as in the atomic case since the relative intensities of bands within a band system require the application of the Franck-Condon principle.

\section{SOME GENERAL CONSIDERATIONS OF DE-EXCITATION OR QUENCHING}

Reactions involving the de-excitation of an atom may be written:

$$
A+B^{*} \rightarrow A^{*}+B
$$

or

$$
\mathrm{A}+\mathrm{B} * \rightarrow \mathrm{A}+\mathrm{B}+\mathrm{kinetic} \text { energy }
$$

where the * implies an excited state. The rate at which such reactions proceed is given either as a cross section, $\sigma$, or as a rate coefficient, $k$. The two quantities are related by

$$
\bar{v} \cdot \sigma=\mathrm{k} \mathrm{cm}^{3} \cdot \text { second }^{-1}
$$

where $\bar{v}$ is the mean relative speed of the atoms. In the case of reactions (4) or (5) we have

$$
\mathrm{n}(\mathrm{A}) \cdot \mathrm{k}=\mathrm{L}\left(\mathrm{B}^{*}\right) \text { second }^{-1}
$$

where $L\left(B^{*}\right)$ is the loss rate of particle $B$ from the excited state as a consequence of reaction (4) or (5) and is directly comparable with the loss rate by spontaneous radiation given by the transition probability A. In Table 7.3 we show some atmospheric properties illustrating these relationships. Column 6 gives the kinetic values of the collision frequencies. If each kinetic collision resulted in a de-excitation, it is apparent that the rate of collisional de-excitation would be much greater than the radiative rate from metastable levels except at very high altitudes. For example, the transition rate of the [OI] $5577 \mathrm{~A}$ radiation is 1.28 quanta/sec (Table 7.1) and it is known to occur near 100 kilometers. The kinetic collision frequency at $100 \mathrm{kilometers}$ is $3620 / \mathrm{sec}$ 


\section{TABLE 7.3 Some Properties of the Atmosphere}

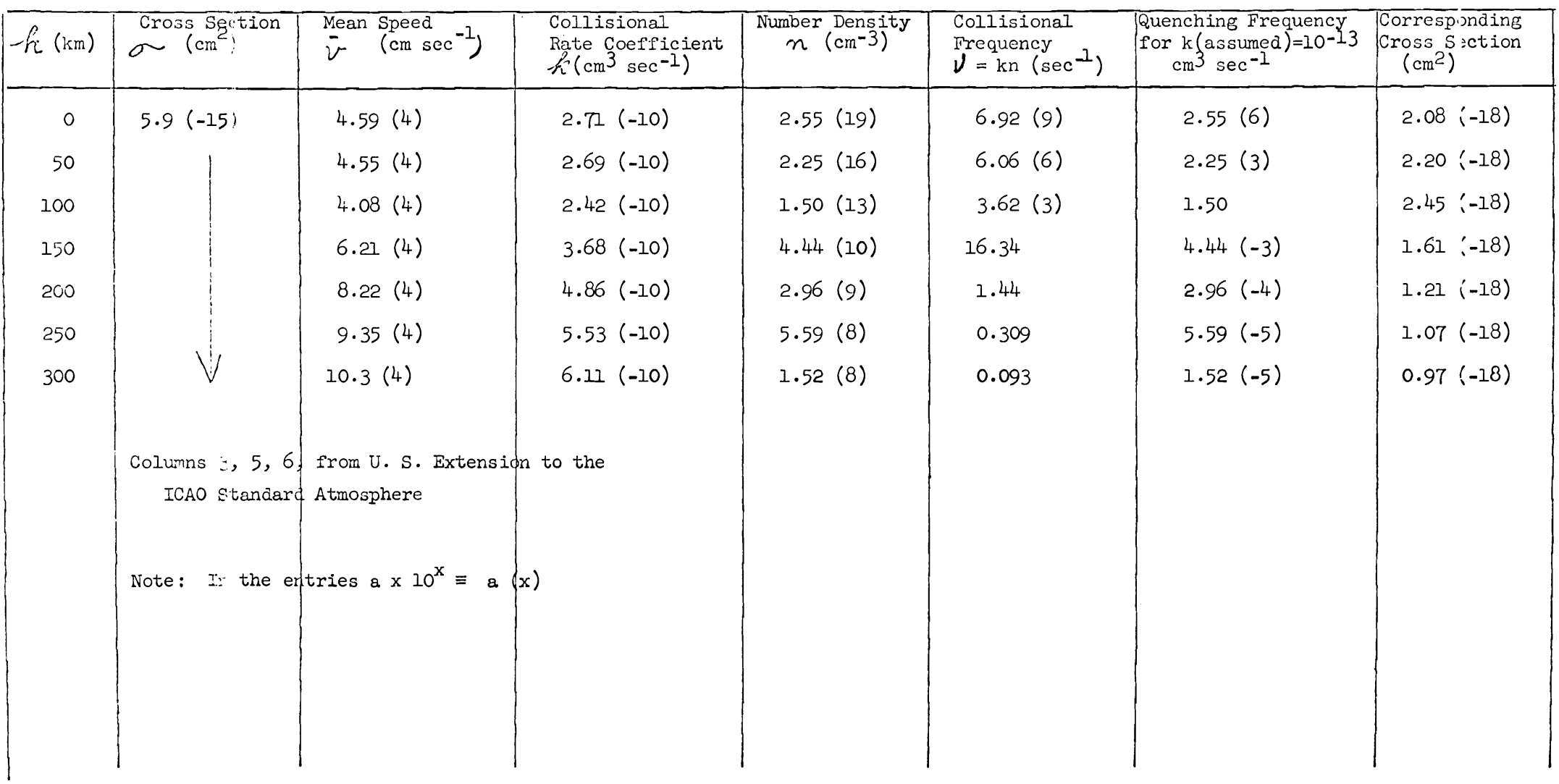

Columns $2,5,6$, from U. S. Extension to the 
(column 6 of Table 7.3). If each collision resulted in a de-excitation of the ${ }^{1} \mathrm{~S}$ level of $O I$ and if there were a constant rate of production of $\left.O{ }^{1}{ }^{1} S\right)$ not directly related to the de-excitation process, then the depletion of the ${ }^{1}$ S state would be

$$
3620 / 3621.28=0.9996 \text { by collisional quenching }
$$
and

$$
1.28 / 3621.28=0.0004 \quad \text { by emission of } 5577
$$

This numerical example illustrates that in the upper atmosphere de-excitation must occur as a result of only a fraction of the kinetic collisions. In column 7 on Table 7.3 , a quenching (de-excitation) frequency is shown based on the assumption of a numerical value of $\mathrm{k}$ equal to $10-13 \mathrm{~cm}^{3} / \mathrm{sec}$ (one de-excitation per 3000 kinetic collisions). Under this assumption the observed emission of [OI] 5577 near 100 kilometers is possible, the radiative and quenching rates being approximately equal. On the other hand the OI $\left({ }^{1} D\right)$ state will be seriously quenched at 100 kilometers where the quenching rate ( 1.50 de-excitation/sec from column 7 of Table 7.3 ) is 160 times the radiative rate ( 0.0091 quanta/second). Thus a quenching coefficient of $10^{-13}$ referred to all the atmosphere components rationalizes the occurrence of $5577 \mathrm{~A}$ and the absence of $6300 \mathrm{~A}$ in the $100-\mathrm{kilometer}$ region. The excitation to the ${ }^{1} \mathrm{D}$ level must, in this case, be at least equal to that of the ${ }^{1}$ S level as each emission of 5577 leaves the oxygen atom in the ${ }^{1} \mathrm{D}$ state. The problem is more complicated than indicated here since all the atmospheric components are not necessarily active in quenching a particular state. Here, however, we merely desire to indicate the general nature of the problem. SOME REACTIONS INVOLVING METASTABLE STATES

In the previous section, reactions which depopulate metastable states were treated as mechanisms which prevent the emission of optical emissions from the state. However, many 
BNWL - 1156

such reactions have an inherent interest, and in this section we propose to briefly mention a few.

$\underline{\mathrm{He}}\left(2^{3} \mathrm{~S}\right)$ and Twilight Emissions of Helium

The observation of HeI $10,830 \mathrm{~A}\left(2^{3} \mathrm{~S}+2^{3} \mathrm{P}^{0}\right)$ in sunlit aurora and in the twilight has been explained as caused by resonance scattering of sunlight from the metastable $2^{3} \mathrm{~S}$ state with subsequent emission. The observed emissions are caused by permitted transitions, but the excitation to the upper level is by way of a metastable level rather than from the ground leve1 some $19.8 \mathrm{eV}$ lower.

He $\left(2^{3} S\right)$ and Penning Reactions

A Penning reaction is one in which ionization of a neutral atom or molecule is caused by an interaction with another atom or molecule in an excited metastable level. Such a reaction has been suggested by Ferguson, Fehsenfeld and Schmeltekopf $(1965)^{(1)}$ to account for helium loss from the atmosphere: $\mathrm{He}\left(2^{3} \mathrm{~S}\right)+\mathrm{O}\left({ }^{3} \mathrm{P}\right) \rightarrow \mathrm{He}\left(1^{1} \mathrm{~S}\right)+\mathrm{O}^{+}\left({ }^{4} \mathrm{~S}\right)+6.2 \mathrm{eV}$

In such reactions there is evidence that the excess energy can be imparted as kinetic energy to the products of the reaction. If $2.4 \mathrm{eV}$ of energy goes to the He ( $\left.{ }^{1} \mathrm{~S}\right)$ it is sufficient to expel it from the earth. Actually, reaction (8) has been written in a simplified form. It seems that there is an intermediate step in which a $\mathrm{HeO}$ or $\mathrm{HeO}^{+}$molecule is formed with a potential minimum that intersects a $\operatorname{He}\left(1^{1} S\right)-0$ repulsive potential curve. At the intersection, a radiationless transition occurs yielding $\mathrm{He}\left(1^{1} \mathrm{~S}\right)$ and $\mathrm{O}\left({ }^{4} \mathrm{~S}\right)$.

$\mathrm{O}^{+}\left({ }^{2} \mathrm{D}^{0}\right)$ and the Excitation of $O\left({ }^{1} \mathrm{D}\right)$

Mahadevan and Roach (1968) (2) have recently suggested that a mechanism somewhat analogous to a Penning reaction might contribute to the population of $O\left({ }^{1} D\right)$ in the high upper atmosphere: 


$$
O^{+}\left({ }^{2} D^{0}\right)+O\left({ }^{3} P\right) \rightarrow O\left({ }^{1} D\right)+O^{+}\left({ }^{4} S^{0}\right)
$$

The speed of the reaction would be enhanced by the intersection of repulsive potential curves of excited $\mathrm{O}_{2}{ }^{+}\left(\mathrm{b}^{4} \Sigma_{\mathrm{g}}^{-}\right)$and of $\mathrm{O}_{2}{ }^{+}\left({ }^{2} \Delta_{\mathrm{g}}\right)$. Such a crossing seems likely, but is not known to occur, so the speed of the reaction relative to competing reactions of $\mathrm{O}^{+}\left({ }^{2} \mathrm{D}^{0}\right)$ with $\mathrm{N}_{2}$ and with electrons is not known and therefore its importance in contributing to $O\left({ }^{1} \mathrm{D}\right)$ is speculative.

Metastable $\mathrm{O}_{2}\left({ }^{1} \Delta\right)$ as a Source of Ionization in the D Region

Hunter and McElroy (1968) (3) have suggested that metastable $\mathrm{O}_{2}\left({ }^{1} \Delta\right)$ contributes significantly to the ionization in the ionospheric $D$ region by the reaction

$$
\mathrm{O}_{2}\left({ }^{1} \Delta\right)+\mathrm{h} v(1027 \mathrm{~A} \text { to } 1118 \mathrm{~A}) \rightarrow \mathrm{O}_{2}{ }^{+}\left(\mathrm{X}^{2} \mathrm{~m}_{\mathrm{u}}\right)
$$

Solar radiation of wavelengths shorter than $1027 \mathrm{~A}$ is able to ionize $\mathrm{O}_{2}$ from the ground level $\left(\mathrm{X}^{3} \Sigma_{\mathrm{g}}{ }^{-}\right)$. This ionization produces the $\mathrm{O}_{2}^{+}$ion well above the $\mathrm{D}$ region but the radiation is depleted before it reaches the $\mathrm{D}$ region and cannot produce the observed $\mathrm{O}_{2}{ }^{+}$ionization there observed. On the other hand, solar radiation in the wavelength domain $1027 \mathrm{~A}$ to $1118 \mathrm{~A}$ can penetrate to the $\mathrm{D}$ region. The other principal ionization found in the $\mathrm{D}$ region is $\mathrm{NO}^{+}$which can be produced by hydrogen Lyman alpha.

\section{O( $\left.{ }^{1} D\right)$ AND THE [OI] 6300,6364 EMISSIONS}

The few randomly selected reactions mentioned in the previous section indicate the complexity involved in understanding the chemistry of the upper atmosphere. The very active field of chemical aeronomy has developed rapidly, especially during the last two decades. A part of the stimulation responsible for interest in the field has resulted from the observation of emissions due to forbidden transitions. It is obvious that an important element in the analysis is a knowledge of rate coefficients for reactions leading to both 
the excitation and the de-excitation of atomic, molecular and ionic states. Reference is made to a recent paper by Donahue (1968) $^{(4)}$ who has synthesized the complexities of the ionosphere into a flow diagram with productivity, transfer, and removal of the ions $\mathrm{O}_{2}{ }^{+}, \mathrm{N}_{2}{ }^{+}, \mathrm{NO}^{+}$, and $\mathrm{O}^{+}$indicated for altitudes 130,160 and 220 kilometers. [OI] 6300, 64 is known to have a close association with the ionosphere and it is here selected as an example of particular interest.

It has already been mentioned that there is a well-defined region of nightglow emission of [OI] $5577\left({ }^{1} \mathrm{D} \leftarrow{ }^{1} \mathrm{~S}\right)$ near 100 kilometers. The transition produces OI $\left({ }^{1} D\right)$ by cascade and there would be emission of [OI] 6300A comparable in intensity with that of $5577 \mathrm{~A}$ were it not for the quenching of OI $\left({ }^{1} \mathrm{D}\right)$ by collisions as mentioned in Section 5. Rocket traversals through the 100-kilometer region clearly indicate both the presence of $5577 \mathrm{~A}$ and the absence of $6300 \mathrm{~A}$.

On the other hand, at a height of about 250 kilometers a nightglow emission of [OI] $6300 \mathrm{~A}$ occurs along with $5577 \mathrm{~A}$, the latter having $1 / 4$ to $1 / 5$ the quantal output of the former. In the tropics this 250-kilometer emission is especially interesting because of frequent large changes in intensity. The reactions responsible for the optical excitation are also important in the maintenance of the balance of ionization in the $\mathrm{F}$ region.

$$
\mathrm{O}_{2}+\mathrm{O}^{+} \rightarrow \mathrm{O}_{2}^{+}+\mathrm{O}\left(\mathrm{k}=2 \times 10^{-11} \mathrm{~cm}^{3} / \mathrm{sec}\right)
$$

followed by

$$
\mathrm{O}_{2}{ }^{+}+\mathrm{e} \rightarrow \mathrm{O}+0+6.96 \mathrm{eV}\left(\mathrm{k}=2 \times 10^{-7} \mathrm{~cm}^{3} / \mathrm{sec}\right)
$$

The rate of the process is controlled by the slower Equation (11). The $6.96 \mathrm{eV}$ is available for excitation of either or both of the atomic oxygen products to the ${ }^{1} \mathrm{D}$ state, or one (but not both) to the ${ }^{1} S$ state. A copious 1iterature has developed with respect to these reactions and the emission of [OI] 6300A. It 
is possible to derive a relationship between the observed intensity, Q, of 6300 and ionospheric parameters (see for example Peterson, 1968) ${ }^{(5)}$ :

$$
Q_{6300}=A+B \cdot n_{e}(\max ) \cdot \exp -[(h \cdot f-200) / H]
$$

where h'f is the virtual height of the $F$ layer, $n_{e}(\max )$ is the peak number density of electrons in the $\mathrm{F}$ region, and $\mathrm{H}$ is the atmospheric scale height referred to molecular oxygen. The reference height, $200 \mathrm{~km}$, is chosen for convenience. Equation (13) is an adaptation of the Barbier (1959) (6) formula. Other formulations are discussed by Peterson (1968) (5).

Equation (13) is very successful in correlating changes in $Q_{6300}$ with concomitant changes in the ionosphere. During the post twilight period, as the $\mathrm{F}$ region is steadily decreasing in $\mathrm{n}_{\mathrm{e}}(\max )$ and increasing in virtual height, $\mathrm{Q}_{6300}$ decreases in value. In the tropics rapid changes in $Q_{6300}$ which are not associated with the post twilight also show excellent agreement with the predictions of Equation (13). The additive quantity, A, presumably due to some mechanism of excitation other than Equations (11) and (12) is small in the tropics but usually measurable. In mid and high latitudes there are other nocturnal emissions of [OI] 6300 which do not "obey" the Barbier formula. For example, in mid latitudes there is a general increase of $Q_{6300}$ with geomagnetic activity (Truttse, 1968) (7) which is not predicted by the formula. At times this general increase in intensity includes a localized high altitude (peak at 400 kilometers) arc which does not include a measurable enhancement of [0I] $5577 \mathrm{~A}$ (see Roach and Roach ${ }^{(8)}, 1963$, for a summary of knowledge of this phenomenon). Also, during times of geomagnetic activity (a) visual red (6300A) arcs are often observed near the auroral zone and (b) widespread red "auroras" have been seen even in tropical regions. The heights of the well-defined arcs, both in the auroral zone and in mid 
BNWL - 1156

$\begin{array}{lcccc}\begin{array}{l}\text { Maximum } \\ Q_{6300}\end{array} & \frac{22 \mathrm{~h} \quad 24 \mathrm{~m}}{535 \times 10^{6}} & \frac{01 \mathrm{~h} 36 \mathrm{~m}}{310 \times 10^{6}} & \frac{\text { Unit }}{\mathrm{qu} . \mathrm{cm}^{-2} \mathrm{sec}^{-1}} \\ \frac{-\mathrm{dn}(\max )}{\mathrm{dt}} & 400 & 230 & \mathrm{e} 1 . \mathrm{cm}^{-3} \mathrm{sec}^{-1} \\ -\tau \frac{\mathrm{dn}(\max )}{\mathrm{dt}} & 2000 \times 10^{6} & 1150 \times 10^{6} & \mathrm{e} 1 . \mathrm{cm}^{-2} \mathrm{sec}^{-1} \\ \varepsilon & 0.27 & 0.27 & \end{array}$

The quantal efficiency by this analysis may be compared with that found by Brown and Steiger (1967) (4) who found an efficiency of 0.15 based on time rate of changes at Maui of total electron content.

THE TROPICAL IONOSPHERE

The example given in the previous section is for a night of significant though not unique photometric activity accompanied by co-varying ionospheric changes. That we are dealing with a general problem of ionospheric dynamics becomes apparent upon examination of systematic plots of critical frequency and virtual height at a tropical station such as that of Maui.

Figure 8.2 shows the median hourly values of $n(\max )$ for October, 1957 for Maui (magnetic dip latitude $21^{\circ} .3$ ) and for Washington (dip latitude $55^{\circ} .45$ ). The contrast between the two stations is immediately apparent.

The Maui plot exhibits a maximum at about $21 \mathrm{~h} 30 \mathrm{~m}$ local standard time which is greater in absolute value than the daytime maximum. At Washington, on the other hand, there is a general uninterrupted decline in $\mathrm{n}(\max )$ during the night until just before dawn. Figure 8.3 illustrates that at Maui there is a minimum in the virtual height which, as in the case of the example of the previous section, coincides with the region of greatest rate of loss of electrons following the $n$ (max) peak. 
BNWL- 1156

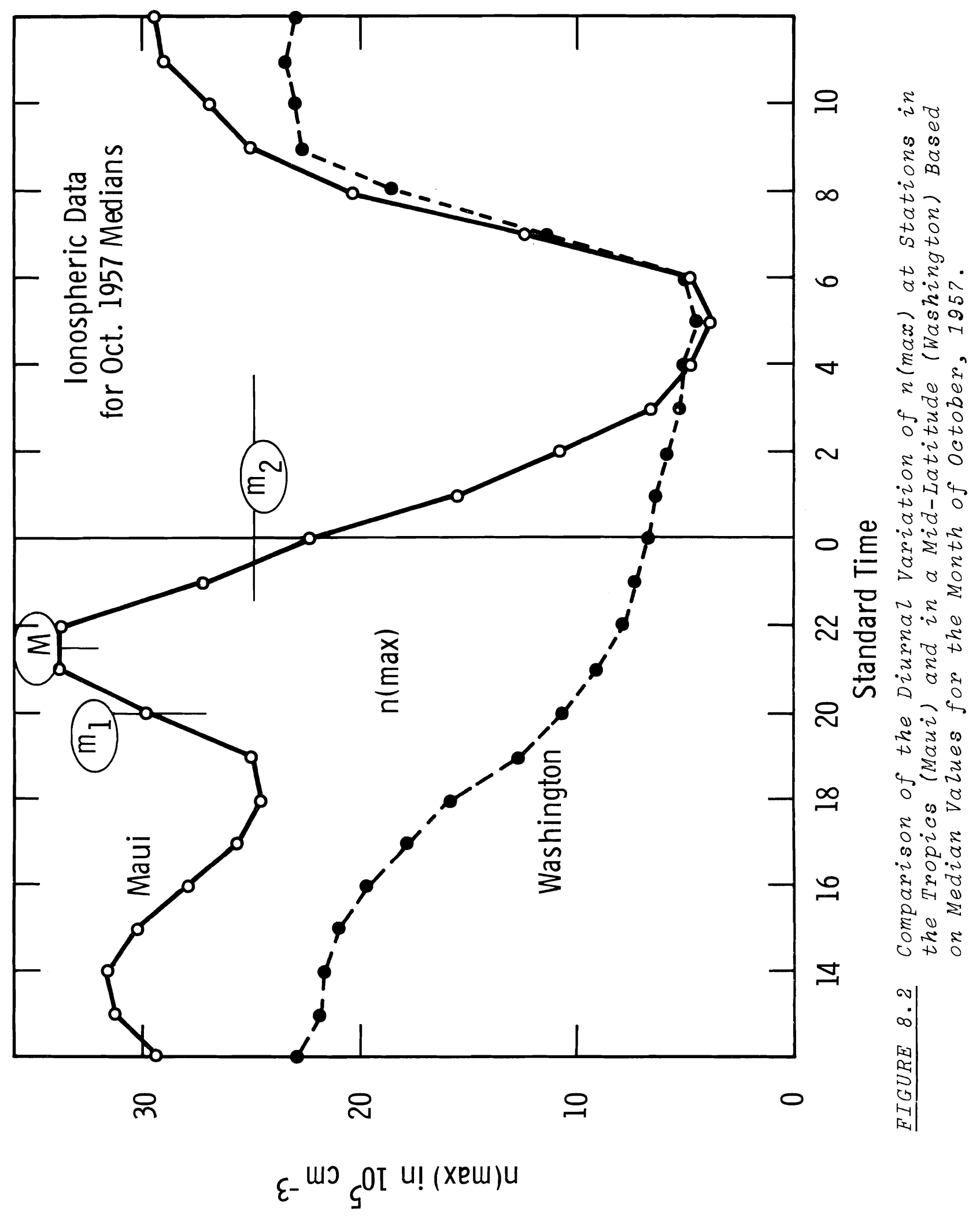


BNWL - 1156

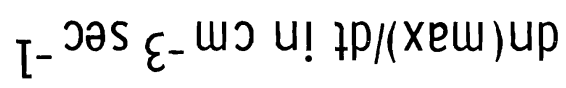

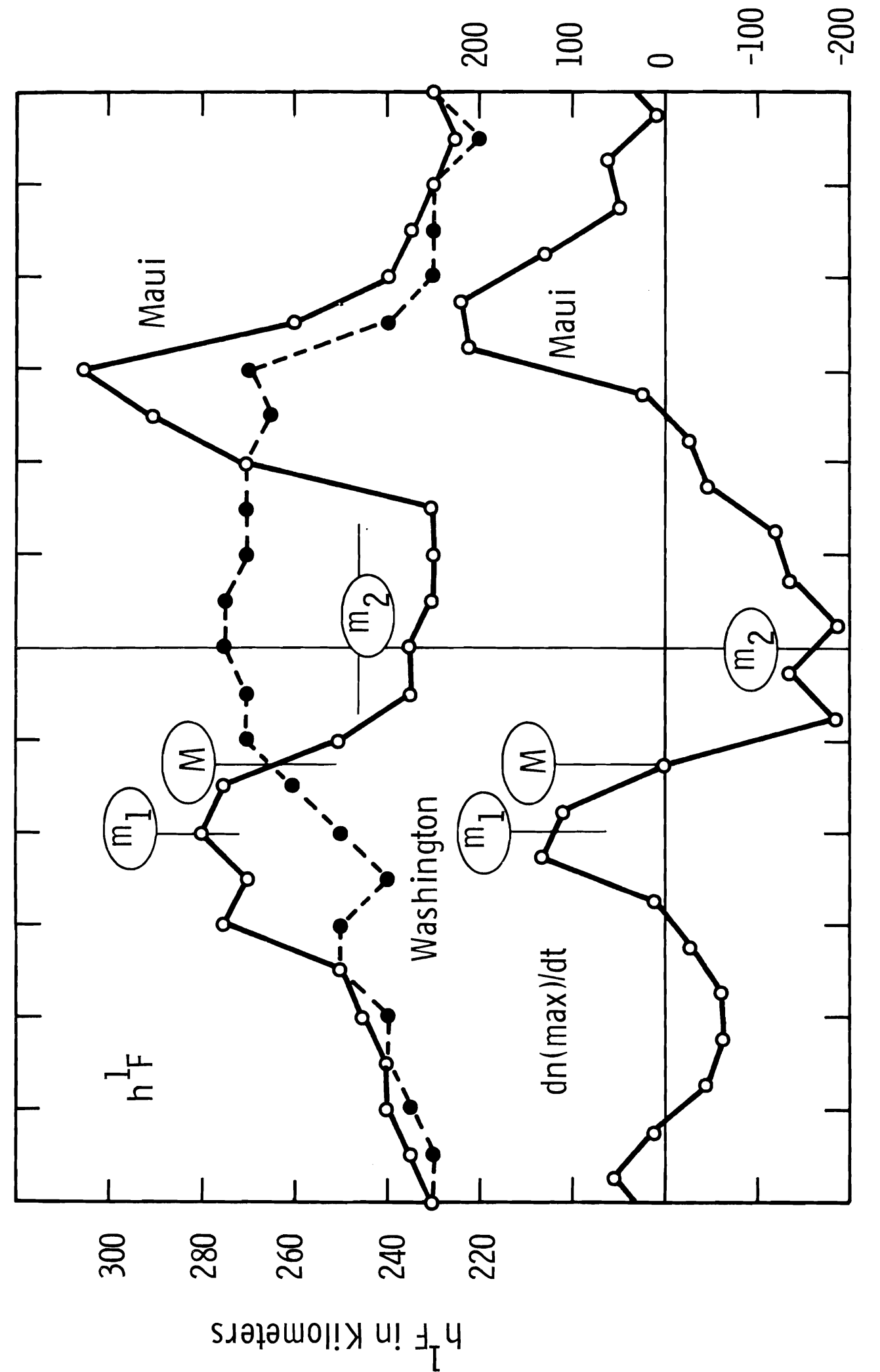

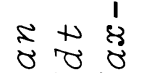

.

(1) है $4 \cdot 2 \cdot$

$\pi 005$

. E $: 5 \infty$

$\ddot{2}=0$

$\bigoplus$

$0 . \overline{2} \cdot \frac{4}{2}$

n E 0 \&

. 50 ne 0

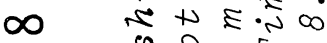

O N

$\sum R \quad 0$ \&

0
n d es

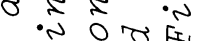

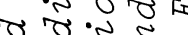

55 in 5

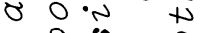

d es 0

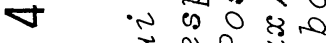

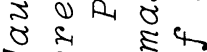

$\sum$ \& 00

N nut a

$\sigma \geqslant 0$

d I I 1 क

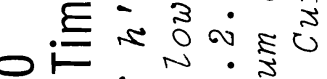

c 4005

I 0 m $0 . \frac{2}{2}$

त्ठ

$\sqrt{2} e_{0} \therefore \sqrt{2}$

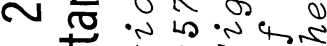

t os a 0 a $0 \mathrm{r}$

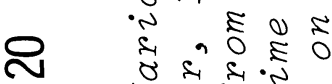

$\triangle$ O द E

no $=0$

$\theta+\bar{\varepsilon} \Sigma+\infty$

$\infty \begin{array}{llll}2 & 0 & 0 & 0 \\ 0 & 0 & 0 & 0\end{array}$

i 0 E $2 \cdot 4$

ง $\bar{a}$

00 ar

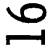

, दूरूत.

(1) a d O

5 5 0 a 2

0 n m a 5

$\underset{\square}{\square}$

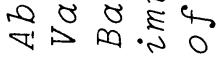

0
0
0
571
0
0
0
0
-1
01 
The coincidence in time of the minimum virtual height and the greatest rate of loss of electrons has been observed without exception on a large number of plots of Maui data and must be considered to be a general property of the tropical ionosphere. The implications of this empirical fact become apparent by placing the following statements in juxtaposition:

- In the case of a static nocturnal ionosphere the period following a general influx of ionization should be one of increasing virtual height as the lower regions of ionization in the denser parts of the neutral atmosphere are preferentially eaten away by recombination processes.

- If, contrary to the expectations of the time sequence of a static ionosphere, the virtual height decreases following an influx of nocturnal ionization it must be concluded that we are dealing with a dynamic ionosphere.

The dynamicism required is that of a downward movement of ionization which may either be naturally timed to follow the influx of ionization or possibly one which becomes apparent only after such an influx.

The example in Figures 8.2 and 8.3 exhibits only a single maximum of $\mathrm{n}(\mathrm{max})$ in contrast with that of Figure 8.1 which has two maxima. In our systematic examination of Maui records, we have noted frequent occurrence of both single and double maxima.

We showed in the previous section that the nightglow intensity changes maximized with the time of high loss rate of electrons for the night of September 11/12, 1961. This is a general property of the [OI] 6300A nightglow at the tropical station of Maui and has been observed systematically. Observations have continued at Maui regularly since 1961. During the sunspot minimum period of 1964-1965 the nightglow photometric activity was very low, suggesting a significant solar cycle effect. The reason is apparent on inspection of 
Figure 8.4 which shows a comparison of $n(m a x)$ median variations at Maui for October, 1957 (sunspot maximum) and October, 1964 (sunspot minimum). The 1964 values are approximately a factor of 10 lower than those of 1957. A definite maximum is noted, however, at about midnight for the lower curve, about $2-1 / 2$ hours later than that occurring in 1957. Although the amplitude of the 1964 maximum is much smaller than that of 1957 in absolute value, its relative amplitude is comparable.

In addition to the sensitivity of the tropical ionosphere to the sunspot cycle, we should mention that there are marked ionospheric seasonal variations which are reflected in the nightglow [OI] 6300A activity. In this short review, it is probably only necessary to say that the relationships between the temporal variations in the nightglow, $n(\max ), \mathrm{dn}(\max ) / \mathrm{dt}$ and h'F which have been discussed for a single night in the first section and for particular months in this section are general.

\section{THE TROPICAL IONOSPHERE AND THE EQUATORIAL ANOMALY}

The critical frequency, foF2, and hence the peak electron density, $n(\max )$, has an equatorial (magnetic) trough in its latitudinal distribution at noon during the equinoxes (Appleton, 1946). (5) There is actually a maximum in peak electron density some $15^{\circ}$ to $20^{\circ}$ from the magnetic equator, hence the appellation anomaly. The considerable literature on the subject, both descriptive and interpretive may be approached by way of the references in Hanson and Moffett (1966) (6) who made a definitive analysis of the problem of ionization transport in the equatorial F region. Their analysis includes evaluations of the effects of photo-ionization, re-combination, diffusion, neutral winds and electromagnetic drift. An important factor is the electromagnetic drift. Hanson and Moffett, following an early suggestion of Martyn (1955) (7) found that upward drifts over the magnetic equator with speeds of $\sim 10 \mathrm{msec}^{-1}$ sould result in a 
BNWL - 1156

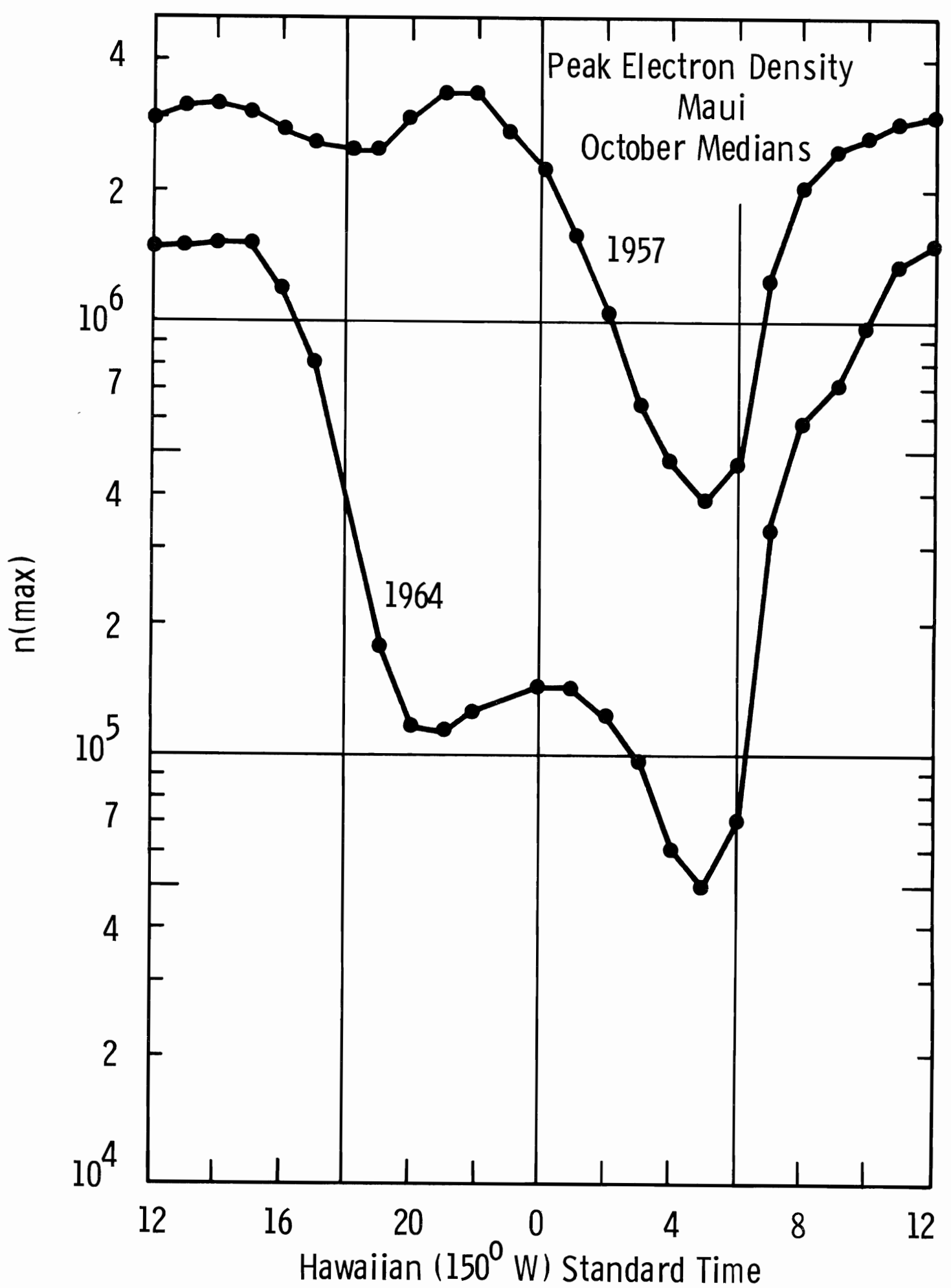

FIGURE 8.4 Diurnal Variation Plotted on a Logarithmic Scale of $n$ (max) at Maui for october, 1957 (Sunspot Maximum) and october, 1964 (Sunspot Minimum). 
concentration of ionization some $15^{\circ}$ to $20^{\circ}$ away from the equator in agreement with observations during the middle of the day. Recently the existence of drifts of this order has been confirmed at Jicamarca (near the dip equator), upward in the daytime and downward at night (Balsley, 1969); (8) (Woodman and Hagfors, 1969).

Maeda (1962) ${ }^{(10)}$ has calculated ionization drifts in the F region on a world-wide scale based on the electric fields associated with the E-region current systems, which electric fields are assumed to be transmitted to the F region along the geomagnetic lines of force. A plot of Maeda's calculations of mean drifts for the period 1932-33 (sunspot minimum) and for times of geomagnetic quiet is shown in Figure 8.5. The daytime upward drift assumed by Hanson and Moffett in their analysis and measured by the Jicamarca observers is clearly evident, not only at the geomagnetic equator but also in the tropical region in general. Also a general downward drift at night of one or two tens of meters $\mathrm{sec}^{-1}$ is apparent in Figure 8.5. The worldscale plot is consistent with the observational fact that at night, the tropical ionosphere is driven down. There is a suggestion in the Maeda plot that a horizontal movement of ionization resulting in the nocturnal bulges in $n$ (max) may be predominately in the west to east direction, corresponding to a movement from the late afternoon into the night regions of the ionosphere.

THE MID-LATITUDE IONOSPHERE AND 6300A EMISSIONS

The $6300 \mathrm{~A}$ emission in mid-latitudes ( $>35^{\circ}$ magnetic latitude) does seem to include a contribution due to the recombination process [Equations $(1,2)$ ] but also another from some other process. In a recent study Truttse (1968) (11) has shown that in midlatitudes (in contrast with low latitudes such as that of Maui) $Q_{63}$ increases markedly with geomagnetic activity. A value of $a_{p}$ of 200 gives an increase of $Q_{63}$ by a factor of 10 . It is 


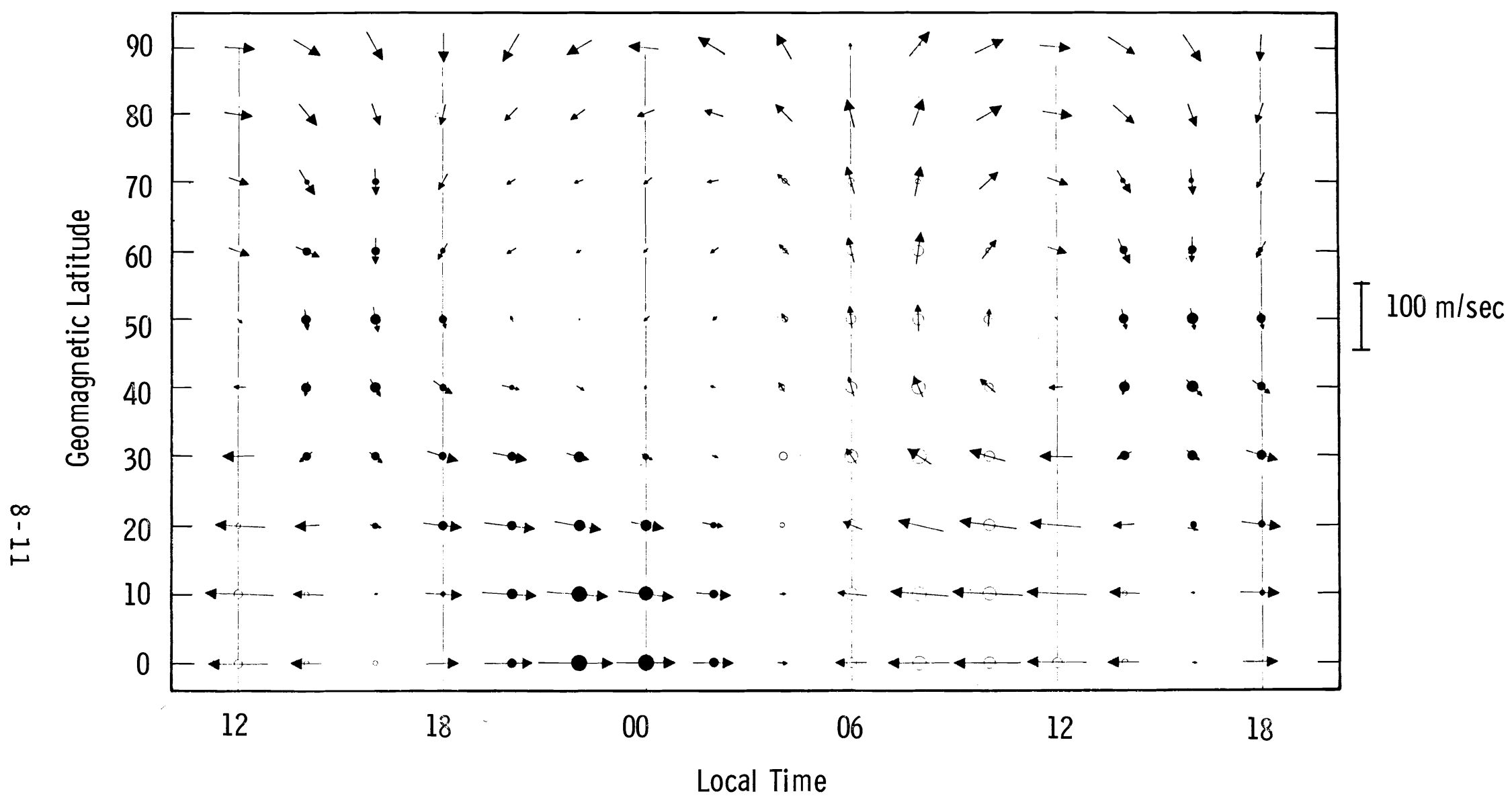

FIGURE 8.5 Graphical Representation of Electromagnetic Drift Speeds (not Fluxes.' of Ionization in the $F$ Region Based on the Calculations of H. Maeda (1962)(10). The Time for Which the Calculations were Made was the Second Polar Year, 1932-33 (Sunspot Minimum), for the Equinox, and for Geomagnetically Quiet Conditions. The Horizontal Component is Shown Vectorially by Arrows, the Vertical Component is Indicated by Circles; Solid Circles Downward Drift; Open Circles Upward. The Scale Shown to the Right Applies to both the Horizontal and the Vertical Components. 
we11 known that, in these same latitudes, geomagnetic activity results in a decrease in foF 2 and hence of $\mathrm{n}_{\mathrm{m}}$ and an increase in ionospheric height [hm, the height of ionization maximum, is better as an indicator of ionosphere height than $h$ 'F, the virtual height during magnetic storms in mid-latitudes (Thomas and Robbins, 1958)]. (12) Both of these ionospheric changes are in the opposite sense from that required to give an increase in $Q_{63}$. Even the known mid-latitude increase in general atmospheric temperature with geomagnetic activity cannot offset the deleterious effect of the h'F(up) and foF2(down) changes.

It appears that some excitation mechanism is operative which becomes efficient at high altitudes. An interesting conjecture is that the general increase in $Q_{63}$ with geomagnetic activity discovered by Truttse may be associated with the discrete $Q_{63}$ activity of the mid-1atitude $M$ (or SAR) areas. If so, the absence of $5577 \mathrm{~A}$ in the mid-1atitude $\mathrm{F}$ region phenomenon under discussion also requires that reactions $(1,2)$ are not responsible for the emission.

CONCLUSION

The use of the virtual height, $h^{\prime} F$, as an indicator of ionosphere height variations is subject to the criticism that it may not be reliable. As already mentioned the parameter is especially unsatisfactory in mid-1atitudes during times of geomagnetic activity (Thomas and Robbins, 1958). (12) For the purpose of the present discussion it is deemed to be satisfactory, however, as an appropriate height indicator in the tropics since Peterson (1968) (13) has found it to better represent the photometric observations in Barbier-type formulas than two alternative parameters: MUF, the maximum usable frequency, and $h^{\prime}(f=0.815$ foF 2$)$.

Attention is called to recent papers which treat the problem of the tropical nightglow and the ionosphere. King $(1968)^{(14)}$ has called attention to a similarity in equatorward 
movements of tropical nightglow and nocturnal movements of the ionospheric crests associated with the equatorial anomaly. Vanzandt and Peterson (1969) (15) discuss the spatial complexity of nightglow patterns at Maui and some of the ionospheric implications. They also refer to the interrelationship between vertical ionospheric drifts near the dip equator (Jicamarca) and nightglow intensities.

\section{BI BL I OGRAPHY}

1. A. Dalgarno and J.C.G. Walker. J.Atmos. Sci., vol. 21, p. 463. 1964 .

2. W. Steiger. Aurora and Airglow, edited by B. M. McCormac. Reinhold Publishing Corporation, New York, 1967. p. 419.

3. I. S. Gulledge, D. M. Packer, S. G. Tilford and J. T. Vanderslice. J.Geophys. Res., vol. 73, p. 5535. 1968 .

4. W. Brown and W. Steiger. Nature, vol. 47, p. 216. 1967.

5. E. V. Appleton. Nature, vol. 157, p. 691. 1946.

6. W. B. Hanson and R. J. Moffett. J. Geophys. Res., vol. 71, p. 5559.1966.

7. D. F. Martyn. Proc. Cambridge Conf., Physical Society, London, pp. 254-259. 1955 .

8. B. Balsley. J. Geophys. Res., vol. 74, pp. 1213-1217. March 1969.

9. R. F. Woodman and T. Hagfors. J. Geophys. Res., vol. 74, pp. 1205-1212. March 1969.

10. H. Maeda. Proc. Intern. Conf. Ionosphere, Physical Society, London, vol. 187. 1962.

11. Yu. L. Truttse. Planetary Space Sci., vol. 16, p. 140. 1968.

12. J. O. Thomas and A. Robbins. J. Atmospheric Terrest. Phys., vol. 13, p. 131. 1958.

13. V. L. Peterson. Anneles de Geoph., vol. 24, p. 101. 1968. 
BNWL - 1156

14. J. W. King. J. Atmospheric Terrest. Phys., vol. 30, p. 391. 1968 .

15. T. E. Vanzandt and V. Peterson. Ann. Geophys., vol. 24, p. 747.1968 . 


\section{AUTOMATION OF AERONOMY EQUIPMENT \\ L. L. Smith and R. J. Ausere}

A large portion of the available manpower is presently invested in observational and data processing programs. The primary purpose of the automation of the aeronomy equipment is to maximize the analysis and reporting output of our group by:

- reducing the amount of professional time required in the observational program so this can be invested in other aspects of the research,

- increasing the reliability of the present observing equipment, thereby, optimizing the availability and accuracy of data for analysis,

- obtaining better spatial and temporal resolution with more sophisticated photometers and recording devices,

- decreasing the time and manpower required to process the raw data into forms necessary for analysis, and

- providing means of presenting reduced data in forms for analysis which are now not available.

To accomplish these goals, an automated system built around a small computer has been designed. Figure 9.1 is a block diagram of the automated system. The following items are now ordered and the expected delivery is July, 1969:

- Varian Computer $620 I$

- Teletypewriter KSR 3b

- High speed paper tape punch

- High speed paper tape reader

- Magnetic tape

- Three interfacing items

Remaining items shown on the diagram which include the disc, CRT display, and plotter, will be purchased as soon as funds become available. Initial checkout and programming of the system can be done with the equipment ordered but, lacking 


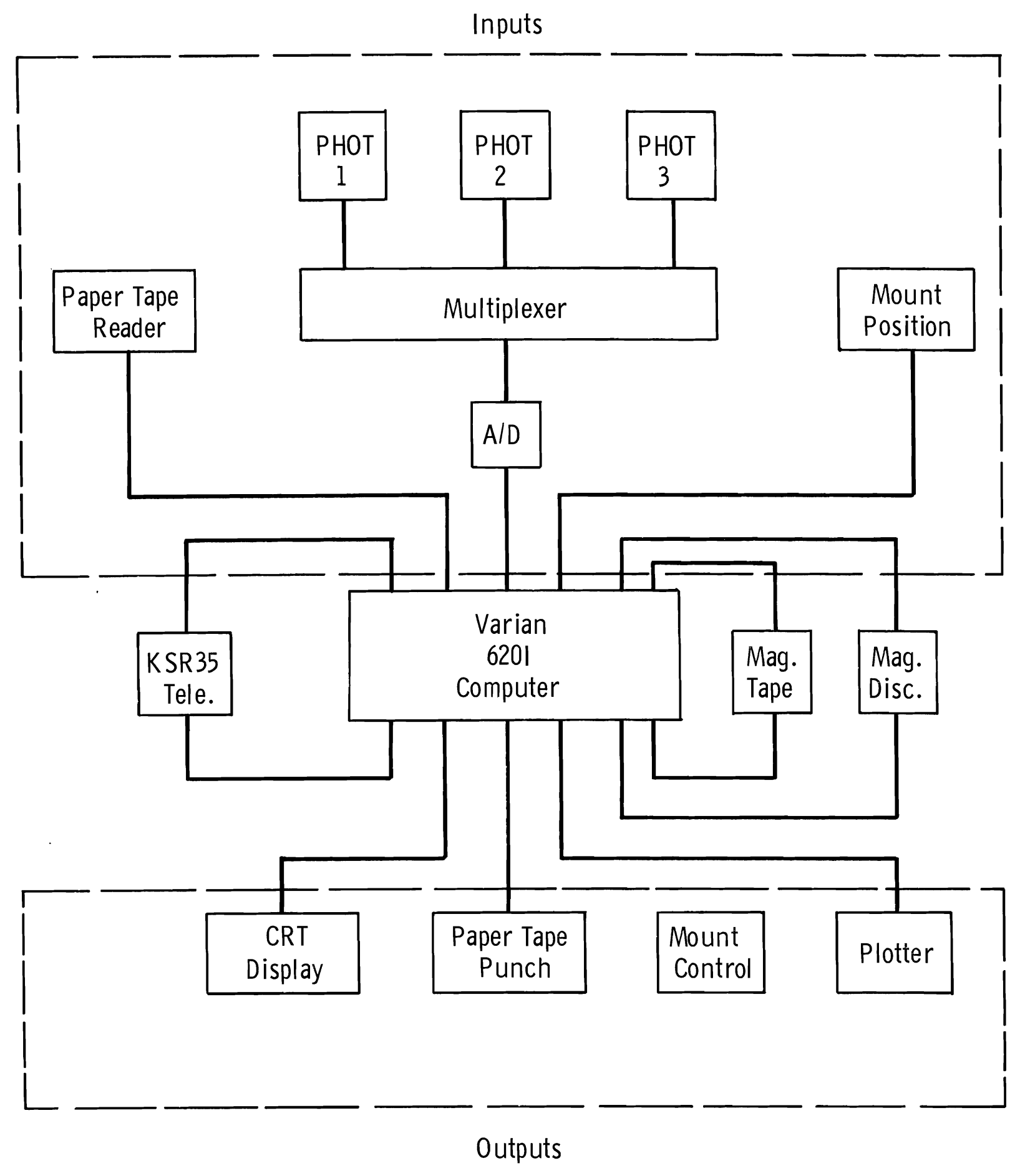

FIGURE 9.1 Block Diagram of Automated System 
the data storage capacity of the disc, the system cannot be used on-line until that item is in place.

The basic organization of the computer includes four interdependent sections: Core memory, control, arithmetic logic, and input/output. All transfers of data are executed in parallel. The random access ferrite core memory contains 8,192 words and can be expanded to 32,768 words. 'The core memcry, data and instruction words are 16 binary bits in length. The read-restore cycle time is $2.1 \mu \mathrm{sec}$ and the basic add instruction requires $4.2 \mathrm{usec}$. The computer contains the following registers;

- A register which performs the major programmed arithmetic and logic operations and serves as a program-controlled data input/output register,

- Program counter register determines the core memory address from which the next instruction of a stcred program is to be taken,

- Memory address register determines the location in core memory from which an instruction, an address, or data is to be read,

- Memory buffer register serves as a buffer for all information passing between the processor and the core memory,

- Instruction register receives and holds the operation code and indirect addressing indicator bit as each instruction work is fetched from memory, decoded and executed,

- Switch register consists of toggle switches mounted on the operator console providing a means of manually establishing a word to be set into the accumulator.

- Multiplier-quotient register operates with the A register to perform multiplication and division operations.

- B register functions with the A register to perform arithmetic and logical operations.

- Index register, in addition to the normal indexing functions, has the capability of being directly added 
to the memory address of an indexed memory reference instruction to form the new address of the information.

The computer is capable of individually selecting and addressing 32 different devices. The input/output (I/0) instruction has 4 bits available for microprogramming. Programmed data transfers using the $A$ and $B$ registers have data rates of $10^{5}$ words per second. The (I/0) devices are as follows:

- A KSR-35 Teletypewriter machine is interfaced to the computer. This unit operates either on-line, in half duplex, or off-line.

- A high-speed paper tape punch which operates at a speed of 100 characters per second using the 8 bit ASCII code.

- A paper tape reader which has a speed of 300 characters per second also using the 8 bit ASCII code. The software provided for the computer are as follows:

- A Fortran compiler to allow expression of a problem in English and Mathematical-like statements fully U.S.A.S.I. Fortran (Fortran IV)

- A symbol assembler which processes a machine-oriented language.

- A correction program which enables corrections and additions to be made on source program statements through the keyboard.

- An operating system which includes a (I/0) control system and executive for compilation, assembly, loading execution, dumping, system maintenance, definition of ( $I / 0)$ units, and magnetic tape positioning.

- Arithmetic subroutines for elementary functions (log, exponential, square root, sine, cosine, tan and arctan) for single precision (multiply and divide) and for double precision (add, subtract, multiply and divide). 
A program consisting of (I/O) subroutines for the purpose of transmitting data to and from peripheral devices and data ready for processing.

- Maintenance programs which enable testing of the entire central processor and all the peripheral equipment connected to the processor for the purpose of locating hardware malfunctions.

The automated system is expected to provide an immediate increase in the amount of useful data obtained. Because online display of data will permit the operator to optimize measurements, we expect an improvement in the quality of the data as we11.

We are establishing the system parallel to the existing control and recording equipment and will use it initially on a trial basis until reliability and intercalibration are established. Our plan is to first program the new equipment to assume control of the scanning mount and accumulate data from three photometers. Programming partial data reduction in real time to provide on-line display will follow. 


\section{SPECIAL EQUIPMENT AND FACILITIES DEVELOPMENT}

\section{SPECIAL EQUIPMENT DEVELOPMENT}

\section{R. L. Skaugset}

\section{Photometric Scanner Improvements}

In order to provide an on-line readout of the digital data in addition to the paper tape output, an ASR teletype was installed. This included the design and fabrication of interface circuitry. In association with this, the control program was modified to provide the proper timing for the teletype control functions, as well as to make the data easier to read by inserting a "space" between data samples.

It is advantageous during periods of high auroral activity to be able to scan a portion of the sky while the moon is up. This problem was attacked in two ways. First, a simple, lowsensitivity photometer was built to sense when the mount scans near the moon. When the moon appears in the field of view of the photometers, the signal is amplified to operate a relay which closes the shutters on the primary photometer. Secondly, a new control program was made up so that the mount would scan only half the sky without scanning near the moon.

An additional turret photometer has been installed on the mount. The operation of this photometer is controlled from the console as with the other turret photometer but differs in that its output is recorded on a strip chart recorder only and is not digitized. This turret is equipped with the following filters: 6080A, 7150A and 5350A. The data obtained with this instrument are used to deduce the contribution of the continuum spectra to auroral and airglow data and to establish the apparent surface brightness of the milky way which serves as a standard brightness reference. 
Pulse Counting

In the present photometric system the analog output is an integration of the pulses caused by individual photons. The photomultiplier senses these pulses over a certain length of time. This analog signal is then converted back to pulses which are counted to give us our digital signal. A more straightforward method of data gathering would be to amplify the pulses from the photons and count these pulses. This method would also eliminate the problem of dark current offset on the analog signal which varies with photomultiplier temperature and voltage.

A pulse counting system is presently under development and is being tested prior to installation in our system.

The pulse counting system consists of a high impedance solid state preamplifier located with the dynode chain in the photomultiplier housing. The pulses are amplified by this preamp then applied to a pulse height discriminator which can be adjusted to cut out all noise pulses. These are then amplified by a pulse amplifier and counted by the counter in the system console. (See Figure 10.1a).

Logarithmic Amplifier

During a bright aurora the sensitivity has to be reduced by several orders of magnitude in order to keep the record of the aurora within the range of the recording equipment. This of course reduces the background variations to nearly nothing. In order to improve this situation, a logarithmic amplifier is being tested on one of the photometers. This amplifier compresses three decades of sensitivity onto one scale, eliminating the need for sensitivity switches.

In this system a Zeltex FET operational amplifier is used as a preamp with its gain adjustable to one or ten. The logarithmic amplifier used is a Burr-Brown type 4008/40. It has an input range of $0.01 \mathrm{~V}$ to $10 \mathrm{~V}$, and an output of $\pm 10 \mathrm{~V}$ which drives an Esterline Angus recorder. (See Figure 10.1b) 
BNWL - 1156
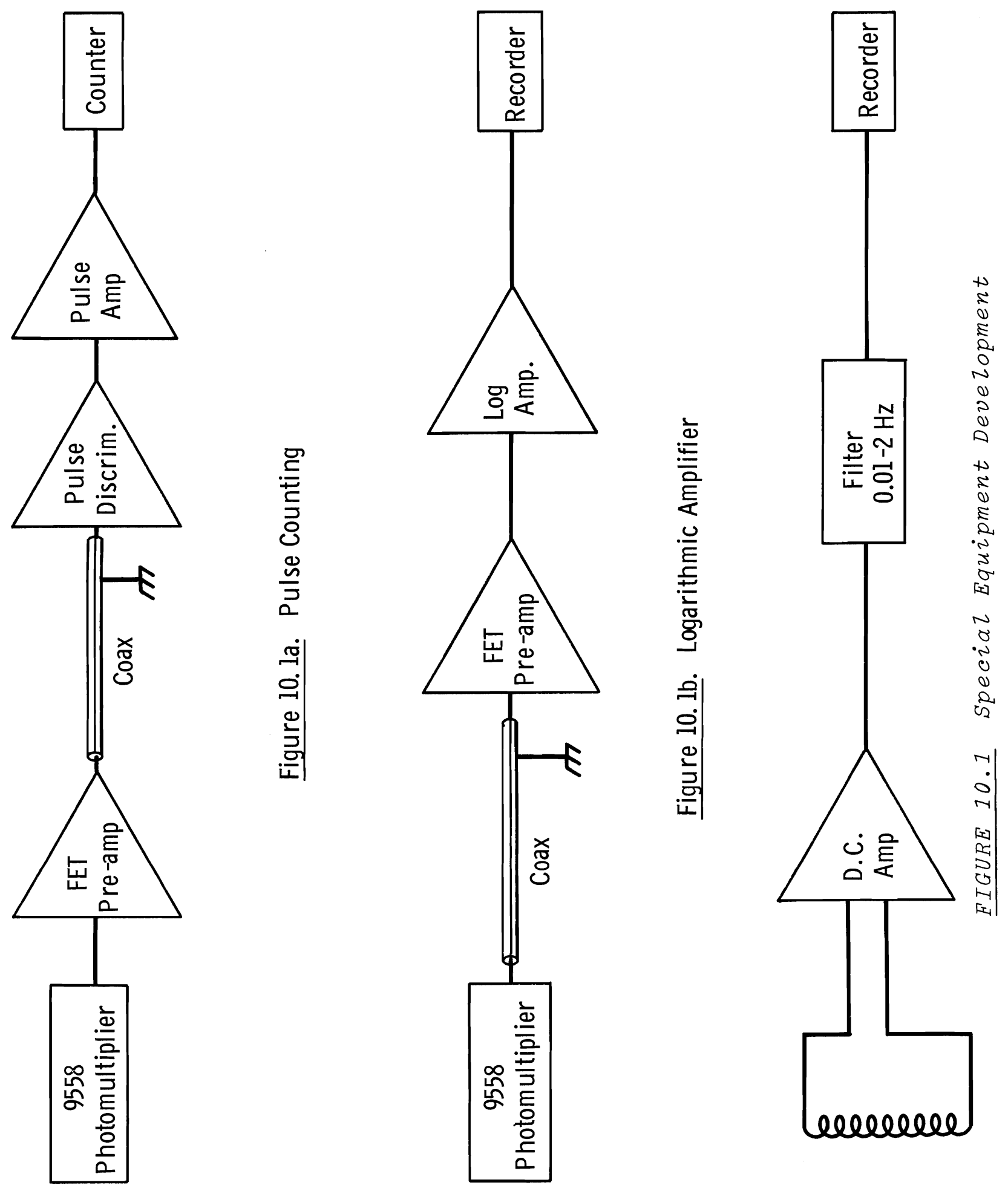
BNWL - 1156

\section{Magnetometer}

The magnetometer loaned to us by Boeing has been installed in an abandoned telephone manhole near the facilities. This keeps it out of the weather and places it far enough away from the observatory that there is no major electrical interference. The only interference is from passing vehicles. We have enclosed the magnetometer in an aluminum shroud to shield it from radio interference as well as protect it from weather conditions.

The magnetometer circuitry which we have constructed consists of $2 \mathrm{dc}$ amplifiers with a combined gain of 30,000 and a 0.01 to $2 \mathrm{~Hz}$ filters. This is used to filter out all magnetic interference outside the range of frequency of changes in the earth's magnetic field in which we are interested. The resulting signal is recorded on a strip Short recorder. (See Figure 10.1c) Absolute calibration prior to data analysis remains to be done.

\section{FACILITIES DEVELOPMENT}

\section{L. Smith}

Several additions and improvements have been made to the facilities at the Rattlesnake Observatory since the last progress report. Some of these have greatly enhanced the research capabilities of our operation and should be mentioned.

Another photometer has been borrowed from the Environmental Science and Services Administration (ESSA). This gives us the capability to scan the night sky at seven different wavelengths. Presently we are monitoring emission radiations [OI] 5577A, [OI] $6300 \mathrm{~A}$, and $\mathrm{N}_{2}^{+} 4278 \mathrm{~A}$ and background radiations at $5300 \mathrm{~A}$, 6080A, and 7150A. The [OI] 6300A emission is monitored by two photometers giving us maximum coverage possible for detailed studies of the $6300 \mathrm{~A}$ mid-1atitude red arc. Figure 10.2 is a photograph of the bank of photometers now in use. Figure 10.3 
BNWL - 1156

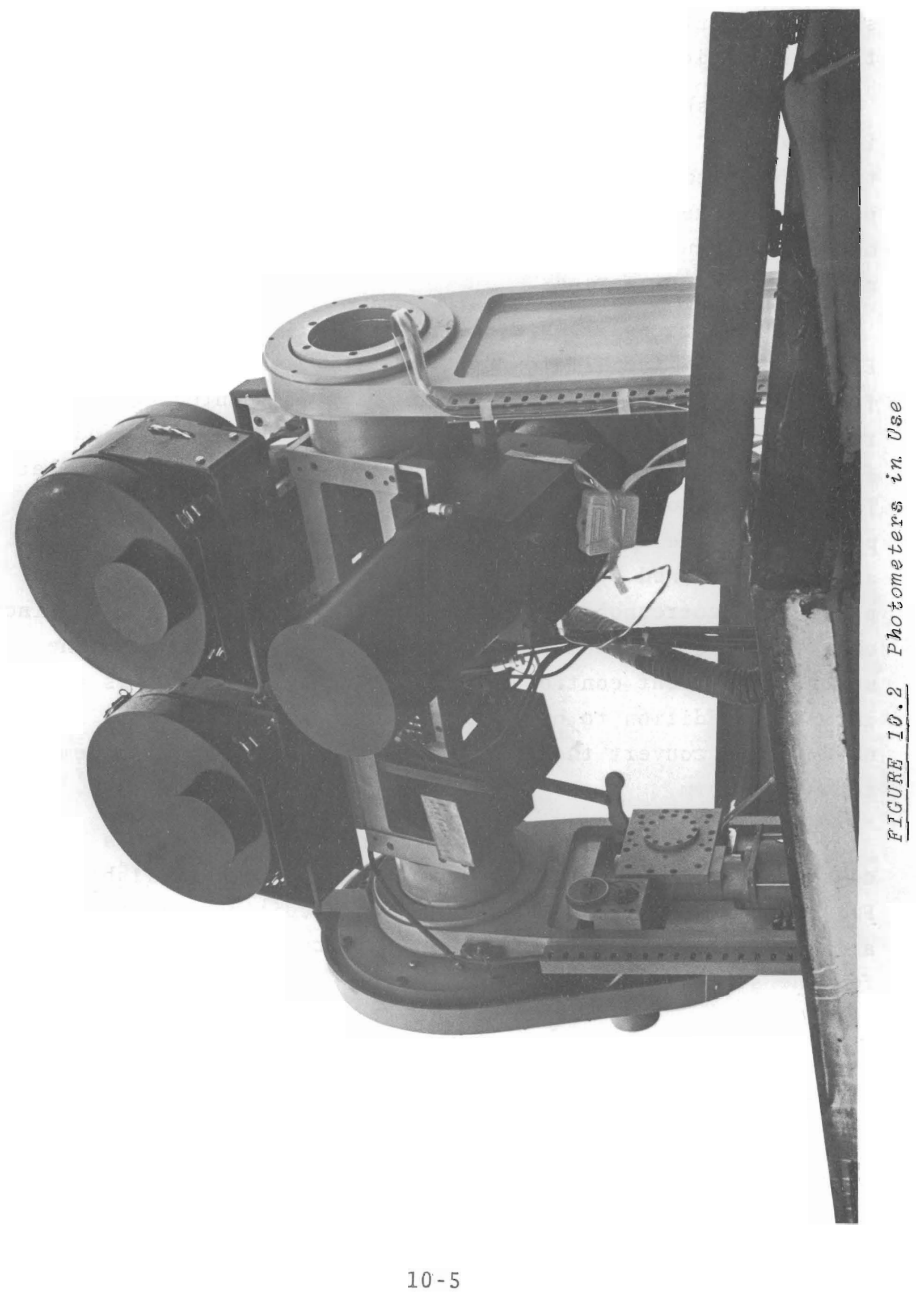


shows the control room for programming the mount and recording the observations from the three photometers.

An all-sky camera is being tested to provide cloud cover information. An automated observing program will require this type of system. Also, during the photometric non-observing period, the meridian spectrograph is operating with no observer on duty. Consequently, cloud cover information is needed for these periods.

A data processing system (Figure 10.4) borrowed from ESSA this year facilitates conversion of analog data to digital form. A strip chart of raw analog data is mounted in the recorder on the desk. The operator starts the system and follows the tracing on the chart with a hand-operated indicator. The amplitude of an analog signal is proportional to the position of the indicator. The system samples the signal at a rate determined by the operator and punches a BCD valve on paper tape corresponding to the amplitude of the signal. Since only one of our photometer outputs can be digitized on line under the present control and recording system, this is an important addition to our data processing program since it gives us a way to convert the data of the two undigitized photometers to useful form.

The working area at the Rattlesnake Observatory is constantly being improved as local funds become available. Figure 10.5 is a photograph of the data editing and storage area and Figure 10.6 is one of six offices presently available for the staff. 
BNWL - 1156

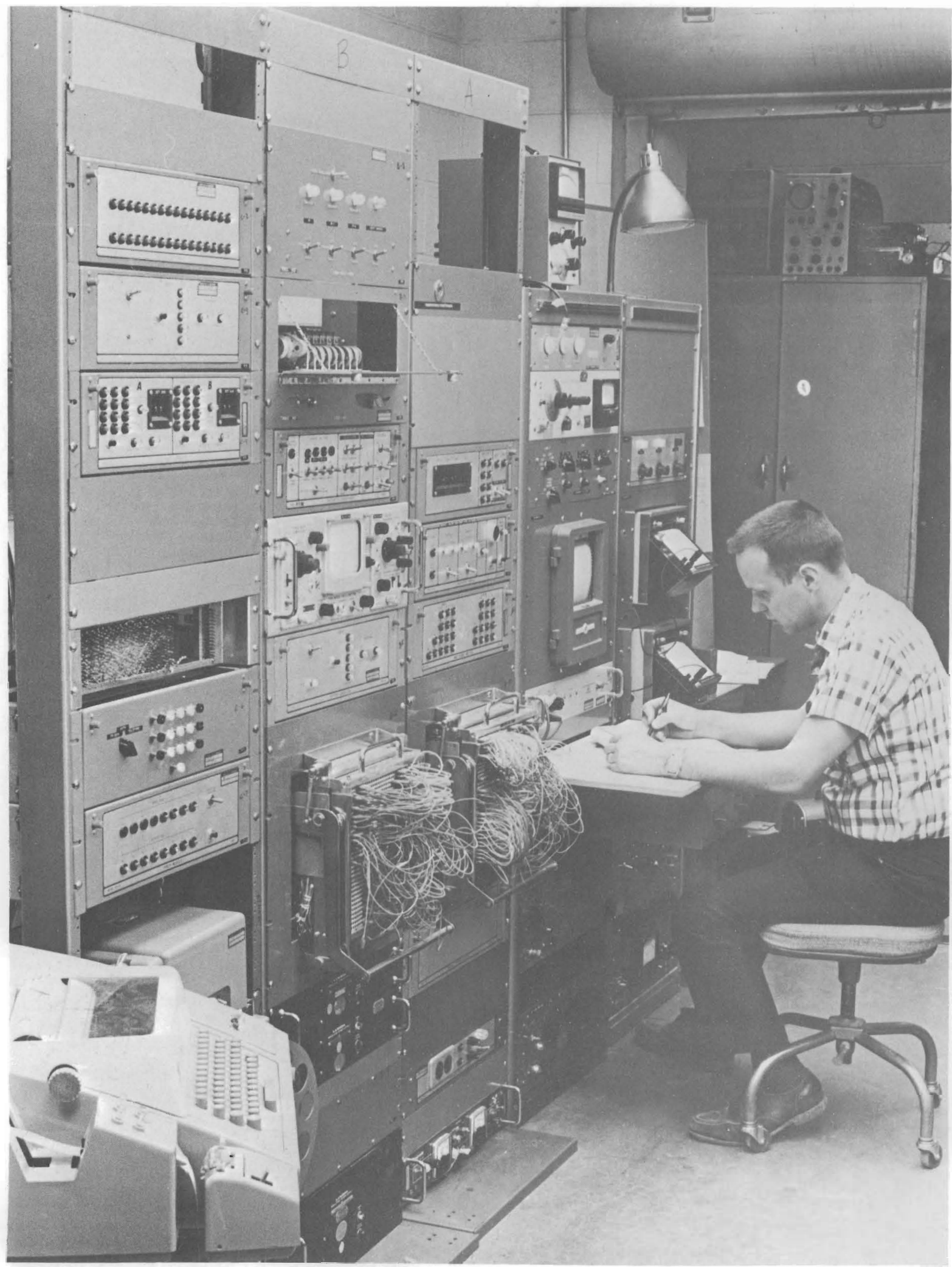

FIGURE 10.3 Control Room for Programming Mount and Recording observations from Photometers 
BNWL - 1156

\section{|IIIIIIIII \\ IIIIIIIIII}

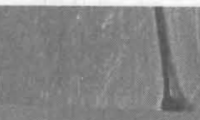

IIIIIIIIII

IIIIIIIIII

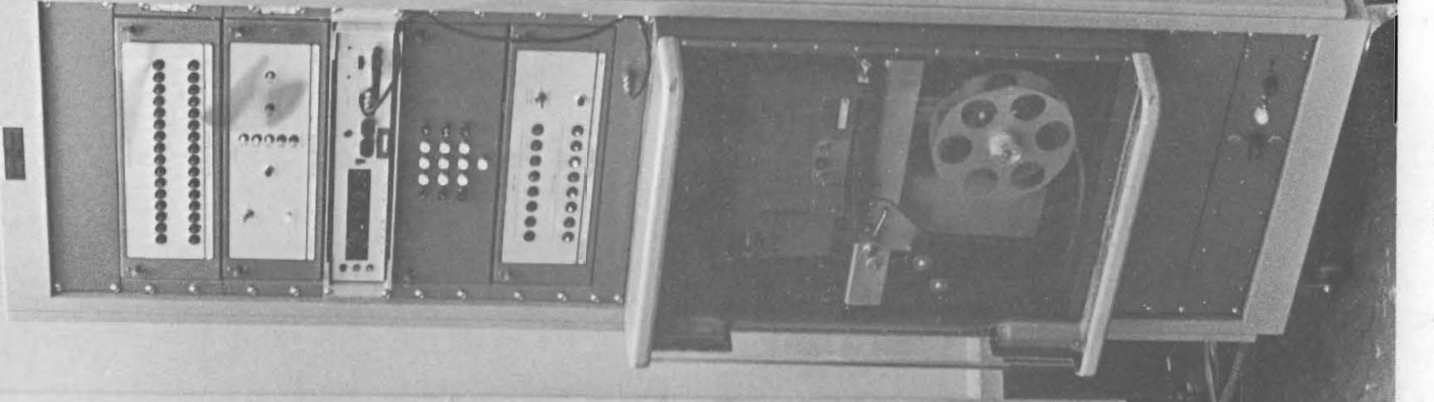

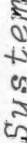

.

is

(1)

0

\&

$\theta$

0
0
0

ค

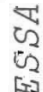
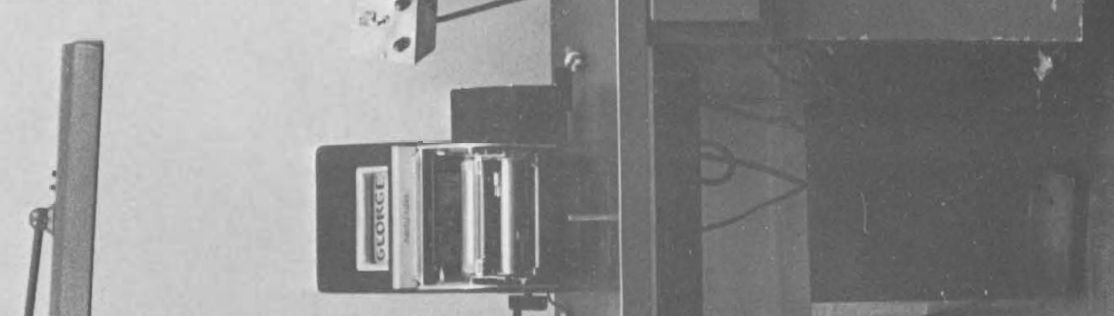

0
0
0
-1
0
07
04
0
0
0
0
0 


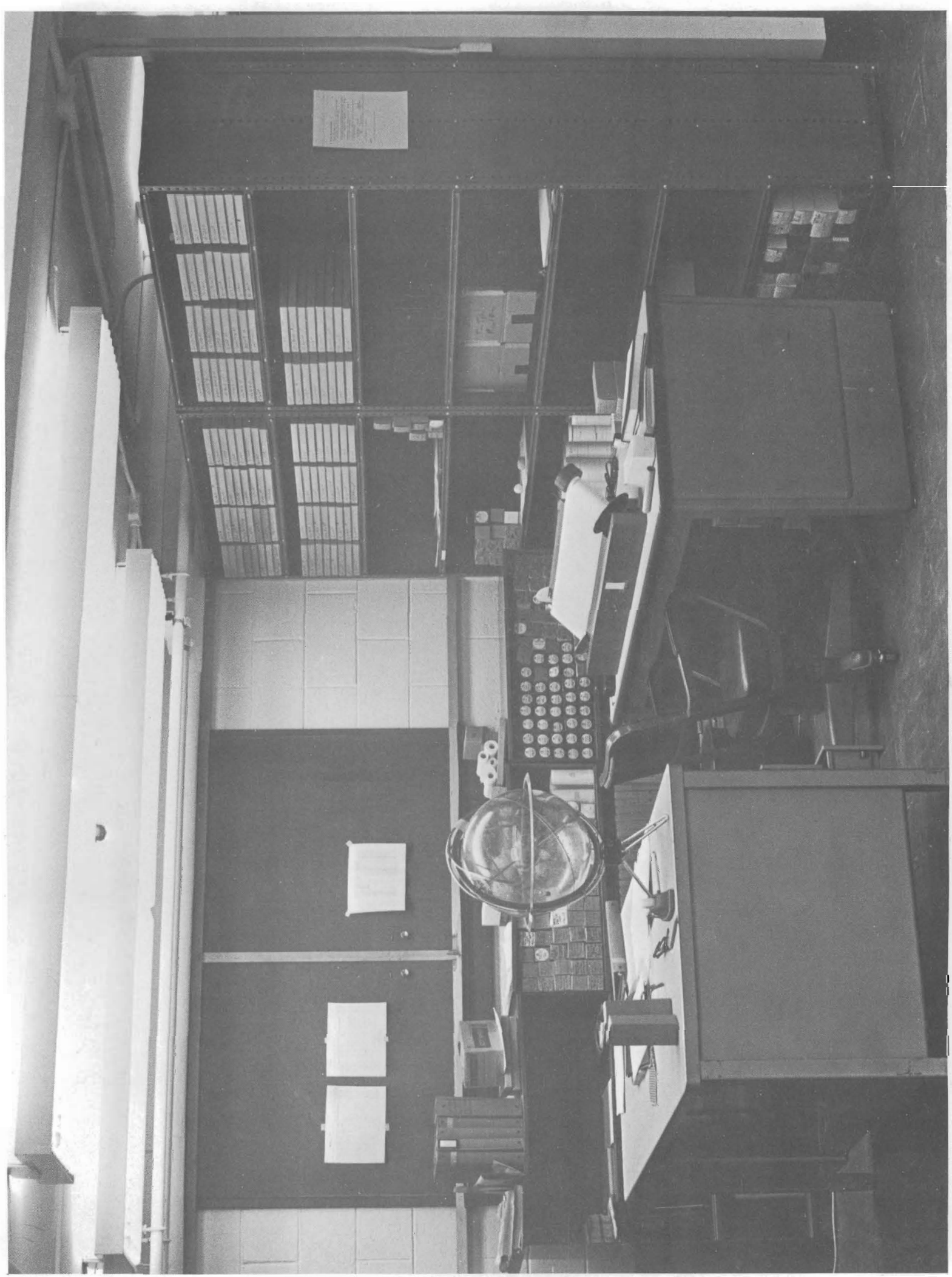

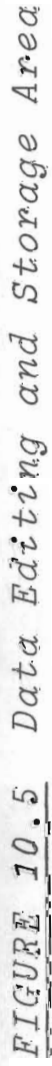




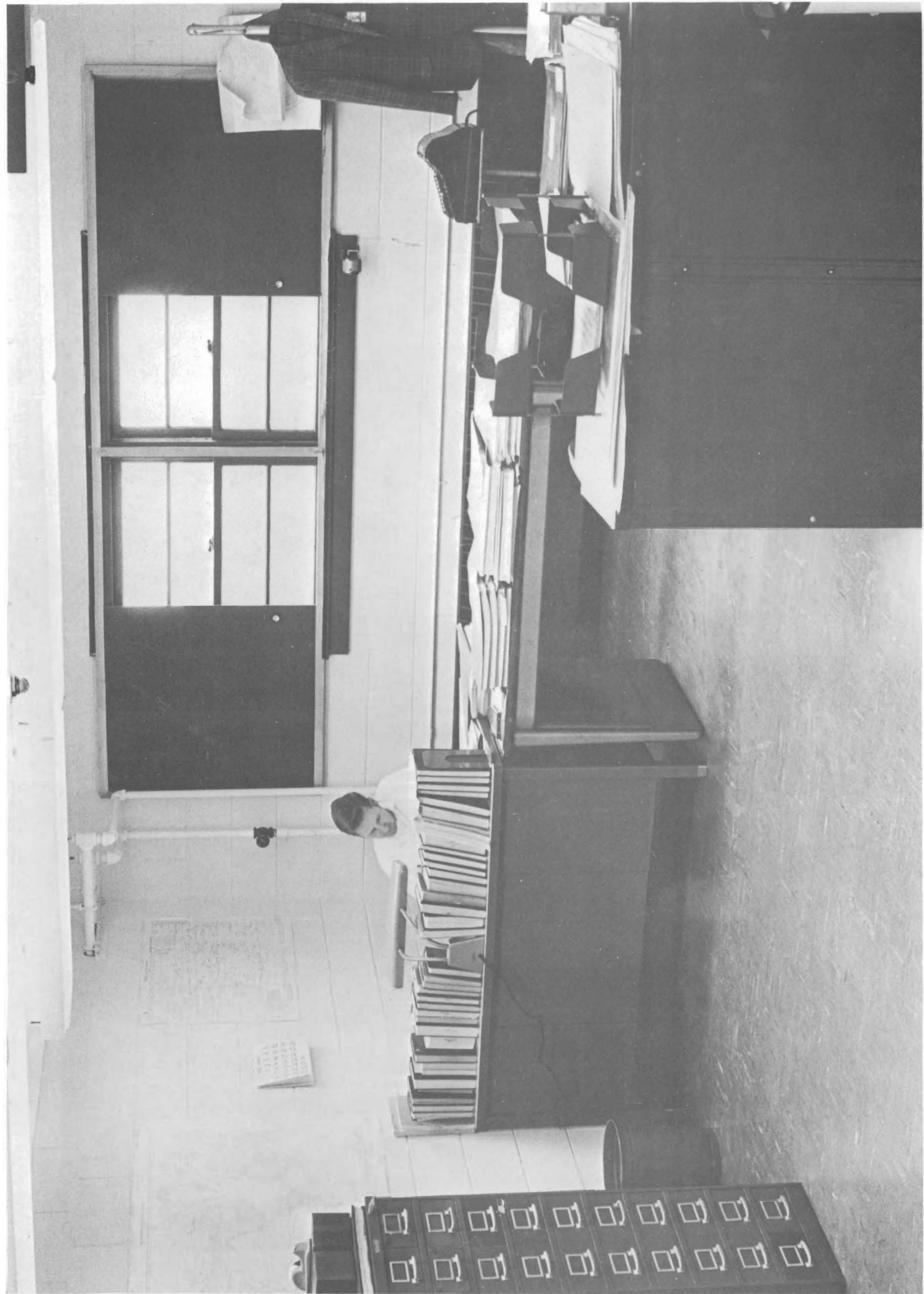

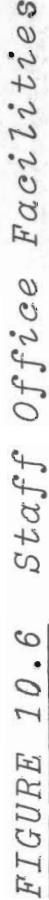




\section{PLANNING}

Last year we found we had to undertake some tasks not anticipated and abandon some we'd planned. This suggests that in stating plans here it might be wiser to set out broad general objectives rather than specific tasks and then plan to undertake those tasks that are necessary to accomplish the end results. There are three such general objectives: (1) analysis, (2) completion of the automated system and, (3) improving and continuing the all-sky mapping program.

The first objective requires that emphasis be shifted toward detailed analysis of the data that have been accumulated and are being obtained. We expect to realize some relief from other time-consuming tasks when the automated system becomes operational this year. Even if the benefits of automation should accrue more slowly than we now anticipate, we plan to make adjustments within the program to concentrate attention on analysis and reporting.

The analysis planned is expected to include a fairly complete treatment of the SAR arc phenomenon. This analysis has been started. Other analytical tasks which we have also begun include spectrographic studies of strong auroral features and a more detailed summary of activity based on the spectrograph records. The latter study considers angular coordinates and intensity for particular emission and thus goes considerably beyond the summary of auroral activity reported this year. Data for investigation of the continuum component of the airglow spectrum are also being taken. This serves the two-fold purpose of providing information necessary to establish the milkyway as a 'standard' surface brightness source and permits analysis of the continuum radiation component of the airglow itself.

The other general objectives for the year are to improve and continue the routine sky mapping, which has been the 
backbone of the research program, and to complete the automated control and recording system which is being installed. Funds permitting, the design and development of the high speed optical scanner is planned. Within the general scope of these objectives, individual tasks of testing, calibrating and working out new measuring techniques are to be undertaken as necessary.

In terms of long-range plans, we want to move toward a better overall balance between observing, theoretical analysis and experimentation. By theoretical analysis we refer to studies of both the macroscopic and the microscopic processes in the aurora and airglow. The need for certain laboratory measurements of low energy collision processes becomes ever more apparent. For example, we need low energy charge exchange cross sections for hydrogen incident on neutral atoms to understand the auroral hydrogen (Balmer) arcs that we have observed. A natural and expedient way to start development of the experimental portion of the program appears to be through cooperative work with our colleagues at the University of Washington. We have discussed the possibility of arranging for complementary efforts in both groups on problems of common interest. 


\section{DISTRIBUTION}

No. of

Copies

OFFSITE

1

AEC Chicago Patent Group

G. H. Lee

$\underline{\text { AEC Division of Technical Information Extension }}$

AEC Library Washington

Division of Research

G. A. Kolstad

2

Boeing Scientific Laboratory

P.0. Box 3981

Seattle, Washington 98124

Glen Morris

J. F. Kenney

1

Center Nat'1 de 1a Recherches Scientifique,

Service 'd' Aeronomie

Verrieres-Le-Buisson, Seine-et-Oise

Paris, France

Jacques Blamont

1

Central Washington State College

E1lensburg, Washington

R. B. Bennett

2

Davidson Optronics

2223 Ramona Blvd.

West Covina, California 91790

D. A. Davidson

D. E. Davidson

1

Det Danske Meteorologiske Institute

Gamlehavea11e-22, Charlottenlund

Denmark

Knud Lassen

Distr-1 
No. of

Copies

4

2

1

1

2
Environmental Sciences Services Administration

Research Laboratory

Boulder, Colorado 80302

Miss J. Virginia Lincoln

E. Marovich

Mike Gadsden

Dick Norton

Harvey Mudd College

Claremont, California

G. Be 11

A. B. Focke

Herron Optica1

2035 E. 223 Street

Long Beach, California 90810

Robb Hendrix

Lewis and Clark College

Portland, Oregon

R. L. Martin

J. H. Karle

Sierra Engineering

123 E. Montecito Ave.

Sierra Madre, California 91024

J. F. Hoch

University Nac de Cuyo

San Juan, Argentina

Ing. Evan Ciner 
No. of

Copies

4

University of Calgary

Calgary, Alberta, Canada

C. D. Anger

P. Hof

John Porter

B. G. Wilson

1

University of Colorado

Boulder, Colorado

Manfred Rees

1

University of Kansas

Lawrence, Kansas

David Beard

7

University of Washington

Seattle, Washington

K. C. Clark

George Wallerstein

1

Whitman College

Wa1la Walla, Washington

T. R. Rice

ONSITE

1

AEC Chicago Patent Group

R. K. Sharp (Richland)

2

AEC RDT Site Representative

P. G. Holsted

3

AEC Richland Operations Office

D. J. Jones

J . L. Rhoades

C. L. Robinson

Distr-3 
No. of

Copies

4

1

66
Battelle Memorial Institute

S. L. Fawcett (1)

Battelle Research Center, Seattle

R. S. Paul

Batte11e-Northwest

F. W. Albaugh

C. R. Batishko

C. A. Bennett

F. I. Carver

G. M. Dalen

J. L. Deichman

G. E. Driver

J . J . Fuguay

R. J. Hoch (30)

C. W. Lindenmeier

R. W. Owen (2)

F. E. Roach

R. E. Schenter

R. L. Skaugset (2)

L. L. Smith (6)

E. Wallace

D. C. Worlton

Technical Information Files 